\title{
Tiarei outer ridge: Sites M0009, M0021, and M0024-M0026
}

\author{
Expedition 310 Scientists $^{2}$
}

\begin{abstract}
Chapter contents
Operations.................. 1

Sedimentology and biological assemblages. . . 3

Petrophysics ................6

Downhole logging . . . . . . . . . 8

Geochemistry .................. 11

References................... 12

Figures..................... 13
\end{abstract}

'Expedition 310 Scientists, 2007. Tiarei outer ridge: Sites M0009, M0021, and M0024-M0026. In Camoin, G.F., Iryu, Y., McInroy, D.B., and the Expedition 310 Scientists. Proc. IODP, 310: Washington, DC (Integrated Ocean Drilling Program Management International, Inc.). doi:10.2204/iodp.proc.310.108.2007

'Expedition 310 Scientists' addresses.

\section{Operations}

\section{Holes M0009A and M0009B}

Following coring in Hole M0008A, and in light of the results obtained, an assessment was made concerning where to drill next. It was decided to attempt to drill the pinnacle at proposed Site TAH02A 4 on seismic Profile SISM 079 (see Fig. F5 in the "Site surveys related to Expedition 310" chapter). Acknowledging that the feature imaged on the seismic line might be the result of side-swipe and was possibly located off the seismic line, a localized search was made for a suitable drilling location using the ship's echo sounder and tautwire to detect a shallower than expected water depth. No suitable position was located, and at $2100 \mathrm{~h}$ on 17 October 2005, the vessel was positioned above a flat terrace (Hole M0009A) nearby and drilling operations commenced and continued until $1915 \mathrm{~h}$ on 18 October. Recovery was moderate to poor (43.1\%) to a total depth (TD) of 23.04 mbsf. However, promising coral material was recovered, and it was decided to attempt to recover the same section in a new hole nearby. By $2000 \mathrm{~h}$, the HQ pipe had been recovered and Seacore's drilling and reentry template (DART) lifted off the seabed, and by $2015 \mathrm{~h}$, the vessel was positioned above Hole M0009B, $\sim 5 \mathrm{~m}$ downslope from Hole M0009A. Coring operations commenced and continued until $1200 \mathrm{~h}$ on 19 October, with an improved recovery of $66.26 \%$.

Prior to logging Hole M0009B, the hole was reamed. Logging began at $1530 \mathrm{~h}$ on 19 October, with the resistivity and hydrochemical tools run open hole over the interval 6-21 mbsf. A hole blockage near the last deglacial/older Pleistocene sequence (lithologic Unit I/II) boundary, which resisted attempts to clear with the chisel tool, prevented the tools from being run below 21 mbsf. Optical image logs were collected between 6 and $18.1 \mathrm{mbsf}$ and acoustic image logs between 6 and 13.8 mbsf. Logging of Hole M0009B was concluded by $2320 \mathrm{~h}$ on 19 October.

\section{Hole M0009C}

Just before $0000 \mathrm{~h}$ on 20 October 2005, the DP Hunter moved to Hole M0009C, 9 m west-northwest of Hole M0009B in $99.85 \mathrm{~m}$ water depth. Coring commenced and continued until $1935 \mathrm{~h}$ that day, reaching a TD of 25.66 mbsf. Coring in Hole M0009C proved very difficult, with many bit blockages and crushed liners, which were due to pieces of the formation breaking off and entering the core barrel without being properly cored. The lattice drilled was 
not strong enough to core, and in many cases it had to be crushed for progress to be made. Recovery improved toward the base of the hole, and total core recovery was $51.86 \%$. At $1935 \mathrm{~h}$, the hole was completed and preparations made to move over to Hole M0009D.

\section{Hole M0009D}

The DP Hunter was positioned above Hole M0009D, $5.5 \mathrm{~m}$ east of Hole M0009B in $103.18 \mathrm{~m}$ water depth, and coring began at $2210 \mathrm{~h}$ on 20 October 2005 . Coring in Hole M0009D continued until $2230 \mathrm{~h}$ on 21 October, to a TD of 44.59 mbsf. Progress was steady, but core runs were short and bit blocking common. After TD was reached, preparations were made to log the hole.

Prior to logging the hole, the hole was reamed and flushed for $30 \mathrm{~min}$. The HQ string was pulled and set with a casing shoe at 19 mbsf to run the logging tools through the open-hole section. Logging commenced at $2230 \mathrm{~h}$ on 21 October in very wet and windy conditions. This, combined with very poor hole conditions, led to a difficult logging period. Nevertheless, good logs were obtained in sections of open hole where it was possible to log. A hole blockage prevented the resistivity tool from reaching the base of the hole, and the chisel tool was used to clear the blockage. The resistivity, spectral gamma ray, and acoustic tools were run. However, large, meter-scale cavities in the formation created sticking points for some of the tools; thus, only some of the open bottom-hole interval was logged. The first optical image tool run was affected by power failures on the drill rig, possibly caused by heavy rainfall. Logging was temporarily interrupted while the cause of the power failures was investigated. After these runs, the casing was pulled to 5 mbsf. The top-hole section was logged with the resistivity and optical image tools, with cavities causing problems for the optical tool. While logging up, the optical image tool became stuck many times and needed to be pulled through obstructions by hand. Logging operations were completed by $1000 \mathrm{~h}$ on 22 October, and preparations were made to move to Hole M0010A.

After logging in Hole M0009D, Sites M0010-M0014 were cored (see the "Tiarei marginal sites" chapter). Then there was a revisit to Hole M0007 (see the "Maraa western transect" chapter), followed by coring at new Sites M0015-M0018 (see the "Maraa eastern transect" chapter). After this, two sites were cored at Faaa (Sites M0019 and M0020) (see the "Faaa" chapter) before a return to the Tiarei outer ridge area to core in Hole M0021A.

\section{Hole M0021A}

At Site M0021, an echo sounder survey (five profiles) was conducted over suspected drowned reefs near to the foreslope imaged on the bathymetry. Water depth was confirmed at two locations using the tautwire. After a seabed camera survey, the DART was drilled in at one of these locations, $\sim 115 \mathrm{~m}$ southeast of proposed Site TAH-02A 5 in $82 \mathrm{~m}$ water depth. Coring operations began in Hole M0021A at $2200 \mathrm{~h}$ on 7 November 2005 and continued until $1640 \mathrm{~h}$ on 8 November. TD was $34.23 \mathrm{mbsf}$, and total recovery was $74.87 \%$. Good core recovery confirmed that the submerged pinnacle was a drowned reef.

\section{Hole M0009E}

After coring in Hole M0021A was completed, the HQ pipe was lifted and the DART raised to 45 meters below sea level (mbsl). The vessel moved $90 \mathrm{~m}$ northwest to previous Site M0009, where a site for Hole M0009E was chosen in a water depth of $93 \mathrm{~m}$. The DART was lowered and drilled in, and coring operations in Hole M0009E began at $2030 \mathrm{~h}$ on 8 November. Coring was completed at $0550 \mathrm{~h}$ on 9 November 2005 at a TD of 20.61 mbsf and with a total recovery of $72.73 \%$.

Prior to logging, the hole was flushed and the HQ pipe pulled and rerun with a casing shoe. From 0715 h on 9 November, Hole M0009E was logged between $\sim 2$ and 15 mbsf. The chisel tool was deployed once to clear a blockage at 6 mbsf. After logging was completed at $1440 \mathrm{~h}$, the HQ pipe was tripped and the DART raised into midwater.

After logging in Hole M0009E, Hole M0022A was cored (see the "Tiarei marginal sites" chapter), followed by operations at Site M0023 (see the "Tiarei inner ridge" chapter), before operations at Site M0024.

\section{Hole M0024A}

After clearing away the logging tools and lifting the DART back into the moonpool, the vessel moved to conduct an echo sounder survey in an area over a drowned reef pinnacle $\sim 100 \mathrm{~m}$ east of proposed Site TAH-02A 5. From 0515 h on 12 November 2005, 14 echo sounder traverses were made ( $\sim 50 \mathrm{~m}$ long), from which a site for Hole M0024A was chosen in 90 $\mathrm{m}$ water depth. Coring operations in Hole M0024A began at $1010 \mathrm{~h}$ on 12 November and finished at $0400 \mathrm{~h}$ on 13 November at a TD of 32.3 mbsf. Total recovery was $83.74 \%$.

\section{Hole M0025A}

A site for Hole M0025A was chosen from the echo sounder survey conducted on 12 November 2005, 25 
m north-northwest of Hole M0024A. The DART touched down in a water depth of $105.4 \mathrm{~m}$, and coring began at $0530 \mathrm{~h}$ on 13 November and finished at $1645 \mathrm{~h}$ that day at a TD of $20.93 \mathrm{mbsf}$. Total recovery was $74.23 \%$.

\section{Hole M0026A}

Following another echo sounder survey over a $50 \mathrm{~m}$ $\times 35 \mathrm{~m}$ area $\sim 180 \mathrm{~m}$ east of proposed Site TAH-02A 4 over a drowned reef pinnacle, a site for Hole M0026A was chosen. It proved difficult to interpret the results of the echo sounder survey (three strong seabed echoes and widely differing water depths over a few meters), and it took some time before identifying a suitable site in $105 \mathrm{~m}$ water depth. Coring operations in Hole M0026A started at $0920 \mathrm{~h}$ on 14 November 2005 and were completed by $1105 \mathrm{~h}$ that day at a TD of 12.4 mbsf. Total recovery was $58.45 \%$.

\section{Hole M0025B}

After lifting the DART in Hole M0026A, the DP Hunter moved to previous Site M0025 to core in Hole M0025B. After taking a tautwire depth of $95 \mathrm{~m}$, the DART was lowered and coring began at $1215 \mathrm{~h}$ on 14 November. Coring finished at $0100 \mathrm{~h}$ on 15 November at a TD of 20.5 mbsf with a total recovery of $71.19 \%$.

\section{Hole M0021B}

After raising the DART to $50 \mathrm{~m}$ above seabed, the vessel was moved back to Site M0021 to core in Hole M0021B (proposed Site TAH-02A 5). Once on position, the tautwire depth was taken as $80 \mathrm{~m}$. The DART and drill pipe were lowered, and coring in Hole M0021B commenced at 0630 h on 15 November 2005 and continued until $2210 \mathrm{~h}$ that day. TD was $32.81 \mathrm{mbsf}$, and total recovery was $65.57 \%$.

Prior to logging, Hole M0021B was flushed before the HQ pipe was run back into the hole with a casing shoe. Logging in Hole M0021B commenced at 0030 $\mathrm{h}$ on 16 November and was competed by $0645 \mathrm{~h}$ that day. All tools were run to 15 mbsf. Once logging was completed, the DART was lifted onto deck and secured for the transit back to the Port of Papeete.

The DP Hunter departed the last site at $0815 \mathrm{~h}$ on 16 November and arrived at the Port of Papeete at 1145 h. Demobilization of the vessel took place on 16 and 17 November.

\section{Sedimentology and biological assemblages Last deglacial sequence (Unit I)}

On the outer ridge of Tiarei, the last deglacial sequence (lithologic Unit I) was recovered from 81.7 to
$122 \mathrm{mbsl}$. The thickest continuous sequence, reaching $30 \mathrm{~m}$, was recovered in Holes M0021A, M0021B, and M0024A.

The last deglacial sequence is mostly composed of coralgal-microbialite frameworks locally interlayered with

- Volcanic sediments, including coarse sand displaying skeletal elements (foraminifers, Halimeda segments, fragments of mollusks, bryozoans, and corals, including branching Porites).

- Rubble and sand consisting mostly of coral fragments (dominated by branching colonies and, to a lesser extent, tabular colonies) associated with crusts of nongeniculate coralline algae and microbialites (Fig. F1) (e.g., interval 310-M0009B-9R-1, 5-20 cm), chunks of microbialite crusts, Halimeda segments (Fig. F2) (e.g., interval 310-M0024A-15R$1,0-20 \mathrm{~cm}$ ), and mollusk shells and fragments (e.g., Cypraea and other gastropods); rhodoliths occur locally. Intraclasts display bioeroded surfaces and encrusting worm tubes. Volcanic pebbles are locally mixed with carbonate elements.

- Skeletal packstone to floatstone rich in Halimeda segments and fragments of corals and mollusks (Fig. F3) (e.g., interval 310-M0026A-6R-1, 88-96 $\mathrm{cm})$.

The top of the last deglacial sequence is characterized by the widespread development of microbialite crusts that display laminar and knobby morphologies; thin thalli of nongeniculate coralline algae (Fig. F4) (e.g., interval 310-M0021A-1R-1, 10-23 cm) are usually associated with those crusts.

Extensive bioerosion, dark brown staining, and hardgrounds are features that have been locally observed within the top 2-3 $\mathrm{m}$ of the sequence (Fig. F5) (e.g., interval 310-M0021B-1R-1, 0-11 cm).

Coralgal-microbialite frameworks are characterized by distinctive internal structure and coral assemblages (Subunits IA-IE). Some of the coral assemblages listed below are intergradational, both laterally and vertically. However, the succession reported in all holes displays a general consistent trend, including Subunits IA-IE.

All coralgal-microbialite frameworks are characterized by the widespread development of dark gray microbialite crusts that extend into primary and bioerosion cavities. Microbialites usually represent the major volumetric and structural component of the frameworks (Figs. F6, F7) (e.g., intervals 310M0021A-5R-1, 58-71 cm, and 8R-1, 18-31 cm). The thickness and morphologies of the microbialite crusts are closely related to the shape and size of the cavities in which they developed. In bindstone formed by encrusting coral assemblages, microbi- 
alites are generally dominated by thrombolitic fabrics, whereas in frameworks made of branching and massive coral colonies, they are characterized by the development of compound crusts, up to $15 \mathrm{~cm}$ thick, in which multiple generations formed by the succession of laminated and thrombolitic fabrics may be closely packed and merged (Fig. F8) (e.g., interval 310-M0021B-5R-1, 63-80 cm). Thrombolites usually represent the last stage of encrustation (Fig. F9) (e.g., interval 310-M0021A-6R-1, 9-20 cm) and consist of closely spaced micritic masses that range from narrow millimeter-sized upward-radiating shrubs to broader dendritic clusters up to $1 \mathrm{~cm}$ high. These masses are intergradational, both vertically and laterally.

In Hole M0025B, the basal part of the last deglacial sequence is composed of an algal bindstone (Core 310-M0025B-12R).

\section{Subunit IA}

Intervals: Cores 310-M0009A-1R through 6R-1 and 8R-1, 310-M0009B-1R through 4R, 310M0009C-4R through 6R, 310-M0009D-1R through 4R, 310-M0009E-1R through 6R, 310-M0021A-1R and 6R, 310-M0021B-1R through 3R-1, 310-M0024A-1R through 3R, $310-\mathrm{M} 0025 \mathrm{~A}-1 \mathrm{R}$ through $4 \mathrm{R}$, and 310M0025B-1R

Subunit IA comprises coralgal-microbialite frameworks (bindstone) dominated by encrusting colonies of Montipora, Montastrea, Leptastrea, Pavona, and Porites and encrusting and foliaceous colonies of agariciids (Pachyseris and Leptoseris) (Figs. F10, F11, F12) (e.g., intervals 310-M0009B-2R-1, 20-30 cm, 310M0021B-1R-1, 65-83 cm, and 310-M0025A-1R-1, 34$61 \mathrm{~cm}$ ). Other corals are less abundant and include branching colonies of Porites and Pocillopora (Fig. F13) (e.g., interval 310-M0021A-5R-1, 88-107 cm) and massive colonies of mussids (Acanthastrea?) (e.g., interval 310-M0021B-1R-1, 30-50 cm).

Coral colonies are usually thinly coated with nongeniculate coralline algae and microbialites to form loose, cavernous frameworks, including large primary cavities that are partially filled with skeletal sand and gravels composed of Halimeda segments and mollusk fragments; volcanic grains are associated locally. Bioerosion is locally extensive, especially at the top of the subunit.

Volcanic sand and occasional volcanic granules and pebbles were observed in vugs and small sedimentary pockets in the carbonate units and in the interstitial spaces in coralgal frameworks and crushed framework intervals in Section 310-M0021-2R-1.

\section{Subunit IB}

Intervals: Section 310-M0009A-8R-2, Cores 310M0009B-5R through 8R and Section 13R-1, Cores 310-M0009C-7R through 10R and 14R through 16R, Cores 310-M0009D-5R, 6R, and 8R and Section 9R-1, Cores 310-M0009E-7R through 10R, Section 310-M0021A-6R-2 through Core 19R, Section 310-M0021B-3R-1 through Core $9 \mathrm{R}$ and Cores $11 \mathrm{R}$ through 19R, Core 310-M0024A-3R through Section 10R-1, Cores 310-M0025B-2R, 4R through $8 \mathrm{R}, 11 \mathrm{R}$, and $12 \mathrm{R}$, and Core $310-\mathrm{M} 0026 \mathrm{~A}-1 \mathrm{R}$

Subunit IB contains coralgal-microbialite frameworks dominated by branching and encrusting colonies of Porites and Montipora; associated corals include encrusting and branching colonies of Pavona and, to a lesser extent, robust branching colonies of Pocillopora, tabular colonies of Acropora, and encrusting colonies of agariciids (Figs. F14, F15, F16, F17, F18, F19, F20, F21) (e.g., intervals 310-M0021A-10R$1,102-117 \mathrm{~cm}$, and $12 \mathrm{R}-1,30-50 \mathrm{~cm}, 310-\mathrm{M} 0021 \mathrm{~B}-$ 7R-1, 70-86 cm, and 15R-1, 46-66 cm, and 310M0024A-3R-1, 72-91 cm, 5R-2, 8-20 cm, 9R-1, 19-49 $\mathrm{cm}$, and 9R-2, 74-90 cm).

Coral colonies are coated with crusts of nongeniculate coralline algae up to $2.5 \mathrm{~cm}$ thick, locally associated with vermetid gastropods and serpulids (Figs. F22, F23, F24, F25, F26) (e.g., intervals 310-M0009B13R-1, 3-18 cm, 310-M0021B-9R-1, 0-12 cm, and 310-M0024A-9R-1, 78-90 cm, 9R-2, 6-19 cm, and 10R-1, 0-6 cm). Nongeniculate coralline algal crusts are generally overlain by microbialites. Traces of bioerosion usually occur on coral colonies, but their abundance is variable.

Pockets of skeletal sand that include Halimeda segments (Fig. F27) (e.g., interval 310-M0025B-8R-1, $52-63 \mathrm{~cm}$ ) and fragments of mollusks, bryozoans, and echinoids occur, usually within primary voids of the frameworks; silt- to sand-sized volcanic grains and basalt gravels are associated locally.

\section{Subunit IC}

Intervals: Cores 310-M0009A-7R, 310-M0009B$11 \mathrm{R}, 12 \mathrm{R}$, and 14R, 310-M0009C-11R through 13R, 310-M0009D-6R and 7R and Section 9R-2 through Core 11R, Cores 310M0009E-7R and 9R, Sections 310-M0021A6R-1 and 310-M0024A-10R-1 through Core 13R, and Cores 310-M0025A-6R and 8R through 10R, 310-M0025B-5R and 8R through 10R, and 310-M0026A-3R, 4R, 6R, and $7 \mathrm{R}$

Subunit IC comprises a coral assemblage dominated by massive colonies of Porites, some of which display 
traces of bioerosion (Figs. F28, F29, F30, F31) (e.g., intervals 310-M0009D-7R-1, 10-30 cm, 310M0021A-6R-1, 59-71 cm, 310-M0024A-12R-2, 10-15 $\mathrm{cm}$, and 310-M0025A-6R-1, 72-90 cm). Associated coral colonies include encrusting and branching Porites, robust branching Pocillopora, and encrusting Montipora.

Coral colonies are usually coated with thin to moderately thick crusts of nongeniculate coralline algae, associated locally with vermetid gastropods and serpulids, and overlain by very thick and massive microbialite masses.

Interlayered volcaniclastic sediments include sand and basalt pebbles (Core 310-M0009A-7R). Limestone clasts and/or shells and skeletal sand rich in Halimeda segments and volcanic grains occur locally between massive coral colonies.

\section{Subunit ID}

Intervals: Cores 310-M0009A-12R and 13R, Section 310-M0009B-13R-2 through Core 15R, Section 310-M0009E-10R-2, Core 11R, and Section 12R-1, Sections 310-M0024A-10R-1 and 11R-2 and Core 15R, and Cores 310-M0025B$6 \mathrm{R}$ and $8 \mathrm{R}$

Subunit ID includes a coral assemblage dominated by robust branching colonies of Pocillopora, encrusting colonies of faviids, and encrusting and branching colonies of Montipora (Figs. F32, F33) (e.g., intervals 310-M0024A-10R-1, 65-85 cm, and 310M0025B-6R-1, 20-37 cm).

Coral colonies are coated with thick crusts of nongeniculate coralline algae, locally associated with vermetid gastropods and serpulids, and overlain by massive microbialite coatings.

\section{Subunit IE}

Intervals: Cores 310-M0009C-17R and 18R, 310M0009D-12R, and 310-M0026A-4R

Subunit IE displays an assemblage composed of encrusting and massive colonies of faviids (Favia and Leptastrea) locally associated with encrusting colonies of Montipora and Psammocora. Associated coral rubble is composed mostly of fragments of branching Porites, Acropora, and Pocillopora (Fig. F34) (e.g., interval 310-M0009C-18R-1, 90-107 cm). Coral colonies are coated with thick crusts of nongeniculate coralline algae overlain by microbialites. Pockets of skeletal sand that includes Halimeda segments and fragments of mollusks occur, usually within the primary voids of the frameworks.

\section{Older Pleistocene sequence (Unit II)}

The contact between Units I and II is characterized by an irregular unconformity typified by the abundance of large solution cavities partly filled with unconsolidated skeletal and volcanic sand that includes fragments of fruticose, coralline algal branches, and Halimeda segments (Section 310-M0009C-20R-CC and Core 310-M0009D-11R) (Fig. F35) and with coral clasts (fragments of Pocillopora and Montipora; Core 310-M0009D-12R). Some cavities are partly filled with skeletal and volcanic sand and gravels and stalagmite crusts (Figs. F36, F37, F38) (e.g., intervals 310-M0009D-14R-2, 48-54 cm, and 24R-1, 14$25 \mathrm{~cm}, 310-\mathrm{M} 0021 \mathrm{~B}-19 \mathrm{R}-1,38-52 \mathrm{~cm}$, and 310M0025A-10R-1, 78-100 cm). These solution cavities are seemingly related to the karstification of the top of the older Pleistocene carbonate sequence. The top of that sequence (lithologic Unit II) is locally characterized by the occurrence of multiple bored and encrusted surfaces (hardgrounds; e.g., Cores 310M0021B-19R and 310-M0025A-10R and interval 310M0025A-10R-1, 22-37 cm) (Fig. F39) and several unconformities (Fig. F40) (e.g., interval 310-M0009C20R-1, 84-104 cm).

The older Pleistocene sequence comprises four major lithologic subunits that are locally interlayered.

\section{Subunit IIA}

Intervals: Cores 310-M0009A-14R and 16R, 310M0009B-15R through 18R, 310-M0009C-18R through 21R, 310-M0009D-13R through 20R, 23R, and 24R, 310-M0009E-12R, 310M0021A-19R through 22R, 310-M0021B-19R and 20R, 310-M0024A-15R and 16R, 310M0025A-10R and 11R, and 310-M0026A-19R and 20R

Subunit IIA is made up of well-lithified gray to brown coralgal frameworks associated with coral rudstone-floatstone and skeletal limestone. Some skeletal grains display brown staining. Volcanic gravels and sand-sized grains are locally abundant; volcanic pebbles and cobbles occur as a component in the coral boundstone subunit beneath the major unconformity at Section 310-M0024A-15R-1, $70 \mathrm{~cm}$. A volcanic siltstone horizon occasionally containing volcanic pebbles and granules is present from Section 310-M0009A-16R-1, $28 \mathrm{~cm}$, to the bottom of the hole in Section 310-M0009A-18R-CC. Holes M0025A and M0025B both terminated in a volcanic siltstone interval, from Section 310-M0025A-11R-1, $120 \mathrm{~cm}$, in the former and from Section 310-M0025B-12R-1, $70 \mathrm{~cm}$, in the latter.

In coralgal frameworks, coral assemblages are dominated by encrusting colonies of Leptastrea, Pachyseris, 
Montipora, and Psammocora and are locally associated with robust branching colonies of Acropora and Pocillopora, tabular colonies of Acropora, and massive colonies of Porites (Figs. F41, F42, F43, F44, F45, F46, F47) (e.g., intervals 310-M0009A-14R-1, 5-23 cm, 310-M0009D-18R-1, 13-31 cm, 310-M0021A-22R-2, 60-80 cm, 310-M0021B-20R-1, 60-68 cm, and 20R-2, $0-10 \mathrm{~cm}$, and $310-\mathrm{M} 0025 \mathrm{~A}-10 \mathrm{R}-1,108-128 \mathrm{~cm}$, and 11R-1, 50-65 cm). Nongeniculate coralline algal crusts are abundant and locally include vermetid gastropods and serpulids. Algal crusts are generally encrusted with columnar laminated and dendritic microbialite fabrics that may form very thick crusts and represent the last stage of encrustation. The matrix of the frameworks is generally composed of skeletal sediments rich in Halimeda segments and mollusk fragments and including volcanic grains. Reworked basalt pebbles occur locally in those beds.

Coral rudstone-floatstone is composed of fragments of corals (massive Porites, robust branching Pocillopora, and encrusting Echinophyllia, Montipora, Millepora, and Pachyseris) locally encrusted with nongeniculate coralline algae and microbialites (Fig. F48) (e.g., interval 310-M0009B-16R-1, 35-60 cm); the matrix is rich in Halimeda segments and echinoid fragments mixed with volcanic sand-sized grains and pebbles and cobbles of basalt.

Skeletal wackestone to packstone is rich in Halimeda segments, foraminifers, and fragments of corals, mollusks, echinoids, and nongeniculate coralline algae (encrusting and fruticose); sand-sized volcanic grains and basalt pebbles and cobbles are usually associated with the skeletal grains.

This subunit is characterized by abundant diagenetic alterations, including the recrystallization and transformation of coral skeletons, and by the occurrence of large solution cavities that usually display brown staining on their walls. Those cavities are filled with several generations of infillings, some of them displaying a geopetal structure, consisting of dark gray to brownish volcaniclastic skeletal silt and sand overlain by microbialite crusts. Some cavities are locally rimmed with multiple generations of cement crusts.

\section{Subunit IIB}

Intervals: Cores 310-M0009A-14R and 15R, 310M0009D-21R through 23R, 310-M0021A20R through 22R, 310-M0024A-15R and 16R, and 310-M0026A-7R and 8R

Subunit IIB contains horizons composed of coral fragments, limestone clasts, basalt pebbles, and reworked coral colonies (branching Porites and robust branching Acropora). Coral fragments include robust branching or tabular Acropora, robust branching Pocillopora, branching Porites, encrusting Montipora, and massive Porites; associated skeletal grains include Halimeda segments and bryozoan colonies. These coral fragments usually display abundant traces of bioerosion. Some of them are encrusted with nongeniculate coralline algae, whereas other clasts are partly embedded in Halimeda packstone.

\section{Subunit IIC}

Interval: Core 310-M0009D-25R

Subunit IIC is a sandy packstone/grainstone with fragments of corals (branching Porites, Acropora, and Pocillopora) (Fig. F49) (e.g., interval 310-M0009D25R-1, 0-11 cm) overlying a coral boundstone consisting mainly of massive Porites and encrusting coral colonies (Fig. F50) (e.g., interval 310-M0009D-25R-1, 52-62 cm) associated with tabular Acropora colonies (Fig. F51) (e.g., interval 310-M0009D-25R-1, 70-95 $\mathrm{cm})$.

\section{Subunit IID}

Intervals: Cores 310-M0009A-16R through 18R, 310-M0025A-11R through 13R and 16R, 310M0025B-12R (bottom) and 13R, and 310M0026A-8R (bottom)

Subunit IID comprises massive poorly consolidated and cemented dark grayish to brownish volcaniclastic siltstone to sandstone that includes fragments of corals (branching Pocillopora and encrusting Montipora) and nongeniculate coralline algal crusts, as well as skeletal components (tiny mollusk shells and Halimeda segments). This siltstone to sandstone is interlayered with sandy limestone and granule- to pebblesized pieces of aphanitic dense basalt (Figs. F52, F53, F54, F55, F56) (e.g., intervals 310-M0009A-16R-1, 4$9 \mathrm{~cm}, 310-\mathrm{M} 0025 \mathrm{~A}-11 \mathrm{R}-1,72-86 \mathrm{~cm}, 11 \mathrm{R}-1,85-107$ $\mathrm{cm}$, and 12R-2, 70-85 cm, and 310-M0025B-13R-1, 65-75 cm). Bioturbation products are locally abundant and infilled with coarse sediments, including gastropods and Halimeda segments.

\section{Petrophysics}

Recovery at Tiarei outer ridge sites, on the northeastern side of the island of Tahiti, was partial (Hole $\mathrm{M} 0009 \mathrm{~A}=43 \%$, Fig. F57; Hole M0009C $=51 \%$, Fig. F58; Hole M0009D $=54 \%$, Fig. F59) and good (Hole $\mathrm{M} 0009 \mathrm{~B}=66 \%$, Fig. F60; Hole M0009E $=72 \%$, Fig. F61; Hole M0021A = 74\%, Fig. F62; Hole M0021B = 65\%, Fig. F63; Hole M0024A = 83\%, Fig. F64; Hole M0025A = 74\%, Fig. F65; Hole M0026A = 71\%, Fig. F66; Hole M0025B = 58\%, Fig. F67). Cores 310M0021A-16R, 310-M0021B-5R, 310-M0024A-15R 
and 16R, 310-M0025A-11R, 12R, and 13R, and 310M0025B-12R and 13R were left unsaturated and therefore have different data coverage and quality (see the "Methods" chapter for more details). Water depths are as follows: Hole M0009A $=99.71 \mathrm{mbsl}$; Hole M0009B $=100.31 \mathrm{mbsl}$; Hole M0009C $=99.85$ mbsl; Hole M0009D = 103.18 mbsl; Hole M0009E = $94.94 \mathrm{mbsl}$; Hole M0021A $=82.30 \mathrm{mbsl}$; Hole $\mathrm{M} 0021 \mathrm{~B}=81.70 \mathrm{mbsl}$; Hole M0024A = $90.44 \mathrm{mbsl}$; Hole M0025 A $=105.40$ mbsl; Hole M0025B $=100.84$ mbsl; and Hole M0026A = 107.30 mbsl.

The last deglacial sequence (lithologic Unit I) ranges in thickness from 10 to $30 \mathrm{~m}$ on the outer ridge of Tiarei, depending on the water depth at which the holes were drilled. The last deglacial sequence was deposited on an irregular topography as confirmed by different depths of the last deglacial-older Pleistocene sequence (Unit I/II) transition/unconformity (see "Sedimentology and biological assemblages").

\section{Density and porosity}

At Tiarei outer ridge sites, gamma ray attenuation (GRA) bulk density ranges between 1.5 and $2.4 \mathrm{~g} / \mathrm{cm}^{3}$ and discrete sample moisture and density (MAD) bulk density ranges between 1.9 and $2.76 \mathrm{~g} / \mathrm{cm}^{3}$ in the last deglacial sequence. MAD density values can be as much as $0.3 \mathrm{~g} / \mathrm{cm}^{3}$ higher than the maximum GRA density values. This difference is the result of intracore spaces and undersized cores. MAD density increases to $2.35 \mathrm{~g} / \mathrm{cm}^{3}$ for the older Pleistocene sequence (e.g., from 21 mbsf in Hole M0009B; Cores 310-M0009B-15R through 18R). In all boreholes, density profiles show large variation downhole with an abrupt increase at the Unit I-Unit II transition. Lower density readings correspond with large primary porosity preserved (e.g., Core 310-M0009B-6R).

Two specific intervals can be recognized in the GRA measurements for Unit I:

- Interval 1: 0-6 mbsf (e.g., Cores 310-M0025A-1R through $4 \mathrm{R}$ and $310-\mathrm{M0025 \textrm {B }}-1 \mathrm{R}$ through $5 \mathrm{R}$ ) and 0-8 mbsf (e.g., Cores 310-M0009B-1R through 7R and 310-M0009D-1R through 6R): Values are variable but mostly $>1.90 \mathrm{~g} / \mathrm{cm}^{3}$ with a maximum of $2.46 \mathrm{~g} / \mathrm{cm}^{3}$.

- Interval 2: 6-19 mbsf (e.g., Cores 310-M0009D-7R through 15R): Average density is $\sim 2.35 \mathrm{~g} / \mathrm{cm}^{3}$. Small-scale variations range from 2.11 to $2.53 \mathrm{~g} /$ $\mathrm{cm}^{3}$.

In Holes M0021A (Fig. F62), M0021B (Fig. F63), and M0026A (Fig. F66), a relationship between density and lithologic units is less apparent. Around $12 \mathrm{mbsf}$ (Hole M0021A; Fig. F62), density decreases gradually from 2.3 to $1.9 \mathrm{~g} / \mathrm{cm}^{3}$, with an average MAD density of $2.19 \mathrm{~g} / \mathrm{cm}^{3}$. Grain density values average $2.75 \mathrm{~g} /$ $\mathrm{cm}^{3}$, range between 2.70 and $2.84 \mathrm{~g} / \mathrm{cm}^{3}$, and do not show any clear downhole trend.

Porosity values range from $10 \%$ to $50 \%$ with few outliers above this maximum, most likely in areas where core is undersized with respect to the liner. The porosity profile with depth mirrors the bulk density profile. Porosity is highly variable at the top of the borehole in Interval 1, 30\% on average, and increases to $40 \%$ on average for Interval 2 . The overall porosity profile shows no clear downhole trend, suggesting that porosity is mainly controlled by largescale primary porosity.

At the Unit I-Unit II transition, a step in density is observed toward higher values. Average density lies at $\sim 2.3 \mathrm{~g} / \mathrm{cm}^{3}$ for this interval with equally lower porosities of $\sim 20 \%$ on average. Both density and porosity show downhole variation with porosity values between $10 \%$ and $30 \%$ with outliers toward 50\%. No clear subdivision in lithologic units, as recognized in "Sedimentology and biological assemblages," is apparent in core log data.

\section{$P$-wave velocity}

$P$-wave velocities were measured with the Geotek MSCL P-wave logger (PWL) on whole cores and the PWS3 contact sensor system on a modified Hamilton frame on $\sim 2-4 \mathrm{~cm}$ long 1 inch round discrete samples of semilithified and lithified sediments (see the "Methods" chapter). Velocities in one transverse (x) direction were measured on the plugs. $P$-wave velocity profiles in the last deglacial sequence are highly discontinuous as result of low recovery (e.g., Hole M0009A; Fig. F57) or drilling disturbance. Values range from 1700 to $4700 \mathrm{~m} / \mathrm{s}$ and show no clear downhole trend. Velocity inversions are sharp and abrupt and occur commonly. Discrete measurements range from 2453 to $4746 \mathrm{~m} / \mathrm{s}$.

A sharp increase in velocity occurs at the lithologic Unit I/II boundary. Velocity profiles are more continuous and less variable in Unit II as result of better cementation and subsequent better recovery. Velocities are generally between 4000 and $5000 \mathrm{~m} / \mathrm{s}$ with a few lower values corresponding to lower density values (e.g., Hole M0009E; Fig. F61). Discrete samples generally correspond to zones of high velocity with a maximum of 5287 m/s (Hole M0024A, 29 mbsf; Fig. F64). Velocity values increase with increased density and decreased porosity. A cross plot of velocity versus porosity for Tiarei outer ridge sites shows a general inverse relationship (Fig. F68). For the time-average empirical equation of Wyllie et al. (1956) and Raymer et al. (1980), the traveltime of an acoustic signal through rock is a specific sum of the traveltime through the solid matrix and the fluid phase. However, porosity and velocity data do not match 
the time-average equation but show large scatter around the general trend line. For a given density of $2.0 \mathrm{~g} / \mathrm{cm}^{3}$, velocity may vary as much as $2000 \mathrm{~m} / \mathrm{s}$. This may have two causes:

1. The multimineralogical character of the sediments. $\mathrm{CaCO}_{3}$ and the weathering products of basalt (mainly olivine-pyroxene; see "Sedimentology and biological assemblages") (Fig. F68) have different matrix velocities. When abundances of the diverse components vary, different velocities can be expected (Stafleu, 1994).

2. In pure carbonates, pore types are the most dominant factor in controlling velocity after porosity (Anselmetti and Eberli, 2001). Moldic pores tend to deliver a stiffer frame than, for example, interparticle porosity. This has a distinct effect on velocity so that at any given porosity velocity may vary along with the specific pore type present.

Comparison of MSCL velocity data with downhole sonic logging data shows scattered MSCL $V_{\mathrm{p}}$ data mostly corresponding with high-velocity excursions in the downhole data (Fig. F69). This indicates that mainly matrix, cored-rock intervals have been directly measured with MSCL with an underrepresentation of slower sediments or rock intervals with extreme high macropores. The latter deliver slow velocity data because of the large contribution of open pore space filled with seawater $(\sim 1535 \mathrm{~m} / \mathrm{s})$.

\section{Magnetic susceptibility}

Magnetic susceptibility at this site shows a clear subdivision into three intervals corresponding to those given in "Density and porosity." The upper two intervals correspond to the last deglacial sequence. Interval 3 corresponds to the older Pleistocene sequence. Interval 1 has highly variable magnetic susceptibility with values from 0 to a maximum of $750 \times 10^{-5}$ SI units. Variations occur over short distances, and individual peaks of locations with a high influx of volcaniclastics have pronounced signatures with spikes toward higher values. Interval 2 reveals variable but lower magnetic susceptibility values, averaging $200 \times 10^{-5}$ SI units with lower limits of 0 units and maxima up to $400 \times 10^{-5}$ SI units. Interval 3 is made up of the older Pleistocene sequence and has a highly variable contribution of magnetic minerals with values ranging from 0 to a maximum of $750 \times 10^{-5}$ SI units. At most sites, the transition from Interval 1 to Interval 2 is sharp (e.g., Hole M00025A, 6 mbsf; Fig. F65). In Hole M0024A (Fig. F64), in contrast, the change occurs at $\sim 10.5$ mbsf but shows a gradual decrease between 10.5 and 20 mbsf toward values lower than $200 \times 10^{-5}$ SI units. In Holes M0021A (Fig. F62) and M0021B (Fig. F63), the subdivision is less pronounced with higher values in the upper part of the last deglacial and slightly lower values, on average $200 \times 10^{-5}$ SI units, toward the lower part of the unit. The higher magnetic susceptibility values may be attributed to the proximal location of the Tiarei River, which brings in higher concentrations of magnetic minerals within generally fine to coarse sand-sized volcaniclastic material. Through time, however, the course of the river and the amount of influx of volcaniclastic material is expected to have varied, causing the trends observed at these sites.

\section{Resistivity}

See "Resistivity" in the "Maraa western transect" chapter.

\section{Diffuse color reflectance spectrophotometry}

No clear downhole trends are observed in Unit I in any hole drilled in this area (Fig. F70). Spikes of higher values (up to $91 \mathrm{~L}^{*}$ units) characterize coral skeletons and calcareous algae (e.g., coralline algae). Color reflectance values of the older Pleistocene sequence are generally lower in $\mathrm{L}^{*}$, which may be indicative of influx of terrigenous clastics such as basaltic grains. In Cores 310-M0009A-16R through 18R (below 18.6 mbsf), 310-M0024A-16R (below 30.8 mbsf), 310-M0025A-12R through 13R (below 30.8 mbsf), and 310-M0025B-13R (below $19 \mathrm{mbsf}$ ) of the older Pleistocene sequence, color reflectance has a lower $\mathrm{L}^{*}$ value, down to $17 \mathrm{~L}^{*}$ units (Fig. F70). This interval consists of volcaniclastic sandstone.

\section{Hole-to-hole correlation}

All holes at the Tiarei outer ridge sites are along the reef (i.e., there are no upslope or downslope holes). Last deglacial-older Pleistocene transitions can easily be correlated and show that the depth of the older Pleistocene sequence is not always constant, indicating that the last deglacial sequence was deposited on an irregular topography. Two distinct zones are recognized in Unit I that can be correlated through specific trends in density, porosity, velocity, and magnetic susceptibility. This trend is more pronounced at the sites toward the northwest (Sites M0025, M0009, and others) and becomes less distinct toward the southeastern sites (Sites M0021 and M0026).

\section{Downhole logging}

Hole M0009B

Geophysical wireline operations were completed in Hole M0009B (100.31 mbsl) from 20.39 mbsf, with data coverage by nearly all slimhole tools to $\sim 5.96$ 
mbsf (position of bottom of the casing). All logs were acquired in an open hole. From the seafloor to 20.39 mbsf, total gamma radiation (TGR) is very low ( $\sim 32$ cps) despite logging speeds up to a maximum of 1.1 $\mathrm{m} / \mathrm{min}$. No clear differentiations between contributions of different elements $(\mathrm{K}, \mathrm{U}$, and $\mathrm{Th})$ can be made. Borehole conditions were very hostile in the lower part of the borehole (16-20.39 mbsf) but were quite stable in the upper part (Fig. F71), with the exception of a cavity at 13.75 mbsf. Optical images were slightly affected by murky borehole waters, but generally the quality was very good. Acoustic images are equal in quality, but the ABI40 tool could not pass the aforementioned cavity at 13.75 mbsf (Fig. F72).

Two intervals can be identified in the logged section of Hole M0009B:

- Interval 1 (13.89-18.12 mbsf; Cores 310-M0009B$12 \mathrm{R}$ through $13 \mathrm{R})$ is characterized by branching and encrusting coral growth forms. The density of the framework increases upsection, resulting in higher formation electrical resistivity values (from $1.1 \Omega \mathrm{m}$ at the bottom of the hole to $1.88 \Omega \mathrm{m}$ ). Sonic $P$-wave velocities $\left(V_{\mathrm{P}}\right)$ range from $\sim 1662$ to $\sim 4530 \mathrm{~m} / \mathrm{s}$. Sonic Stoneley waves could not be recorded in this interval. The temperature of the borehole fluid at the time of logging was $\sim 25.87^{\circ} \mathrm{C}, \mathrm{pH}$ values were $\sim 8.16$, and electrical conductivity was $\sim 55.32 \mathrm{mS} / \mathrm{cm}(0.180 \Omega \mathrm{m})$.

- The quality and resolution of the optical image allows for the identification and characterization of a second interval. Encrustations with microbialites are less pronounced in the basal part of Interval 2 (5.96-13.89 mbsf; Cores 310-M0009B$6 \mathrm{R}$ through 11R). Upsection, thickness and framework density increase, and the uppermost part of this interval (from $8.5 \mathrm{mbsf}$ ) is characterized by the occurrence of branching coral assemblages and a marked increase in microbialite encrustation. Formation electrical resistivity increased from 1.36 to $3.65 \Omega \mathrm{m} ; V_{\mathrm{p}}$ ranged from $\sim 2145$ to $\sim 3479 \mathrm{~m} / \mathrm{s}$. Sonic Stoneley wave velocities ranged from $\sim 932$ to $\sim 1463 \mathrm{~m} / \mathrm{s}$ (Fig. F71). Because of the extremely porous (mesoscale) character of the formation, sonic data are not continuous and are of poor quality. Natural gamma ray values are slightly higher in Interval 2 than in Interval 1.

\section{Hole M0009D}

Geophysical wireline operations were completed in Hole M0009D (103.18 mbsl) from 31.80 to 4.58 mbsf. Open-hole logging was performed in two different stages because of borehole instability:
1. By positioning an open shoe casing at $19.55 \mathrm{mbsf}$, most of the older Pleistocene sequence could be logged (19.55-31.80 mbsf; Cores 310-M0009D13R through 19R). Borehole conditions were very hostile for high-quality logging in the lower part, as can be observed from the caliper log (Fig. F73) and the borehole images. Cavities up to $0.5 \mathrm{~m}$ in height can be observed. Optical images were slightly affected by murky borehole fluids where cavities are present, but overall the quality is very good. Acoustic images were not affected by murky water conditions, and they complement the optical images by imaging the acoustic hardness of the borehole wall (Fig. F74). A spectral gamma ray log was made from 31.80 to $13.70 \mathrm{mbsf}$, where the upper $5.85 \mathrm{~m}$ were logged through the steel casing. Total gamma radiation (TGR) is very low (ranging from $\sim 13$ to $\sim 32 \mathrm{cps}$ ), despite logging speeds up to a maximum of $1.1 \mathrm{~m} / \mathrm{min}$. No clear differentiation between contributions of different elements $(\mathrm{K}, \mathrm{U}$, and $\mathrm{Th}$ ) can be made. Resistivity values ranged from 1.39 to $23.5 \mathrm{~m}$ (Fig. F73), and a marked interval between 18.0 and 20.5 mbsf with aboveaverage (compared to the other data obtained during the expedition) resistivity values was observed in the uppermost part of this section. The temperature of the borehole fluid was $\sim 25.55^{\circ} \mathrm{C}, \mathrm{pH}$ values ranged from $\sim 7.82$ to 8.09 , and electrical conductivity was $\sim 55.0 \mathrm{mS} / \mathrm{cm}(0.182 \Omega \mathrm{m})$. Because of the limited length of open hole below the casing and the hostile borehole conditions evidenced by low recovery and borehole images, it was decided not to run the mechanical caliper-sonic tandem in this interval.

2. By positioning an open shoe casing at $4.58 \mathrm{mbsf}$, most of the last deglacial sequence could be logged (4.58-19.55 mbsf; Cores 310-M0009D-5R through 13R). For safety reasons and time constraints, it was decided to make only two runs in this interval: (1) the Induction Resistivity Probe (DIL45) to probe for depth and at the same time measure an important lithological parameter and (2) an optical borehole televiewer (OBI40). Whereas the DIL45 tool could make the overlap with the previous section (below $19.55 \mathrm{mbsf}$ ), the OBI40 reached a maximum depth of 18.04 mbsf, just above the Unit I/II boundary. However, borehole conditions were extremely hostile in this interval, and major problems were encountered while lowering the tools in the borehole and logging up. The latter resulted in a substantial degradation of image data quality in the lower part of this section. The last deglacial sequence can be divided into three intervals.

- In Interval 1 (9.92-18.82 mbsf; Cores 310M0009D-8R through 12R) from $16.75 \mathrm{mbsf}$ 
(poor-quality optical image), encrusting coral growth forms can be identified and grade to more branching coral assemblages from 14.91 mbsf onward. Formation electrical resistivity increased from 0.97 to $2.04 \Omega \mathrm{m}$ in a cavity at 15.1 mbsf. A gradation of relatively thick to thinner branches upsection can be observed from the optical image (Fig. F74). The top of this interval is marked by a heavily encrusted surface and shows a formation electrical resistivity maximum $(2.48 \Omega \mathrm{m})$.

- Interval 2 (7.05-9.92 mbsf; Core 310-M0009D7R) is characterized at the base by an extremely open framework of branching coral growth forms. The overlying section consists of massive coral growth forms (Porites) ( 8.50 mbsf). Formation electrical resistivity values decrease within this interval from 1.93 to $1.06 \Omega \mathrm{m}$. The top-bounding surface consists of an extensively bored massive Porites.

- Interval 3 (4.58-7.05 mbsf; Cores 310-M0009D5R through 6R) consists of a coralgal framework with branching and encrusting coral growth forms. The top part (from $5.56 \mathrm{mbsf}$ ) is dominated by thin encrusting corals. Formation electrical resistivity increases upsection.

\section{Hole M0009E}

Hole M0009E (94.94 mbsl) was logged for geophysical parameters. Geophysical wireline operations were completed from 14.92 mbsf with data coverage by all slimhole tools without repositioning the open shoe casing (fixed at $2.55 \mathrm{mbsf}$ ).

Borehole conditions were hostile, and the borehole was highly unstable, especially below 11 mbsf. The calipers show a large increase in borehole diameter below this depth, and the logging tools could not pass an obstruction at 15 mbsf even after repetitive cleaning and hammering efforts. The optical image was affected by murky borehole waters. Acoustic images were not affected by this and show a high-quality virtual (acoustic) representation (at millimeter scale) of the lithologies cored (Fig. F75).

The logged section can be divided into three intervals:

- Interval 1 (11.03-14.92 mbsf; Cores 310-M0009E7R through 9R) has branching coral growth forms in the middle part where framework density and pronounced encrusting increases upward, with massive Porites at the top. Natural gamma ray values are lowest in dense sections and show elevated values in the lower part of the interval. Resistivity values increase slightly from $1.4 \Omega \mathrm{m}$ at the base to $1.72 \Omega \mathrm{m}$ at the top, indicating less pronounced encrusting and infilling of pore space by microbialite crusts. Acoustic velocities could not be measured over this interval.

- Interval 2 (7.33-11.03 mbsf; Cores 310-M0009E$4 \mathrm{R}$ through $6 \mathrm{R}$ ) is dominated by microbialite boundstone lithofacies that include encrusting coral growth forms. Resistivity values increase slightly from $1.78 \Omega \mathrm{m}$ at the base to $2.09 \Omega \mathrm{m}$ at the top. Compressional acoustic velocity $\left(V_{\mathrm{p}}\right)$ is highly variable (small-scale changes) and ranges from a minimum of $1823 \mathrm{~m} / \mathrm{s}$ to a maximum of $2898 \mathrm{~m} / \mathrm{s}$. Stoneley wave velocity ranges from 930 to $1842 \mathrm{~m} / \mathrm{s}$. Gamma ray values (TGR) are fairly constant over the entire interval (Fig. F76).

- Interval 3 (2.55-7.33 mbsf; Cores 310-M0009E-2R through $4 \mathrm{R}$ ) has a rubbly character at the base with encrusting coral growth forms that dominate the remainder of the interval. The abundance of encrusting microbialite varies within this interval, which is observed on the acoustic image and in the variation in formation resistivity (highest in intensely encrusted intervals). Natural gamma ray values are fairly constant but decrease toward the top (2.55 mbsf). Within the casing, a further decrease can be observed. $V_{\mathrm{p}}$ is highly variable, but a general increase in velocities can be observed from base to top (1823-3715 m/s). Stoneley wave (tube wave) velocities range from 1185 to $1825 \mathrm{~m} /$ $\mathrm{s}$, but proper data coverage, especially in the rubbly and most open framework intervals, is poor. The temperature of the borehole fluid a few hours after drilling decreased from $26.2^{\circ}$ to $25.0^{\circ} \mathrm{C}$ from base to top in Hole M0009E, $\mathrm{pH}$ values were 8.14, and borehole fluid electrical conductivity decreased upsection from 55.79 to $55.1 \mathrm{mS} / \mathrm{cm}$ $(0.179-0.181 \Omega \mathrm{m})$.

\section{Hole M0021B}

Hole M0021B (81.70 mbsl) was logged for geophysical parameters (Fig. F77). Drilling depth was 32.81 mbsf, and geophysical wireline operations were completed in Hole M0023A from 17.07 mbsf with data coverage by all slimhole tools without repositioning the open shoe casing (fixed at $2.88 \mathrm{mbsf}$ ) under open (and very hostile) borehole conditions. Borehole conditions were harsh, and the borehole was highly unstable especially below 15 mbsf. The calipers show a large increase in borehole diameter below this depth, and the logging tools could not pass an obstruction at $\sim 17$ mbsf even after repetitive cleaning and hammering efforts. Optical images were seriously affected by murky borehole waters. Toward the top of the hole, the quality was better. Acoustic images were not affected and are a high-quality visual 
representation (millimeter scale) of cored lithologies (Fig. F78). In Hole M0021B, the last deglacial sequence can be divided into three intervals:

- Interval 1 (13.15-17.09 mbsf; Cores 310-M0021B$8 \mathrm{R}$ through 10R) consists of a rubbly basal section and a framework composed of branching coral colonies that can be identified from the acoustic image. Formation resistivity increased from 0.72 to $1.88 \Omega \mathrm{m}$, natural radioactivity values decreased, the temperature of the borehole fluid was $\sim 27.56^{\circ} \mathrm{C}, \mathrm{pH}$ values were $\sim 7.96$, and borehole fluid electrical conductivity was $\sim 56.48 \mathrm{mS} / \mathrm{cm}$ $(0.177 \Omega \mathrm{m})$.

- Interval 2 (6.5-13.15 mbsf; Cores 310-M0021B-4R through 7R) displays branching and encrusting coral growth forms in which the volume of microbialite crusts increases upsection; a more open framework with less microbialite dominates the top $1 \mathrm{~m}$ (7.5-6.5 mbsf). Formation resistivity increases from 1.82 to a maximum value of 3.85 $\Omega \mathrm{m}$ at $7.59 \mathrm{mbsf}$, after which it decreases to a minimum of $1.8 \Omega \mathrm{m}$ at $6.51 \mathrm{mbsf}$. Natural radioactivity values were constantly low but slightly decreased upsection, the temperature of the borehole fluid was $\sim 27.49^{\circ} \mathrm{C}, \mathrm{pH}$ values were $\sim 7.96$, and borehole fluid electrical conductivity was $\sim 56.4 \mathrm{mS} / \mathrm{cm}(0.177 \Omega \mathrm{m})$. Acoustic formation velocities $\left(V_{\mathrm{P}}\right)$ are highly variable but show a general decrease from $3059 \mathrm{~m} / \mathrm{s}$ at $7.8 \mathrm{mbsf}$ to a minimum of $1797 \mathrm{~m} / \mathrm{s}$.

- Interval 3 (2.88-6.5 mbsf; Cores 310-M0021B-2R through 3R) has a cavity at its base with frameworks formed successively by branching coral colonies and encrusting growth forms at the top. Formation resistivity increased from 1.49 to 3.41 $\Omega \mathrm{m}$; natural radioactivity values increased in the rubble section but remained constant throughout the rest of the interval. Borehole fluid properties remained constant, and $V_{\mathrm{p}}$ was highly variable but showed a slight increase from base to top, where the minimum and maximum $V_{\mathrm{p}}$ values were 1797 and $3601 \mathrm{~m} / \mathrm{s}$, respectively.

\section{Synthesis: geophysical downhole logging at Tiarei inner and outer ridges}

Wireline logging operations at Tiarei sites produced nearly complete downhole coverage of the last deglacial sequence from 72 to $122 \mathrm{mbsl}$. Tools have different data coverage in various holes (see the "Downhole logging" sections in the individual site chapters). It was not possible to image the boundary between Units I and II, except in Holes M0021B and M0023B.
In Figure F79, borehole images and natural radioactivity logs (total counts) are plotted in meters below modern sea level. In each logged borehole, the boundary between the last deglacial and older Pleistocene sequences is indicated. The basal part of Unit I directly overlying this boundary is often semiconsolidated and poorly recovered and shows elevated natural gamma radioactivity values in proximal locations (e.g., Hole M0023B). Distal locations do not show this higher gamma ray signature, with the exception of Hole M0021B.

In Figure F80, borehole images and formation electrical resistivity (resistivity) are plotted in meters below modern sea level. The general resistivity pattern and absolute values in the last deglacial sequence along this transect are comparable across the holes. In each hole, the basal interval has the lowest resistivity values and values increase gradually uphole to a maximum value, after which a sharp negative excursion to lower values can be observed. However, the interval of increasing resistivity values is interrupted once by a subtle decrease in the middle part of the last deglacial sequence. The absolute values of this decrease are higher at distal sites than at the proximal ones. Caliper, borehole fluid characterization, and acoustic tools all contain particular information on parameters for specific intervals and lithologies.

Similar to the Maraa transects, the depth of the top of the older Pleistocene sequence below modern day sea level is highly variable and indicates a very uneven paleotopography before the last deglaciation.

\section{Geochemistry}

All geochemical pore water data are presented in tables allsitesIW.xls and IWsaturation.xls in "Supplementary Material."

\section{$\mathrm{pH}$, alkalinity, ammonia, chloride, and sulfate}

The $\mathrm{pH}$ of all pore water samples from the Tiarei outer ridge is generally like seawater, with samples from Hole M0009A having slightly lower $\mathrm{pH}$ (Fig. F81A). Alkalinity in these pore waters is generally that of seawater or slightly lower (Fig. F81B). Of the few pore water samples obtained from Tiarei outer ridge sites, ammonia was only detected in a single sample (Sample 310-M0025A-11R-1, $130 \mathrm{~cm}$ ). Chloride and sulfate concentrations do not significantly deviate from seawater values, indicating that no freshwater influence is observed on the interstitial water (IW) geochemistry. 


\section{$\mathrm{Mg}, \mathrm{K}, \mathrm{Ca}$, and Sr}

$\mathrm{Mg}, \mathrm{K}$, and $\mathrm{Ca}$ (Fig. F81C) concentrations are within error of seawater values in all pore water samples from the Tiarei outer ridge. $\mathrm{Sr}$ is elevated above seawater values only in Hole M0009A samples (Fig. F81D), suggesting some aragonite dissolution may have occurred as a result of the lower $\mathrm{pH}$ values in these pore waters.

\section{$\mathrm{Li}, \mathrm{P}, \mathrm{Mn}, \mathrm{Fe}$, and $\mathrm{Ba}$}

Compared to a seawater Li concentration of $174 \mu \mathrm{g} /$ $\mathrm{L}, \mathrm{Li}$ is enriched in some samples but depleted in others (Fig. F81E), suggesting the presence of both sinks and sources of Li in Tiarei outer ridge material. Most samples display P concentrations in the same range as those found for Tahitian seawaters sampled during drilling operations (53-90 $\mu \mathrm{g} / \mathrm{L}$; M. Kölling, unpubl. data), but a couple of the samples are slightly enriched (Fig. F81F). Mn, Fe, and $\mathrm{Ba}$ are highly elevated compared to seawater in most samples (Fig. F81G-F81I), and the source of these cations is most likely the dissolution of microbialites (Camoin et al., 2006).

\section{References}

Anselmetti, F., and Eberli, G., 2001. Sonic velocity in carbonates: a combined product of depositional lithology and diagenetic alterations. In Ginsburg, R.N. (Ed.), Subsurface Geology of a Prograding Carbonate Platform Margin, Great Bahama Bank: Results of the Bahamas Drilling Project. Spec. Publ.—SEPM (Soc. Sediment. Geol.), 70:193-216.

Camoin, G., Cabioch, G., Eisenhauer, A., Braga, J.-C., Hamelin, B, and Lericolais, G., 2006. Environmental significance of microbialites in reef environments during the last deglaciation. Sediment. Geol., 185(3-4):277-295. doi:10.1016/j.sedgeo.2005.12.018

Raymer, L.L., Hunt, E.R., and Gardner, J.S., 1980. An improved sonic transit time-to-porosity transform. Trans. SPWLA 21st Annu. Log. Symp., Pap. P.

Stafleu, J., Everts, A.J.W., and Kenter, J.A.M., 1994. Seismic models of a prograding carbonate platform: Vercors, South-east France. Mar. Pet. Geol., 11(5):514-537. doi:10.1016/0264-8172(94)90065-5

Wyllie, M.R.J., Gregory, A.R., and Gardner, L.W., 1956. Elastic wave velocities in heterogeneous and porous media. Geophysics, 21(1):41-70. doi:10.1190/1.1438217

Publication: 4 March 2007

MS 310-108 
Figure F1. Coral framework of branching Porites colonies encrusted with coralline algae and microbialites (Unit IA; interval 310-M0009B-9R-1, 5-20 cm).

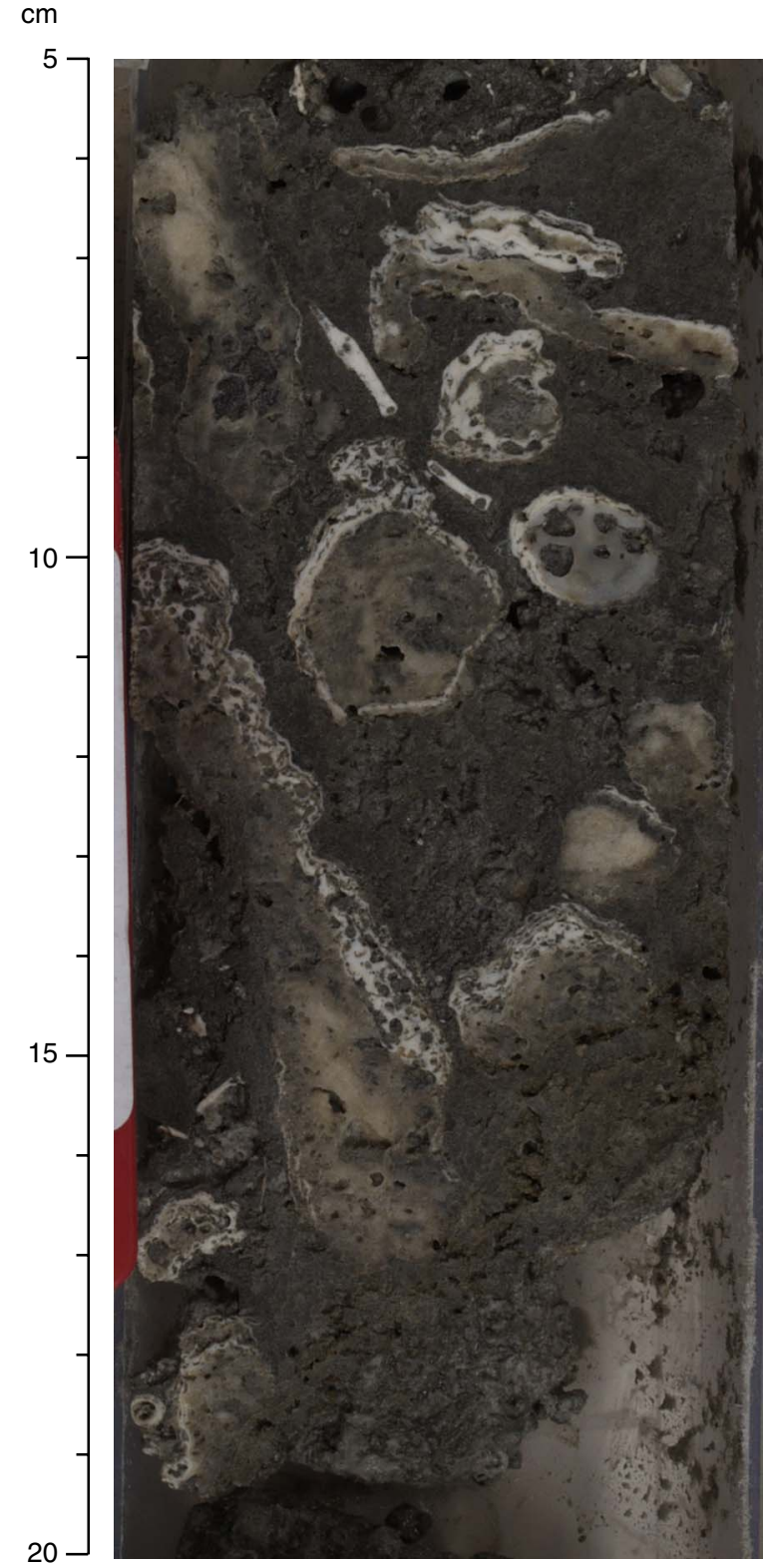


Figure F2. Unconsolidated coral rubble and Halimeda segments (Unit I; interval 310-M0024A-15R-1, 0-20 $\mathrm{cm})$.

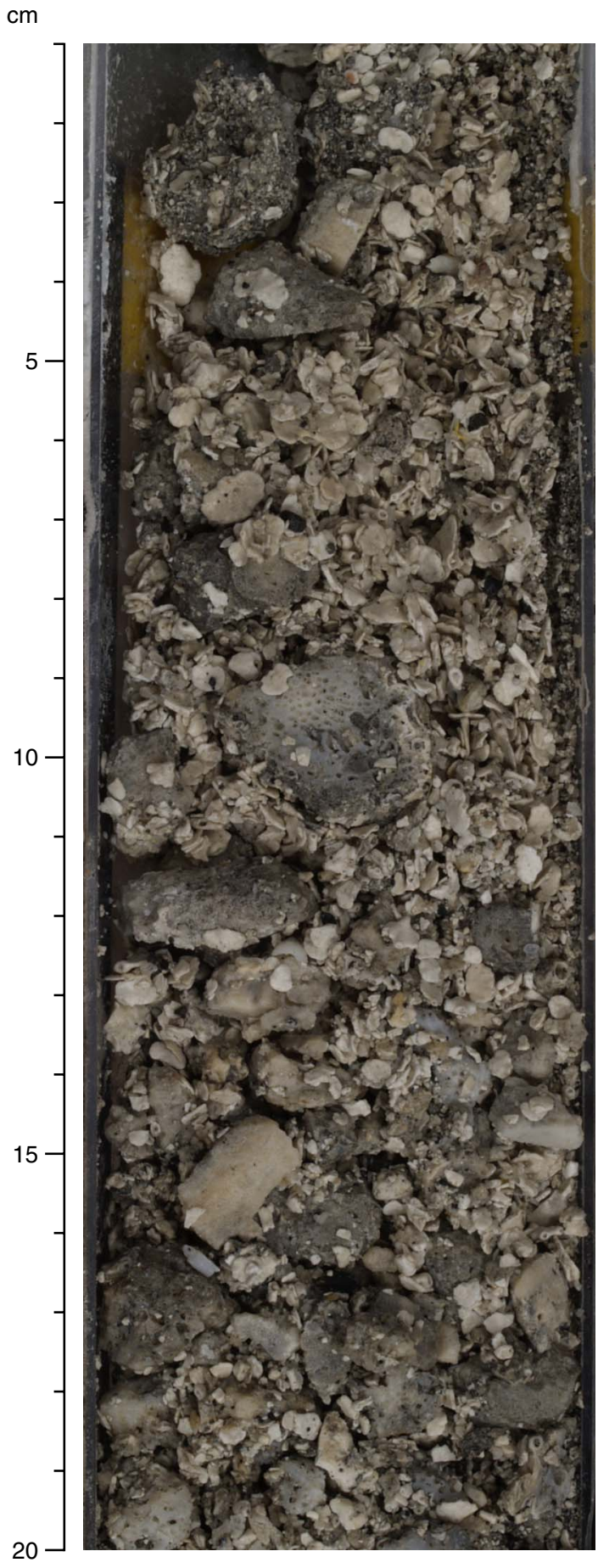


Figure F3. Halimeda packstone (Unit I; interval 310-M0026A-6R-1, 88-96 cm).

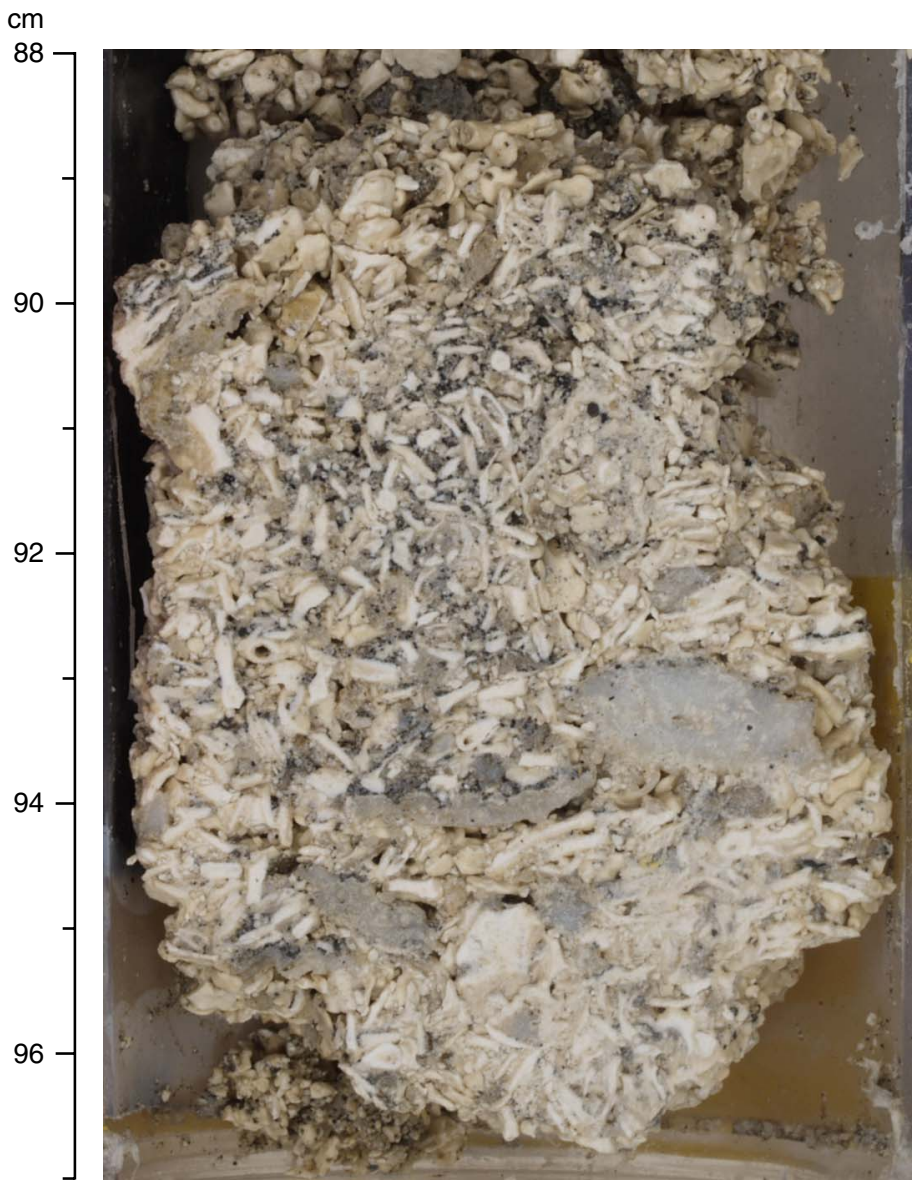


Figure F4. Multiple encrustation with thin crusts of coralline algae (Unit I; interval 310-M0021A-1R-1, 10-23 $\mathrm{cm})$.

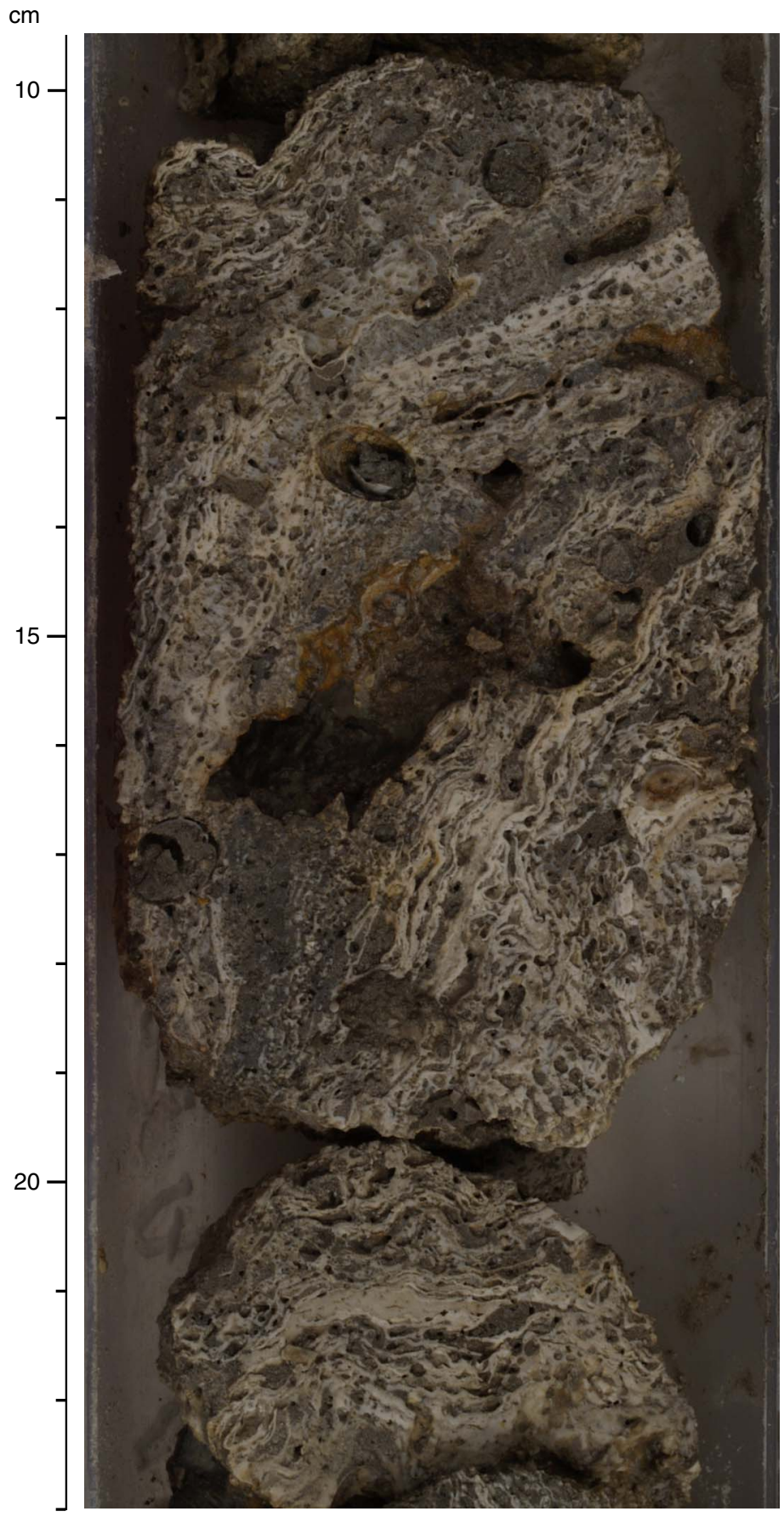


Figure F5. Hardground at the top of Unit I characterized by dark staining and intense bioerosion (Unit I; interval 310-M0021B-1R-1, 0-11 cm). Sediment contains multiple thin coralline algal encrustations.

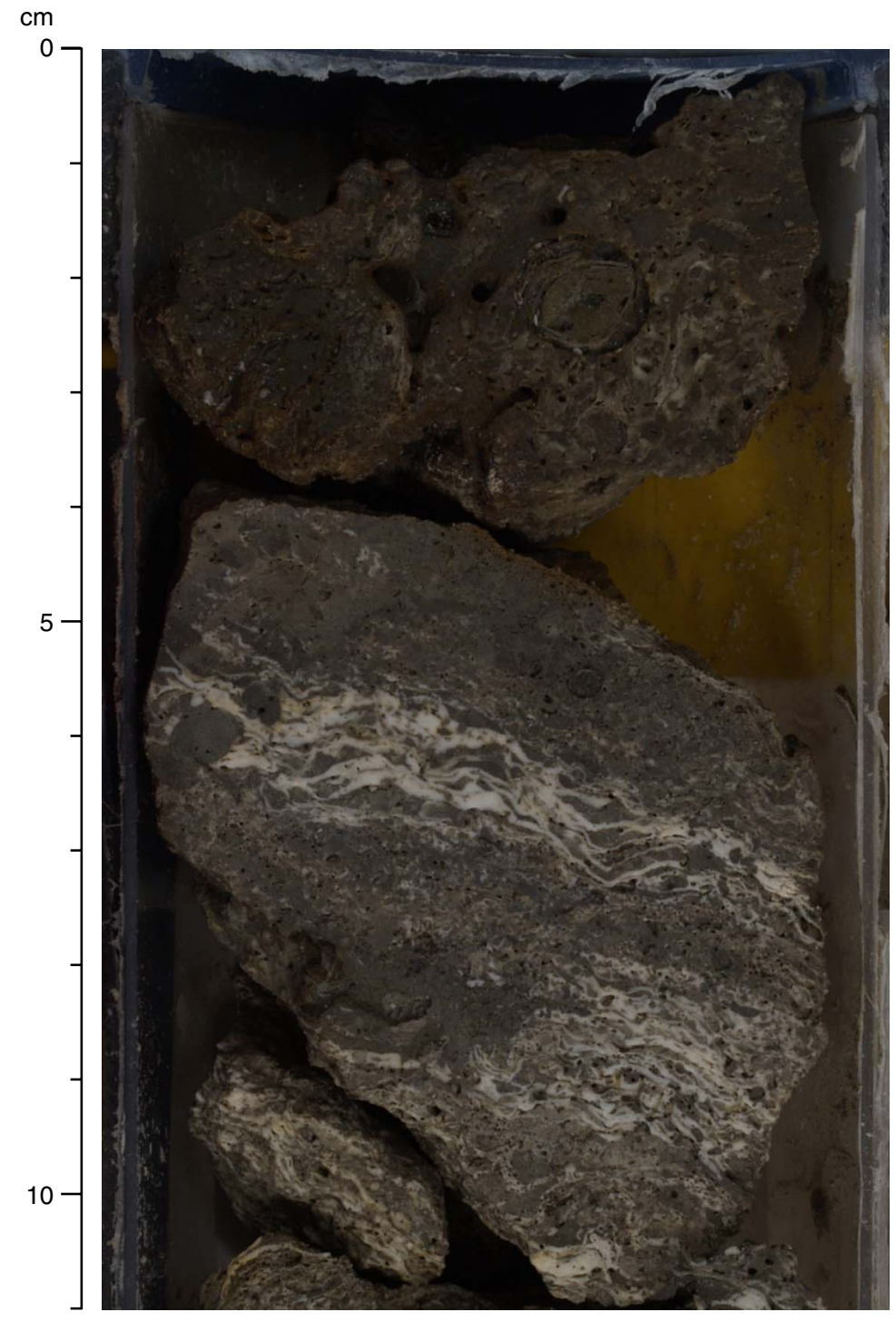


Figure F6. Coral framework of branching colonies of Porites with thick laminated microbial crusts (Unit I; interval 310-M0021A-5R-1, 58-71 cm).

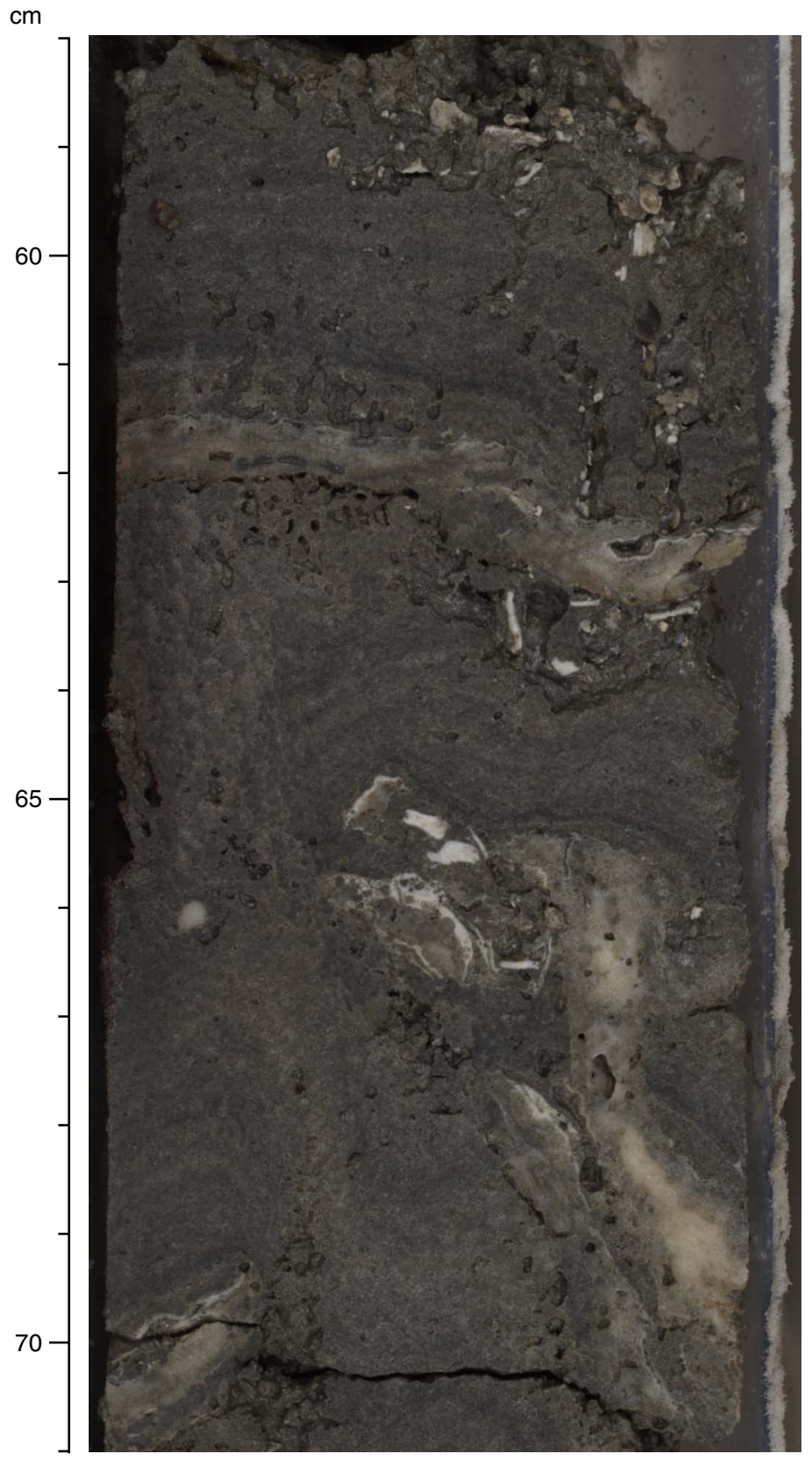


Figure F7. Branching colonies of Porites encrusted with thin coralline algal crusts and subsequent thick laminated microbialite crusts (Unit I; interval 310-M0021A-8R-1, 18-31 cm).

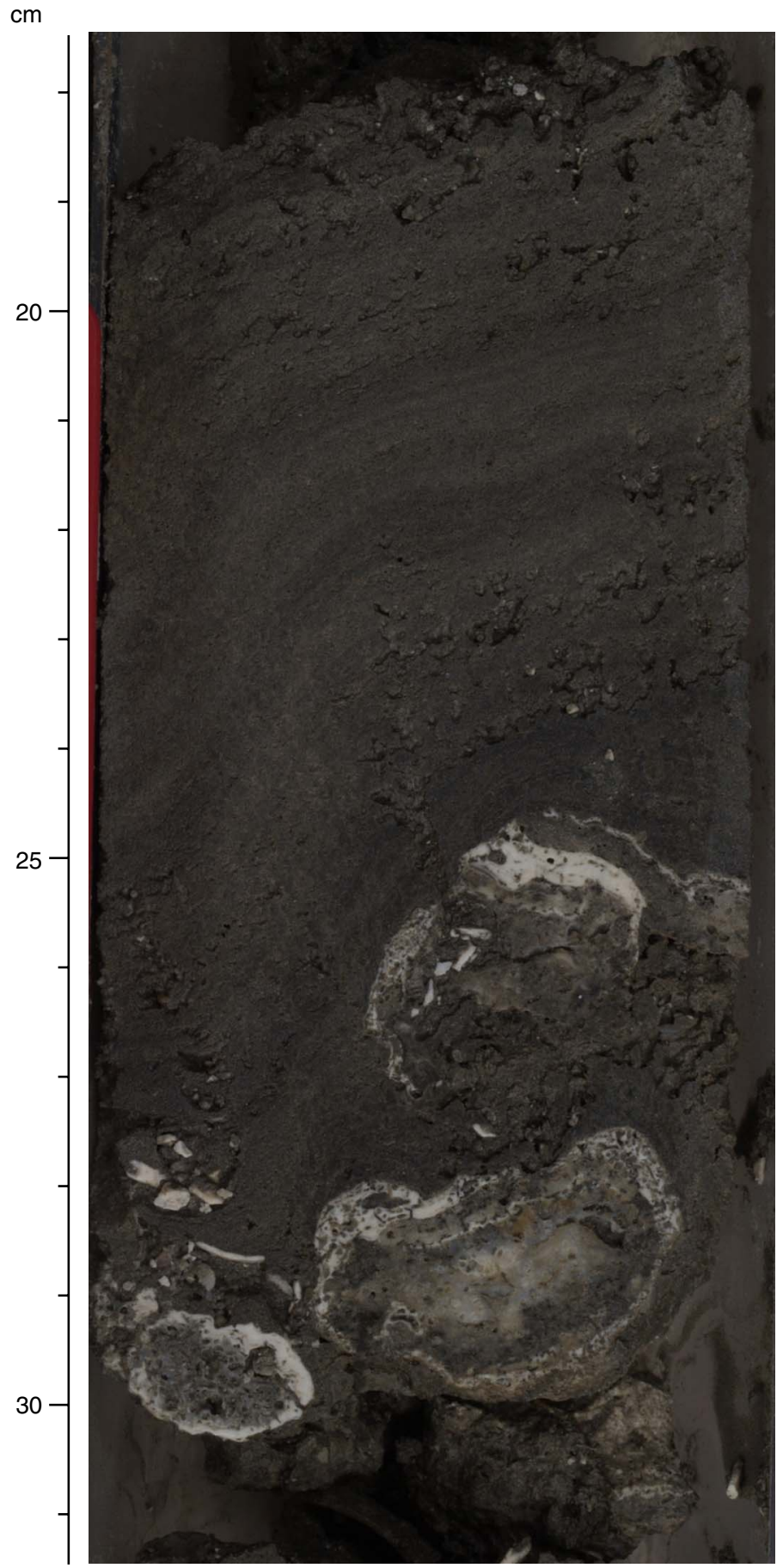


Figure F8. Coral framework of branching Porites colonies with thin crusts of coralline algae and subsequent thick microbialite crusts (Unit I; interval 310-M0021B-5R-1, 63-80 cm).

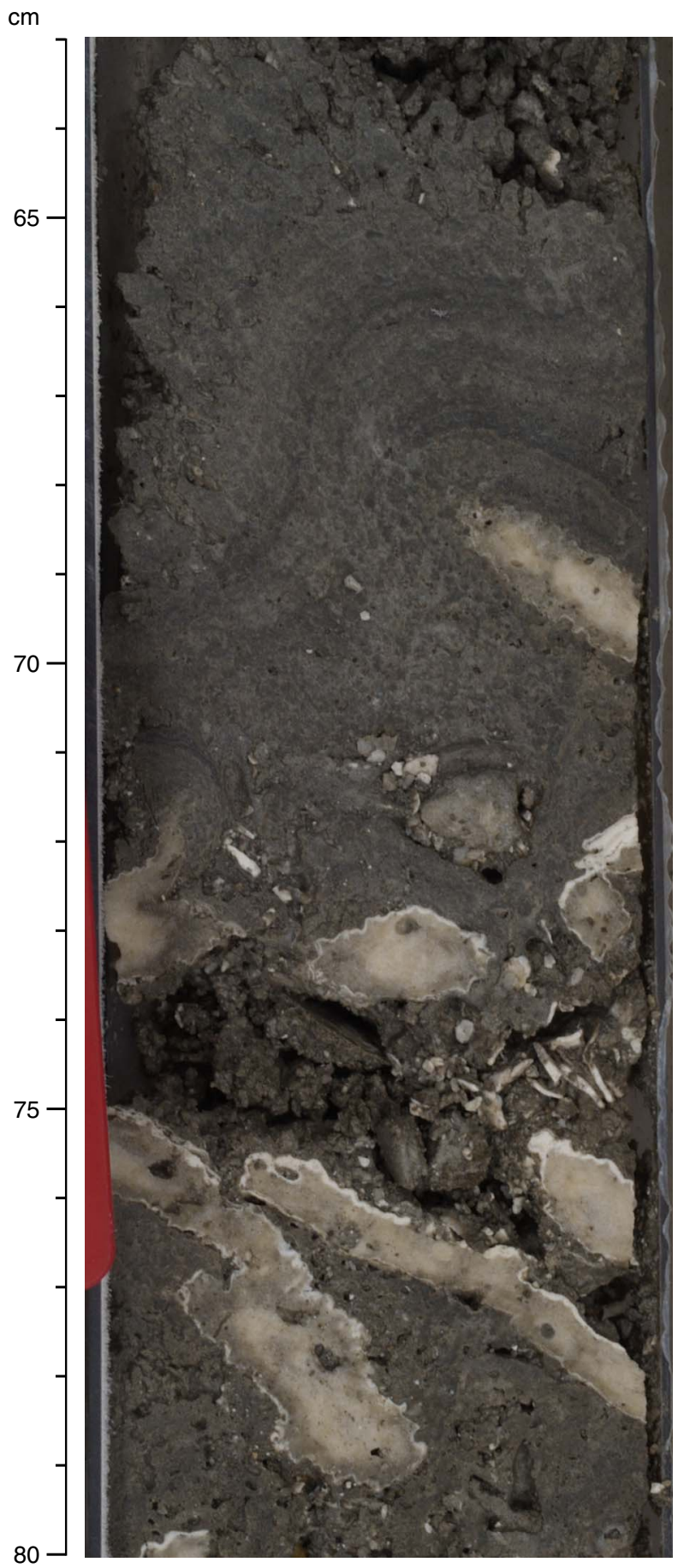


Figure F9. Massive microbialite crust (thrombolitic to laminated) (Unit I; interval 310-M0021A-6R-1, 9-20 $\mathrm{cm})$.

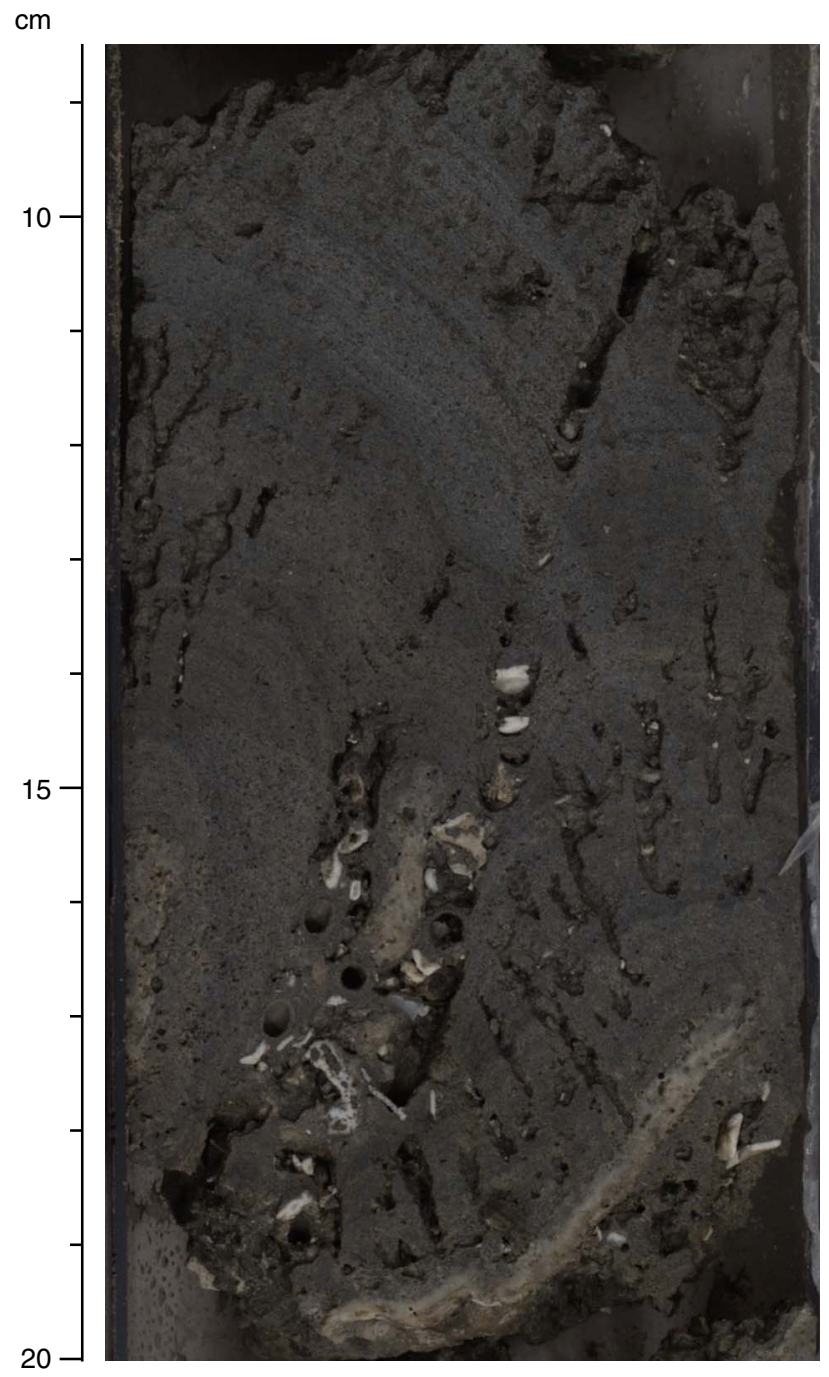


Figure F10. Coralgal bindstone with encrusting colonies of Leptastrea and agariciids (Subunit IA; interval 310M0009B-2R-1, 20-30 cm). Note extensive bioerosion.

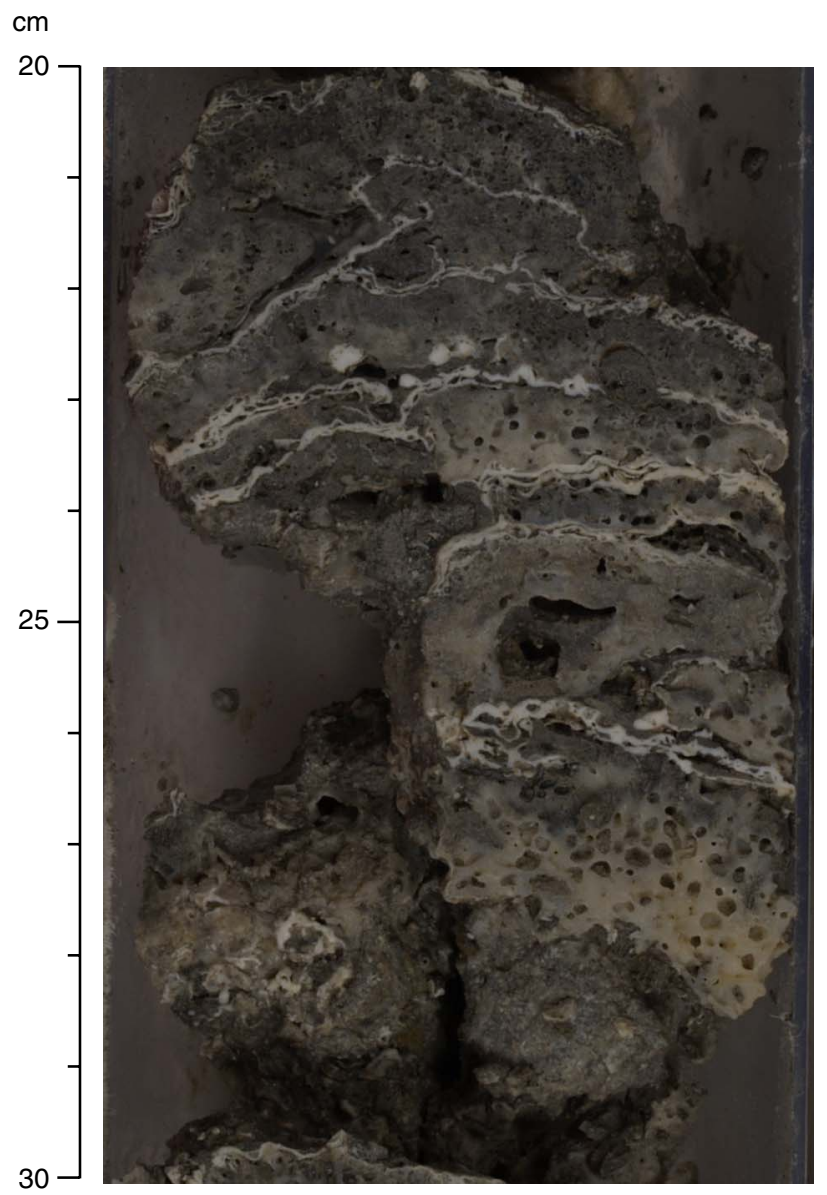


Figure F11. Encrusting colonies of Leptastrea (Subunit IA; interval 310-M0021B-1R-1, 65-83 cm).

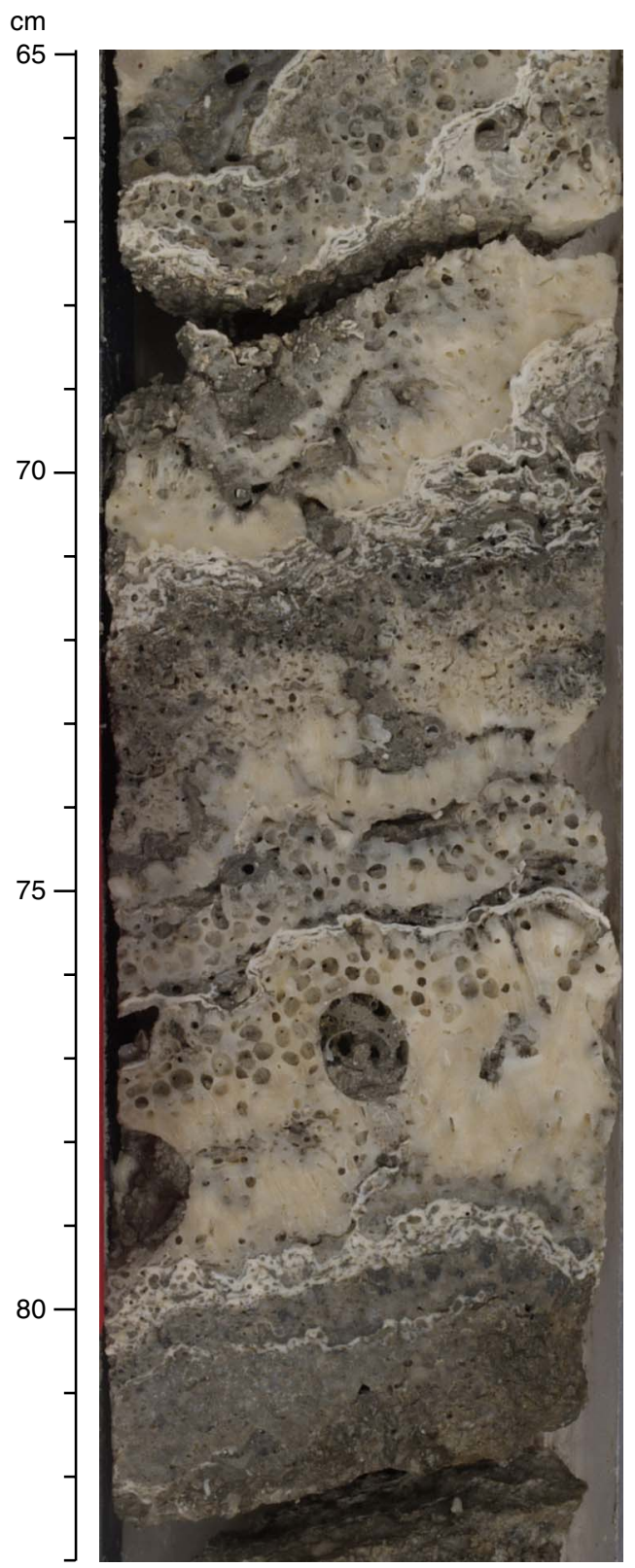


Figure F12. Coral framework of encrusting colonies of agariciids (Pavona?) with multiple thin encrustations of coralline algae and thick microbialite crusts (Subunit IA; interval 310-M0025A-1R-1, 34-61 cm).

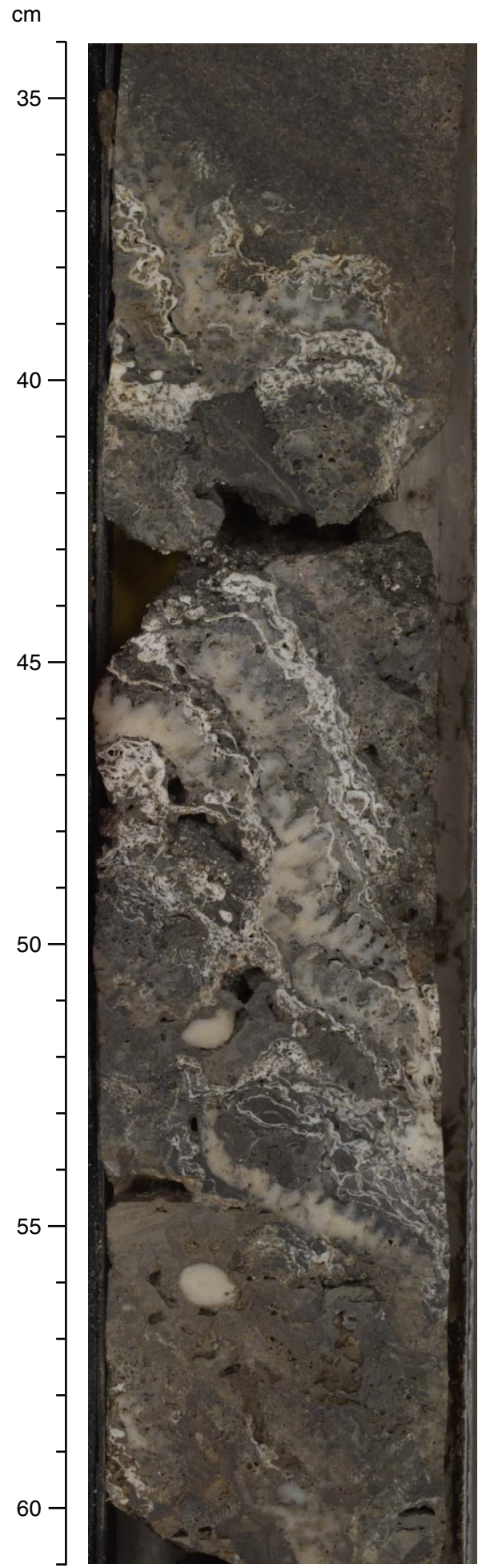


Figure F13. Coral framework of branching colonies of Pocillopora with thick coralline algal crusts on tips of branches and subsequent thick microbial encrustations (Subunit IA; interval 310-M0021A-5R-1, 88-107 cm). Note Halimeda segments in primary pore space.

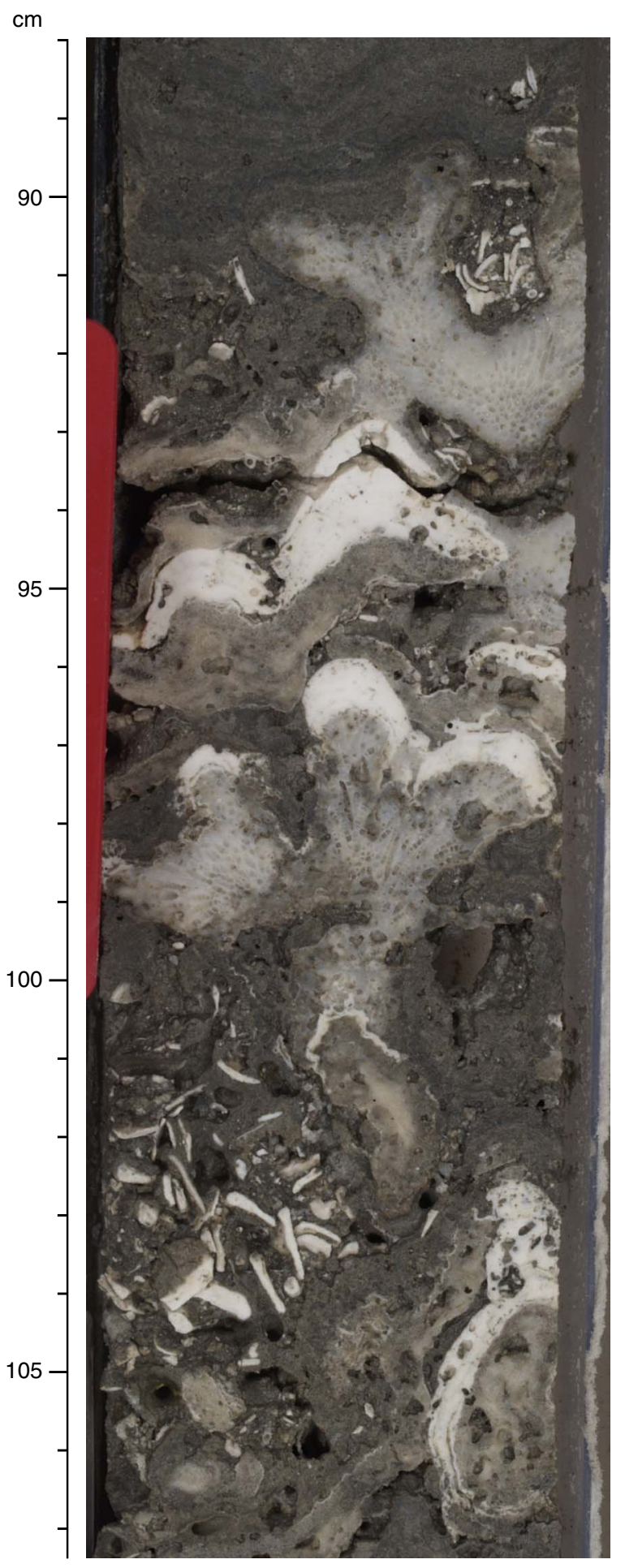


Figure F14. Branching Porites framework with thick crusts of coralline algae on tips of colonies (Subunit IB; interval 310-M0021A-10R-1, 102-117 cm). Microbialites represent last stage of encrustation. Note open primary pore spaces.

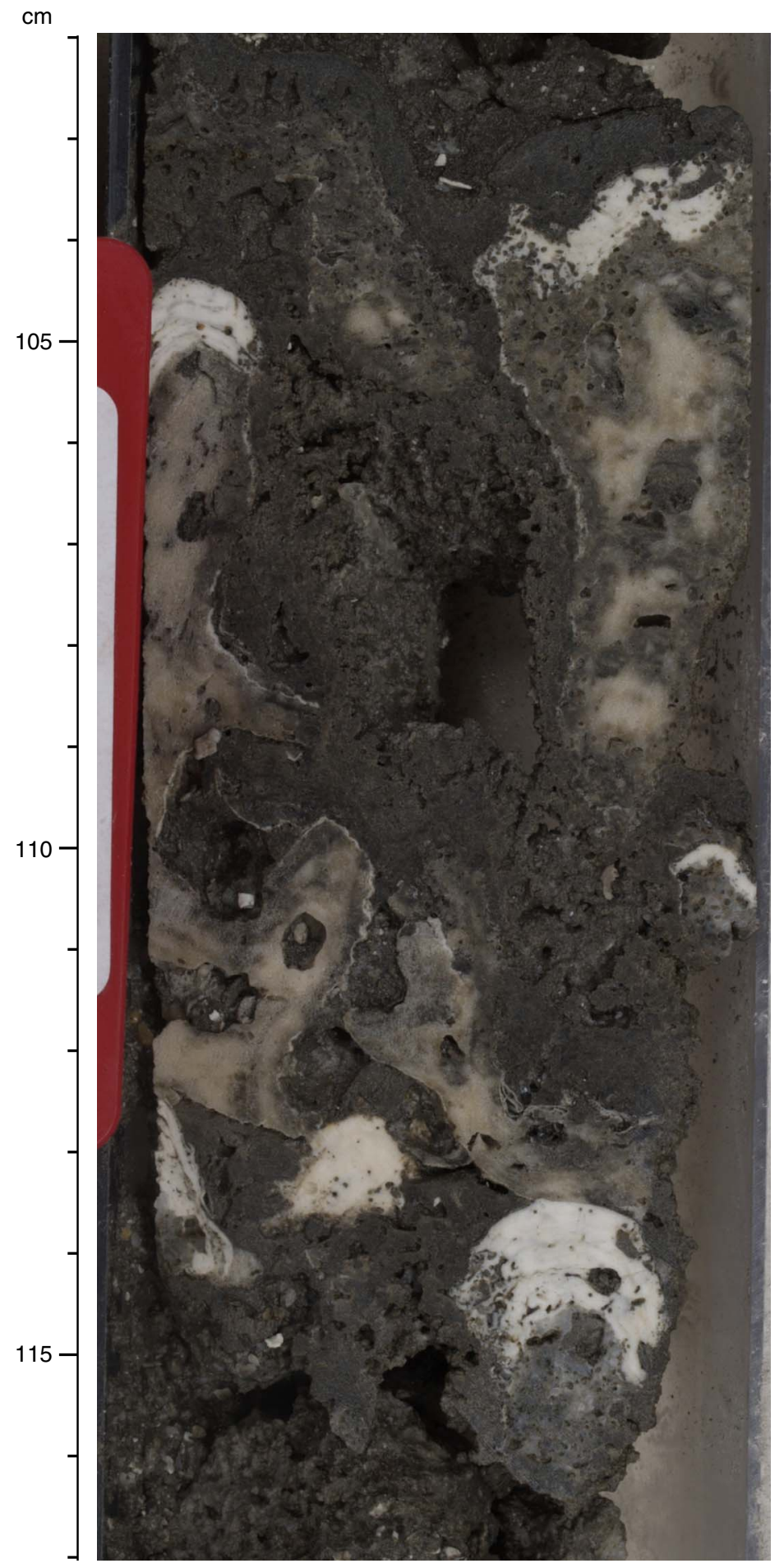


Figure F15. Coral framework of branching colonies of Porites with coralline algal crusts (thick crusts on tips in upper part of image) (Subunit IB; interval 310-M0021A-12R-1, 30-50 cm). Microbialite crusts represent last stage of encrustation. Note open primary pore spaces.

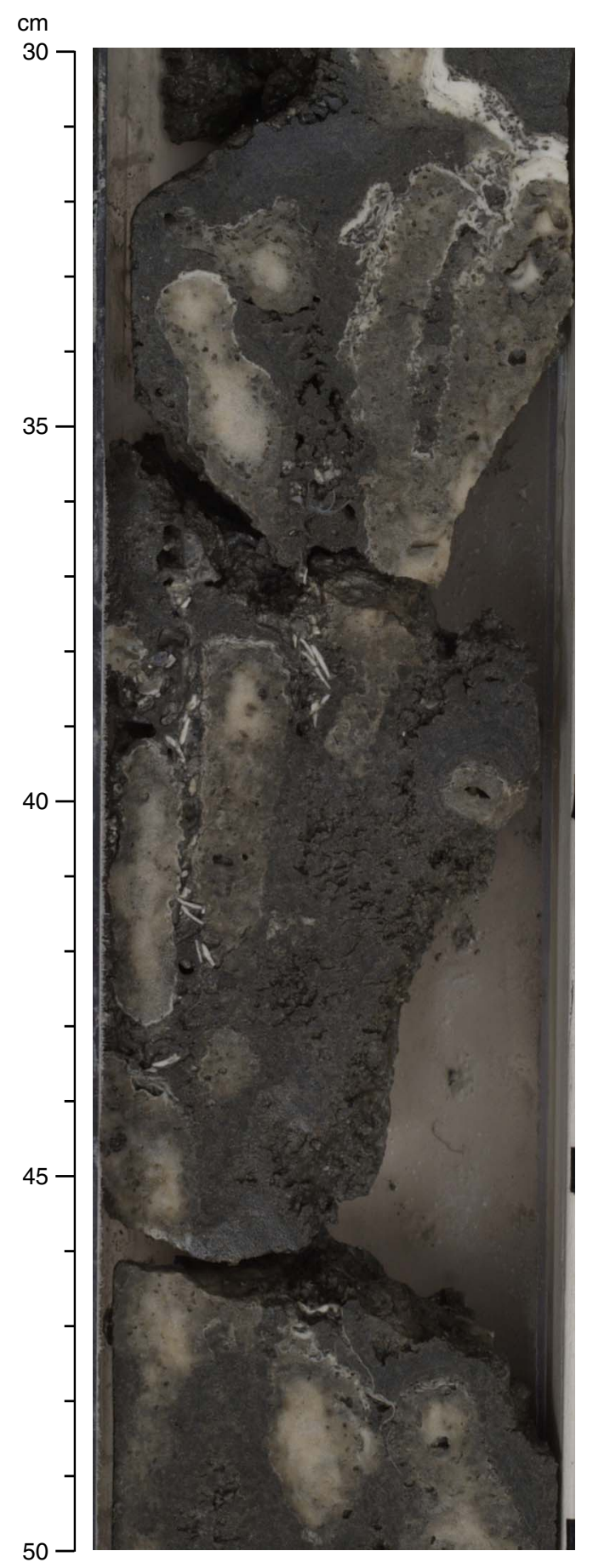


Figure F16. Coral framework of branching Porites colonies with coralline algal crusts that are thicker on tips of colonies and subsequent thick microbialite encrustations (Subunit IB; interval 310-M0021B-7R-1, 70-86 cm).

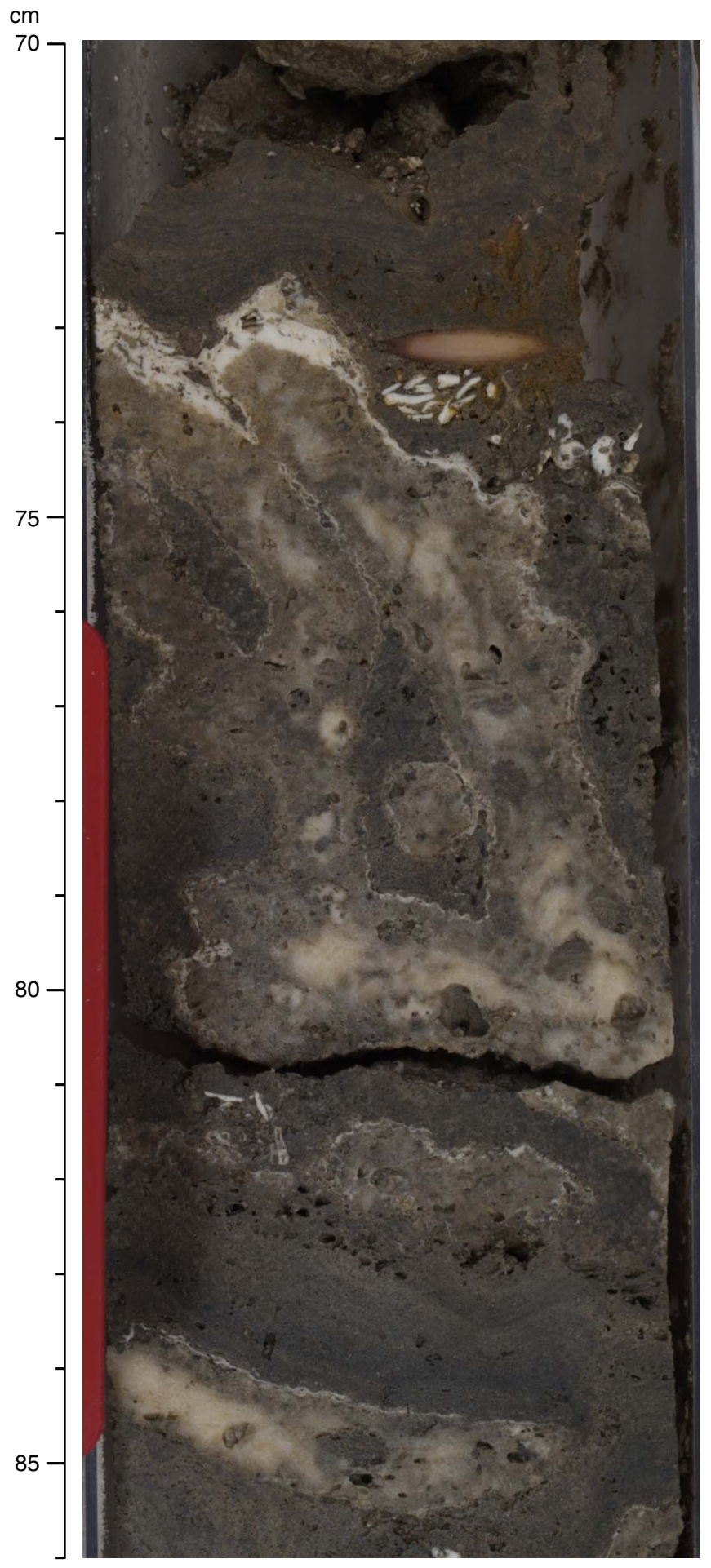


Figure F17. Coral framework of branching Porites colonies in grainstone bearing Halimeda segments (Subunit IB; interval 310-M0021B-15R-1, 46-66 cm).

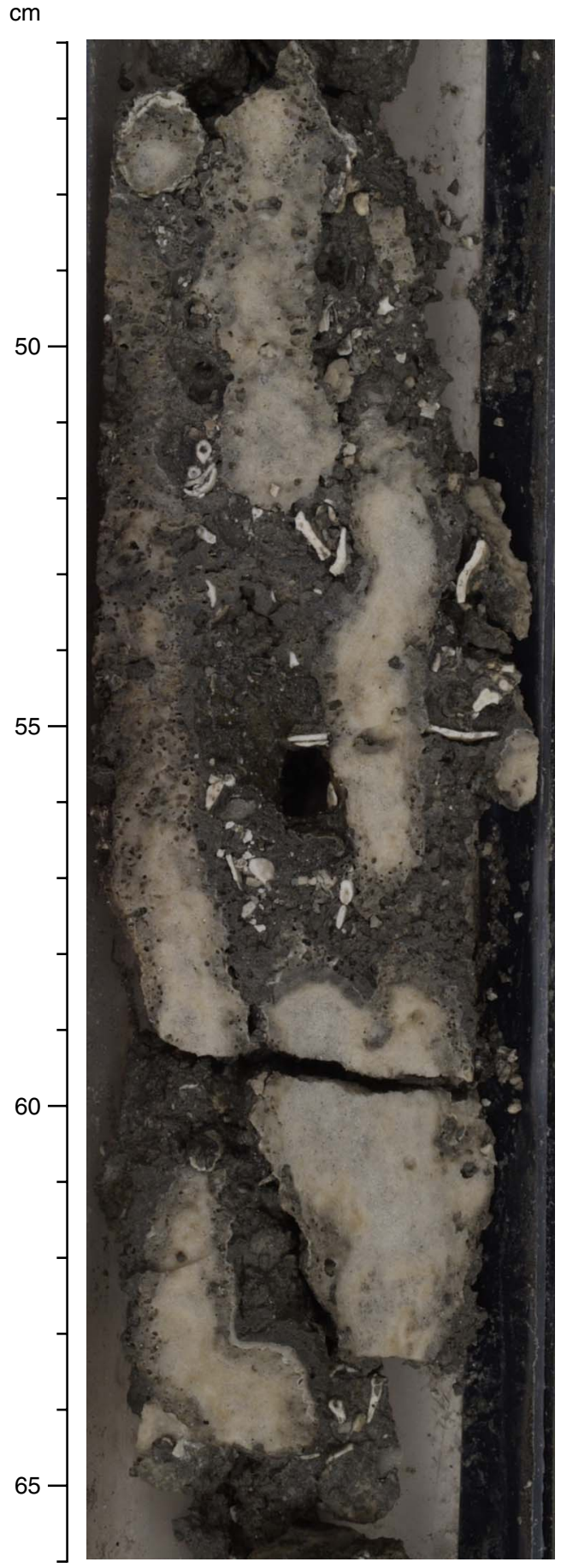


Figure F18. Coral framework of robust branching Pocillopora colonies with skeletal sand and gravels in primary porosity (Subunit IB; interval 310-M0024A-3R-1, 72-91 cm). Framework is overlain by thick microbialite crusts.

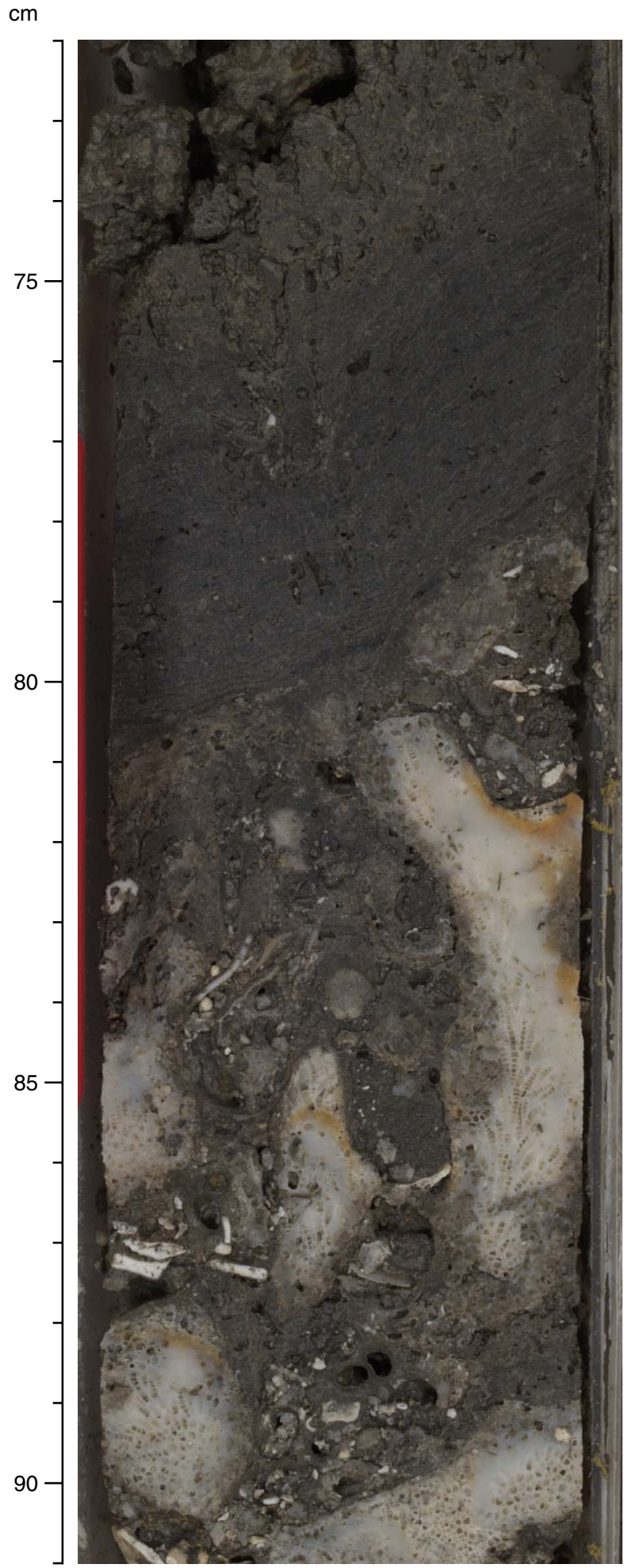


Figure F19. Encrusting colonies of Montipora interlayered with thin microbial crusts and Halimeda segments (Subunit IB; interval 310-M0024A-5R-2, 8-20 cm).

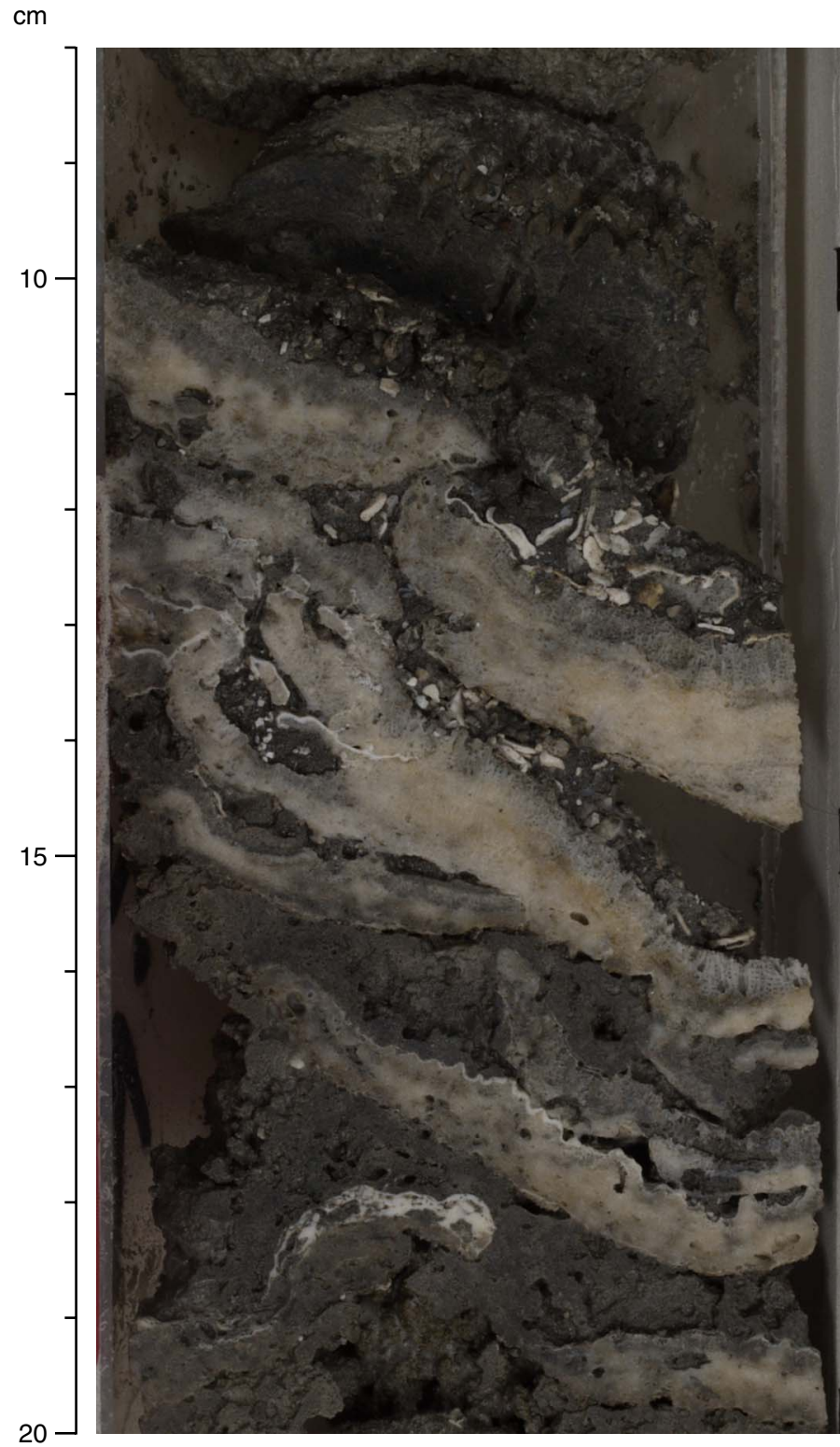


Figure F20. Coral framework of branching colonies of Porites with thick coralline algal crusts on tips (Subunit IB; interval 310-M0024A-9R-1, 19-49 cm). Coral framework is encrusted with thick thrombolitic masses of microbialites. Note open primary pore spaces.

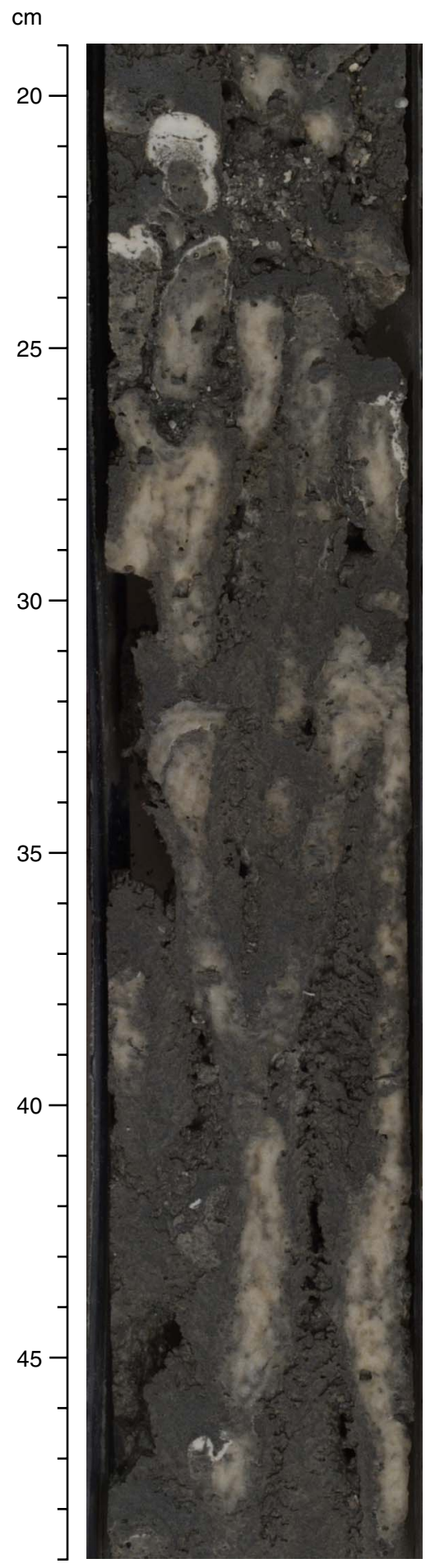


Figure F21. Coralgal framework composed of branching colonies of Porites encrusted with thick coralline algal crusts on tips and subsequent microbialites (Subunit IB; interval 310-M0024A-9R-2, 74-90 cm).

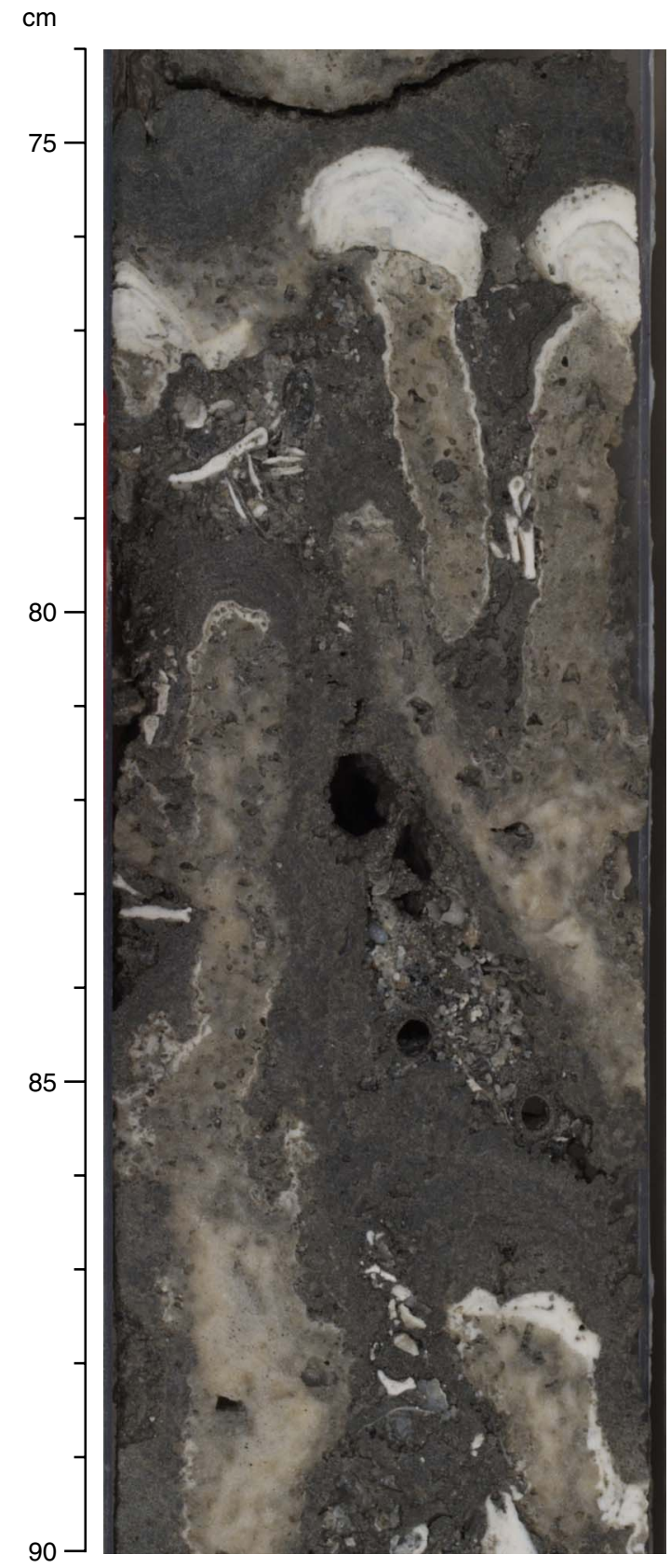


Figure F22. Tabular colony of Acropora (Subunit IB; interval 310-M0009B-13R-1, 3-18 cm). Note thick crusts of coralline algae covering tips of coral branches. Sediment matrix contains abundant Halimeda segments.

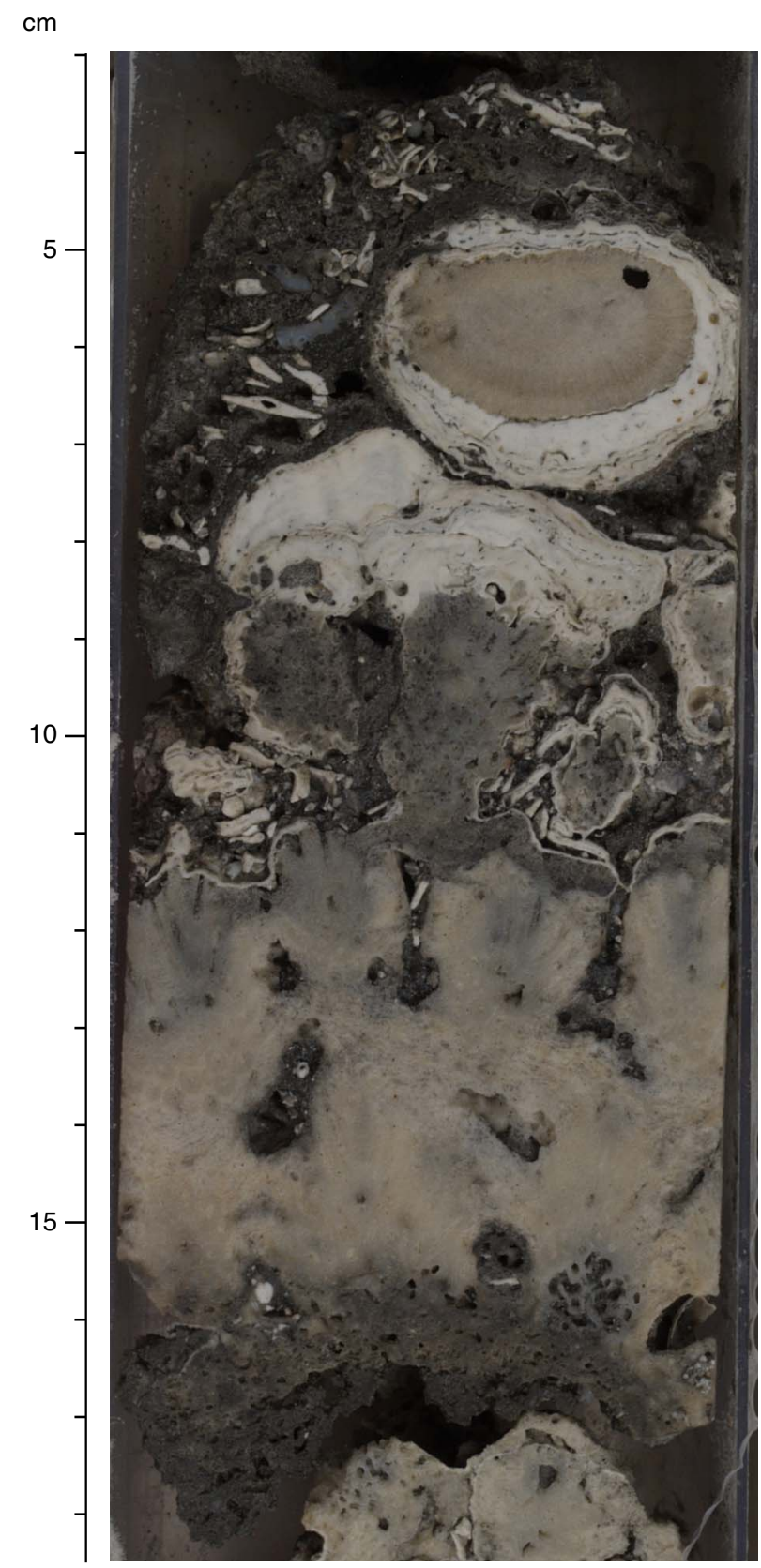


Figure F23. Branching colonies of Porites encrusted with thick crusts of coralline algae on upper side; both are extensively eroded (Subunit IB; interval 310-M0021B-9R-1, 0-12 cm). Last stage of encrustation is represented by thick microbialite crusts (thrombolites).

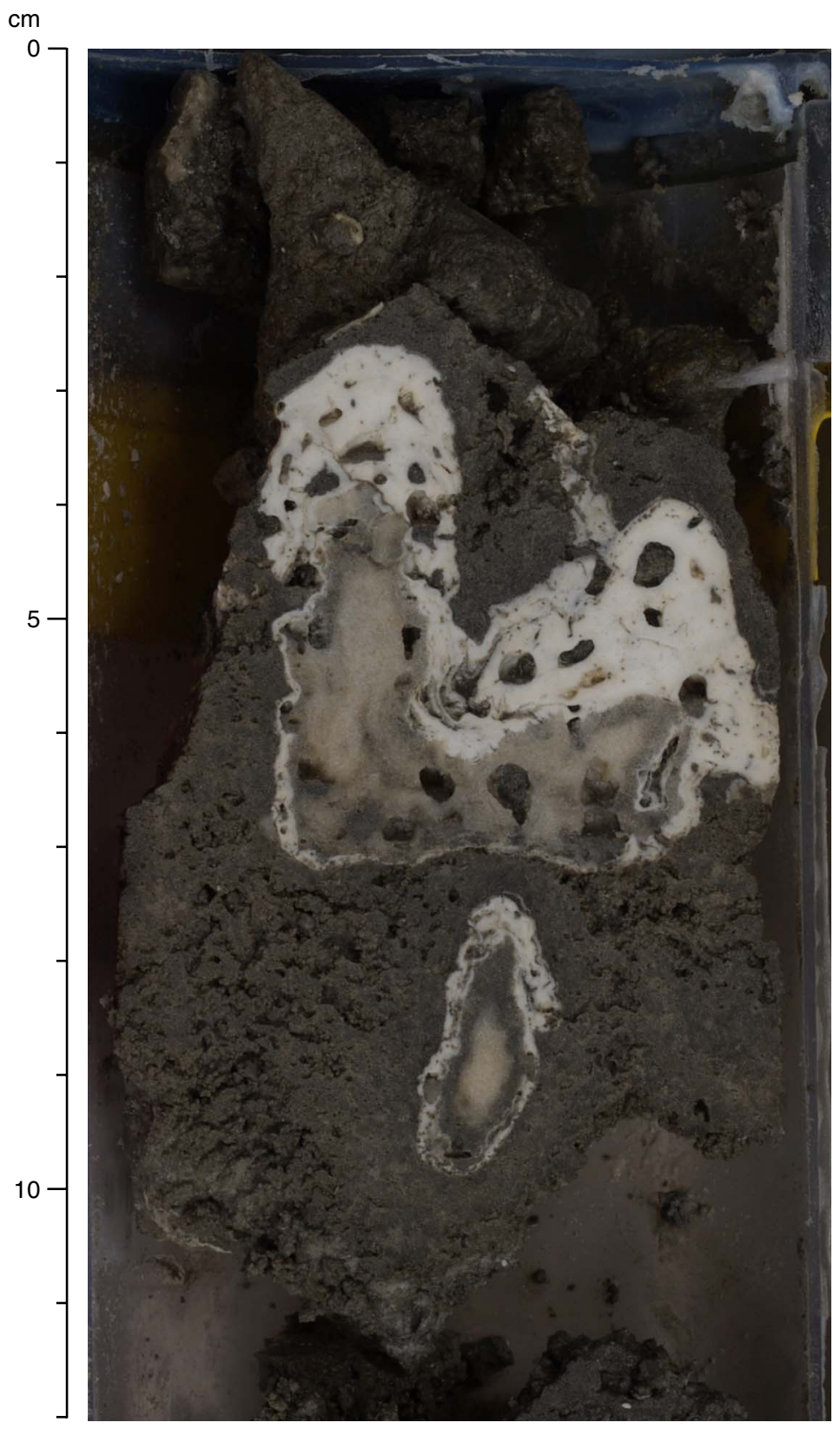


Figure F24. Multiple encrustation with thick coralline algae, branching colonies of Porites, and microbialite crusts (Subunit IB; interval 310-M0024A-9R-1, 78-90 cm).

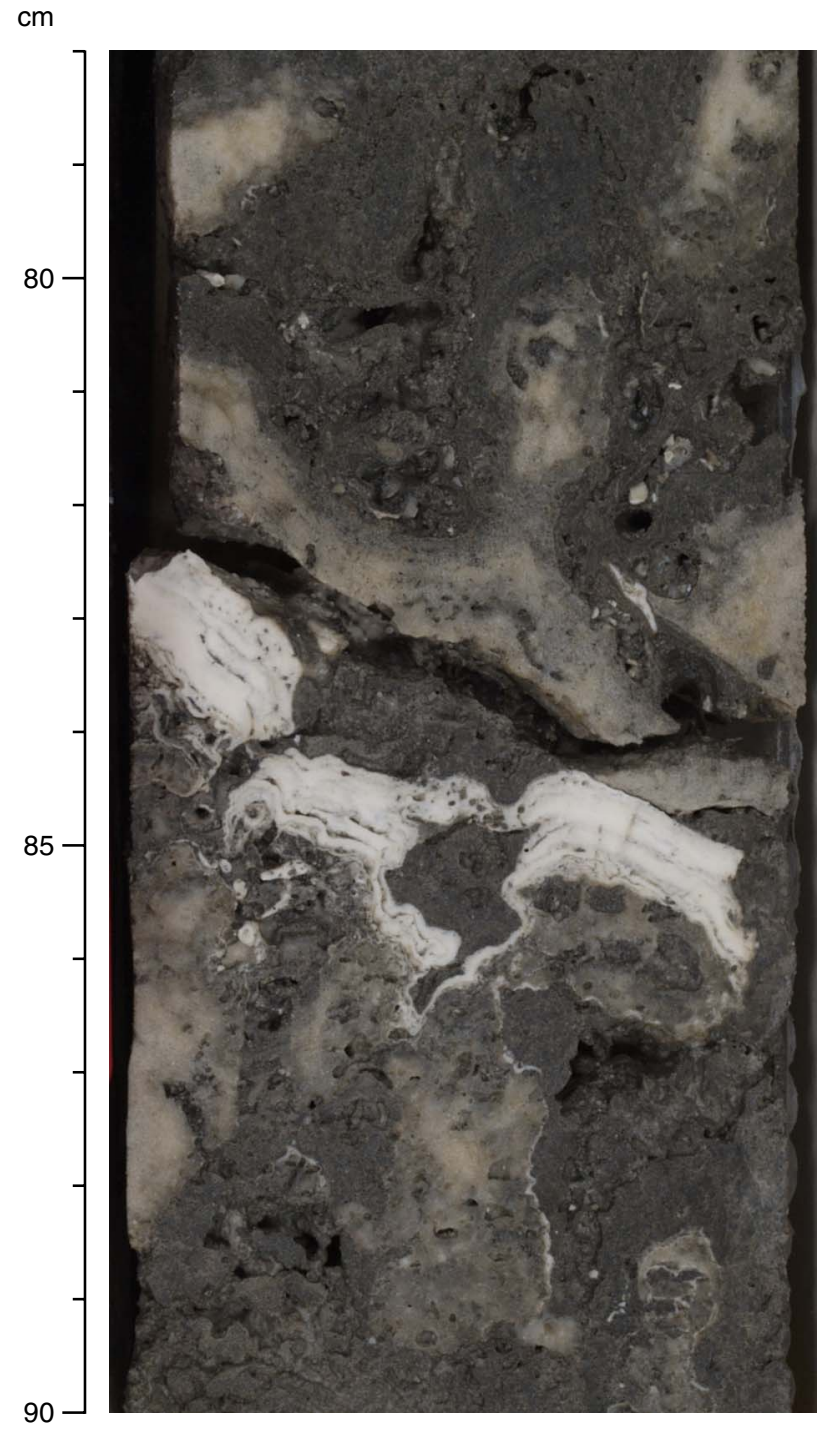


Figure F25. Thick crust of coralline algae on tips of branching Porites colonies (Subunit IB; interval 310M0024A-9R-2, 6-19 cm). Coralgal framework is heavily encrusted with microbialites (thrombolitic and laminated fabrics).

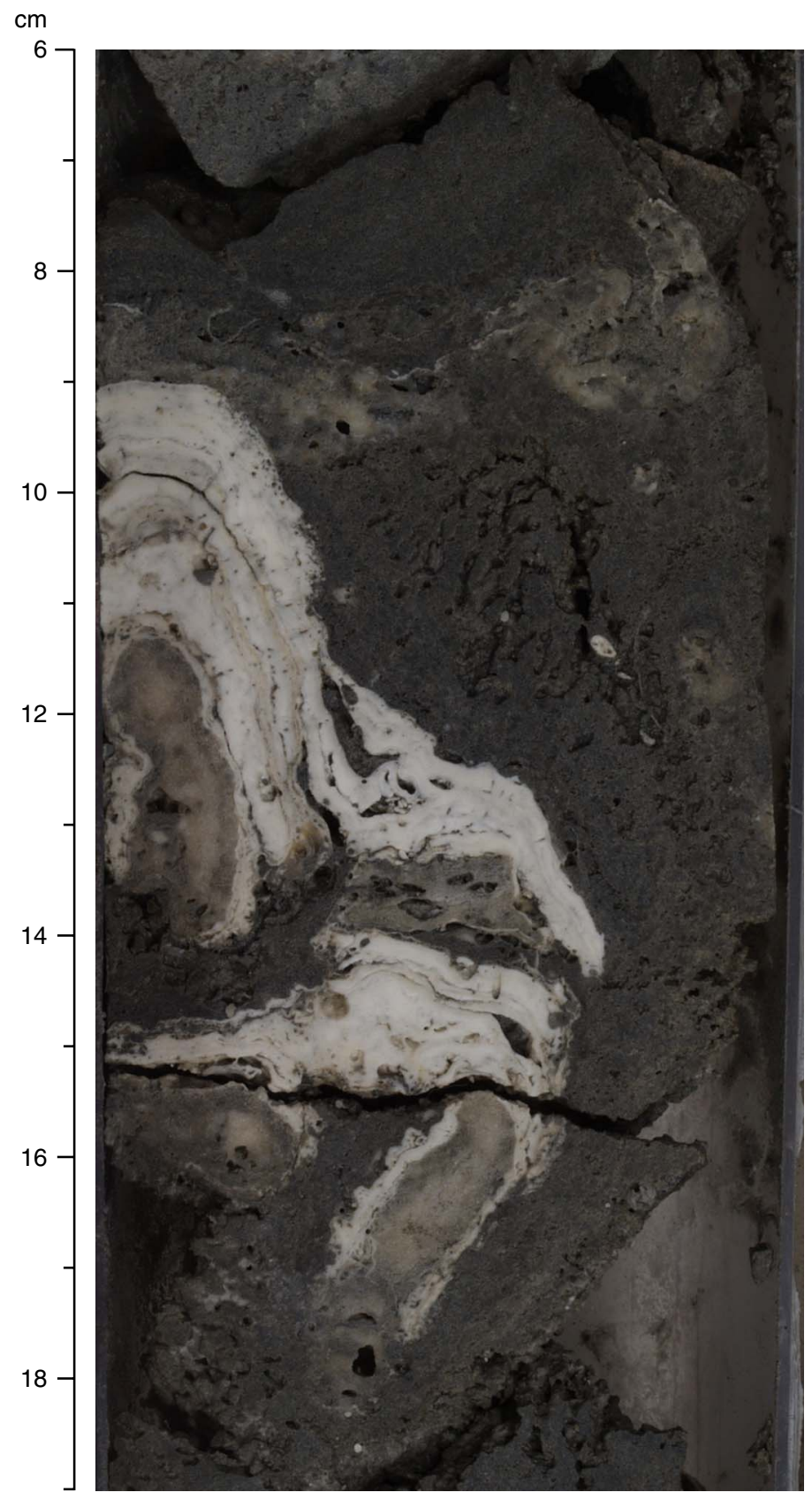


Figure F26. Thick coralline algal crusts including vermetid gastropods on top of encrusting Porites colonies that are in turn encrusted with microbialites (Subunit IB; interval 310-M0024A-10R-1, 0-6 cm).

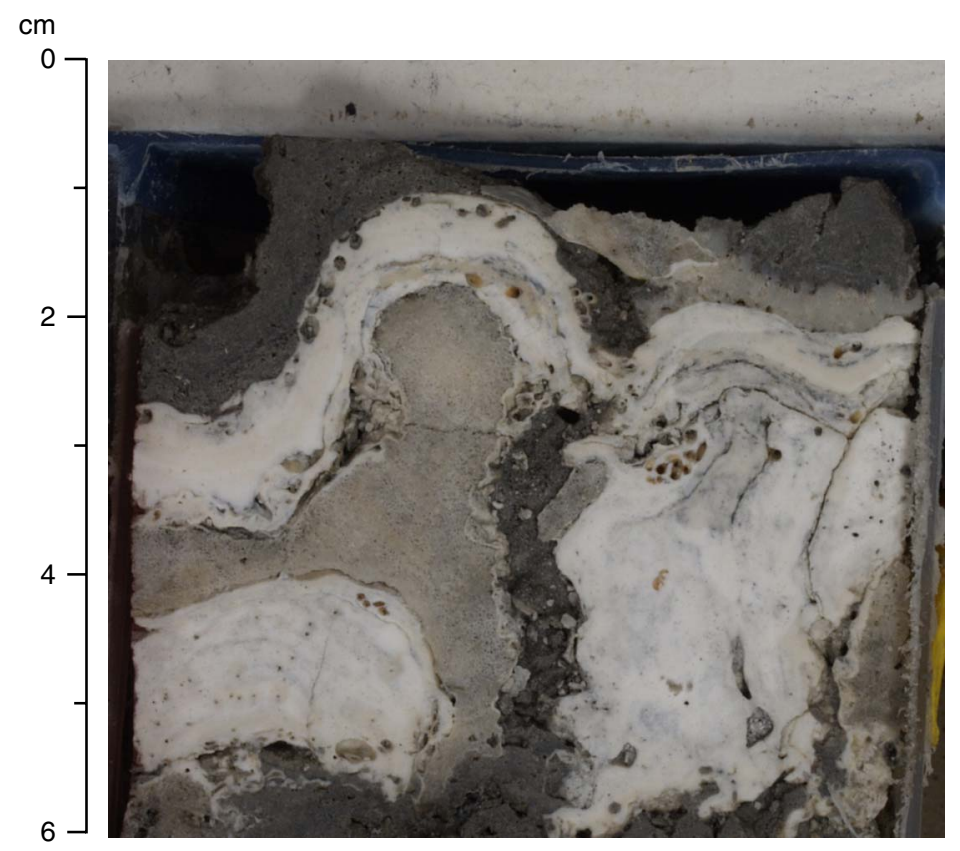


Figure F27. Pocket of coarse skeletal sand dominated by Halimeda segments in primary pore spaces of framework (Subunit IB; interval 310-M0025B-8R-1, 52-63 cm).

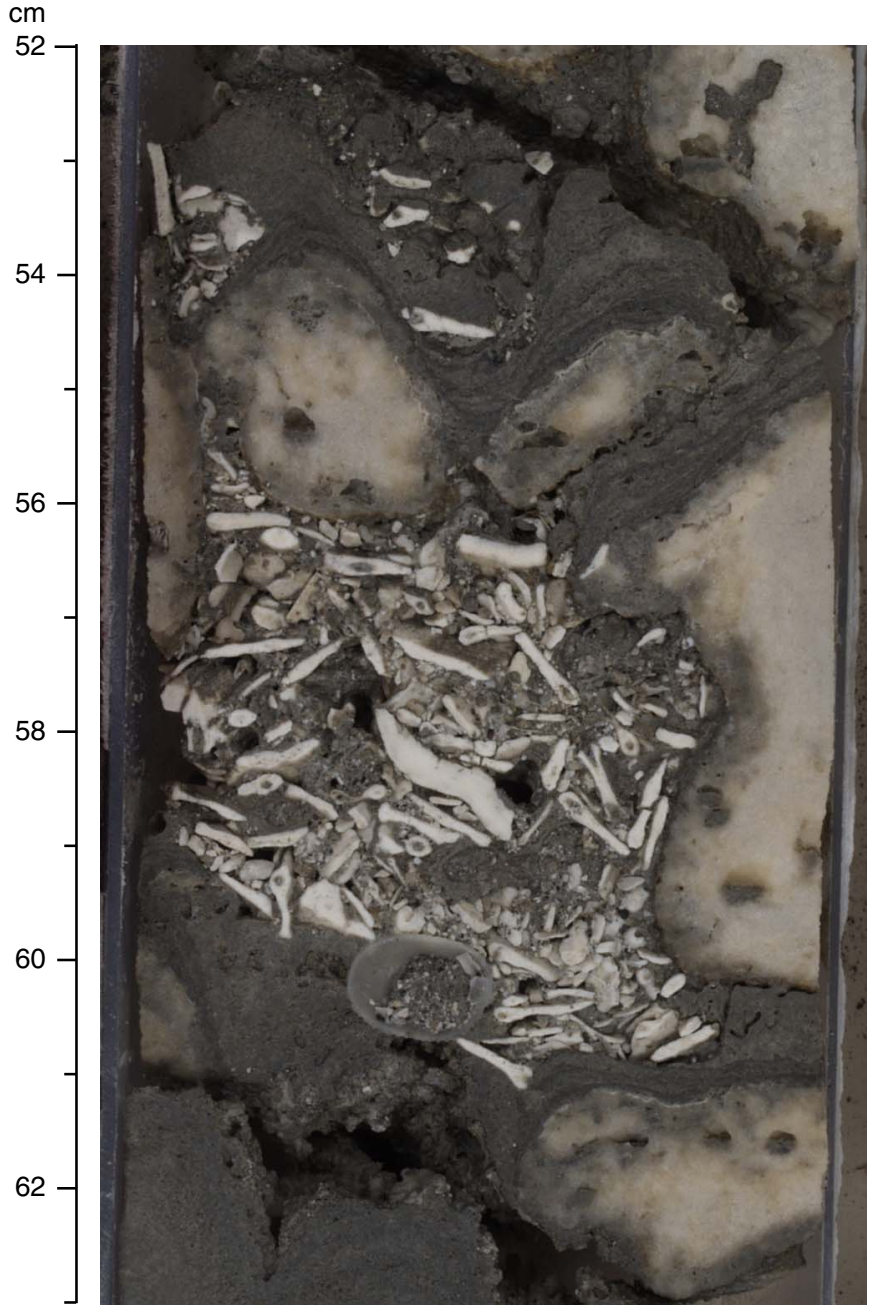


Figure F28. Massive colony of Porites (Subunit IC; interval 310-M0009D-7R-1, 11-30 cm).

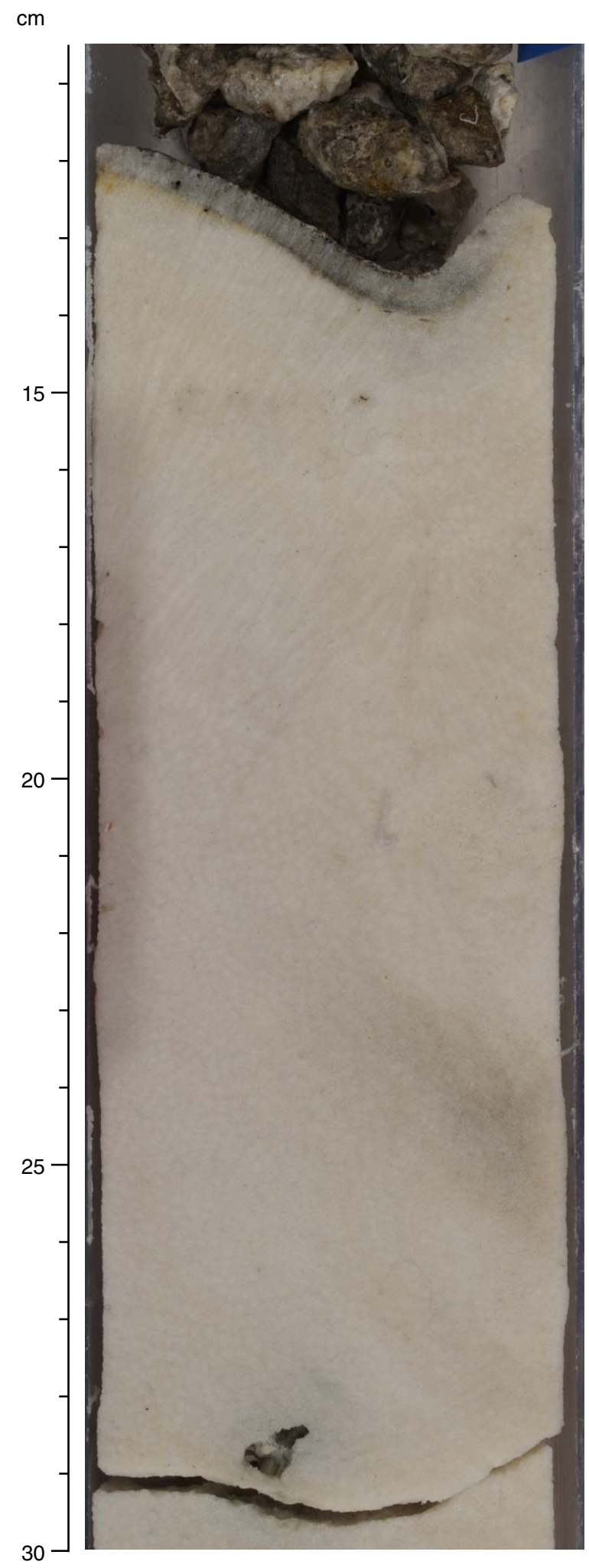


Figure F29. Massive Porites colony coated with a microbialite crust (Subunit IC; interval 310-M0021A-6R-1, $59-71 \mathrm{~cm})$.

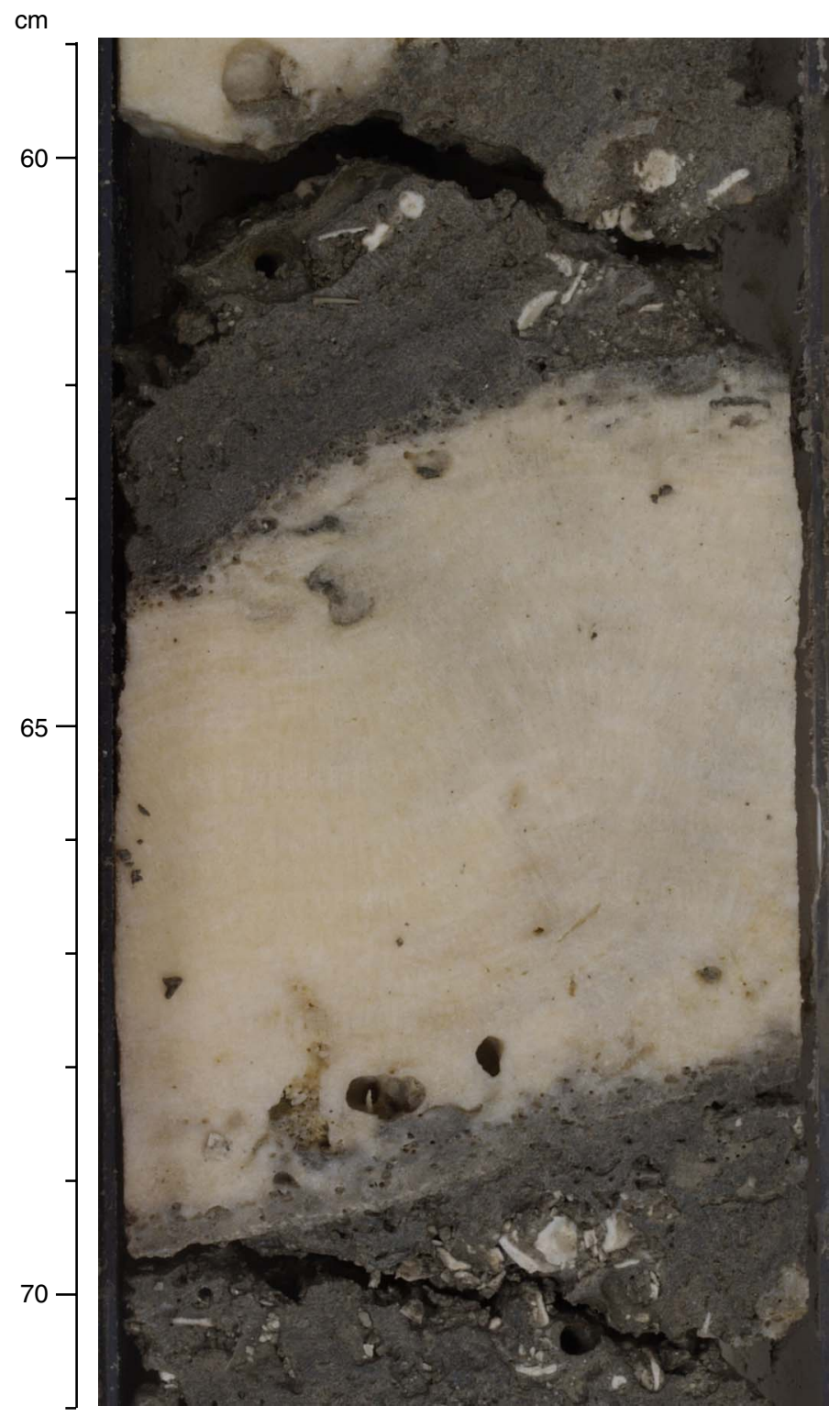


Figure F30. Bioeroded colony of branching Porites with thin coralline algal encrustation (Subunit IC; interval 310-M0024A-12R-2, 10-15 cm). Microbialites form last stage of encrustation.

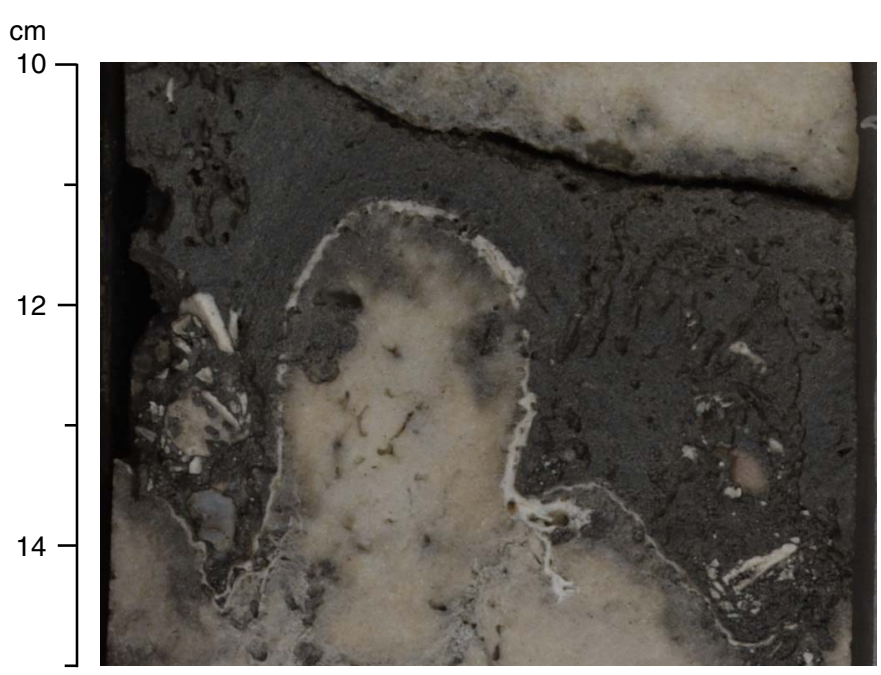


Figure F31. Massive colonies of Porites with traces of bioerosion, thin coralline algal encrustations, and very thick thrombolitic microbialite masses (Subunit IC; interval 310-M0025A-6R-1, 72-90 cm). Note open primary pore spaces.

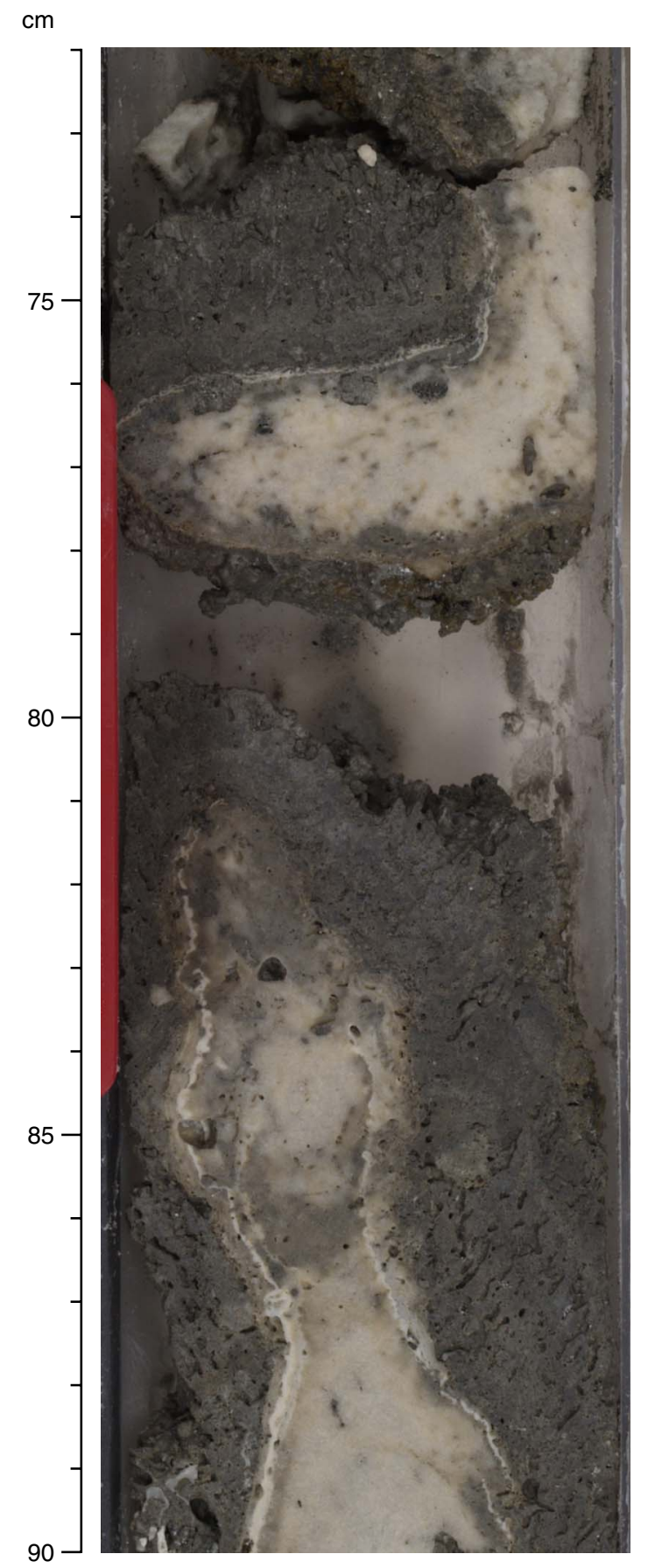


Figure F32. Robust branching colony of Pocillopora encrusted with microbialites (mostly laminated) (Subunit ID; interval 310-M0024A-10R-1, 65-85 cm).

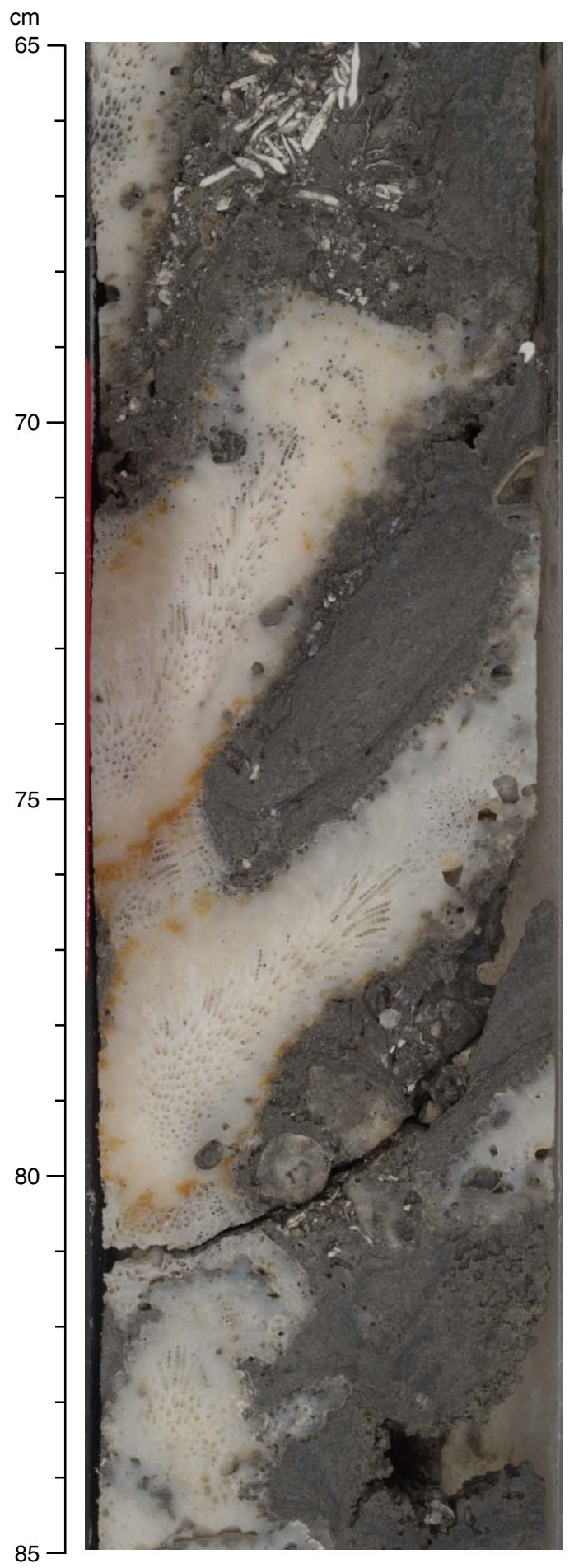


Figure F33. Robust branching colonies of Pocillopora surrounded by skeletal sediments rich in Halimeda segments (Subunit ID; interval 310-M0025B-6R-1, 20-37 cm).

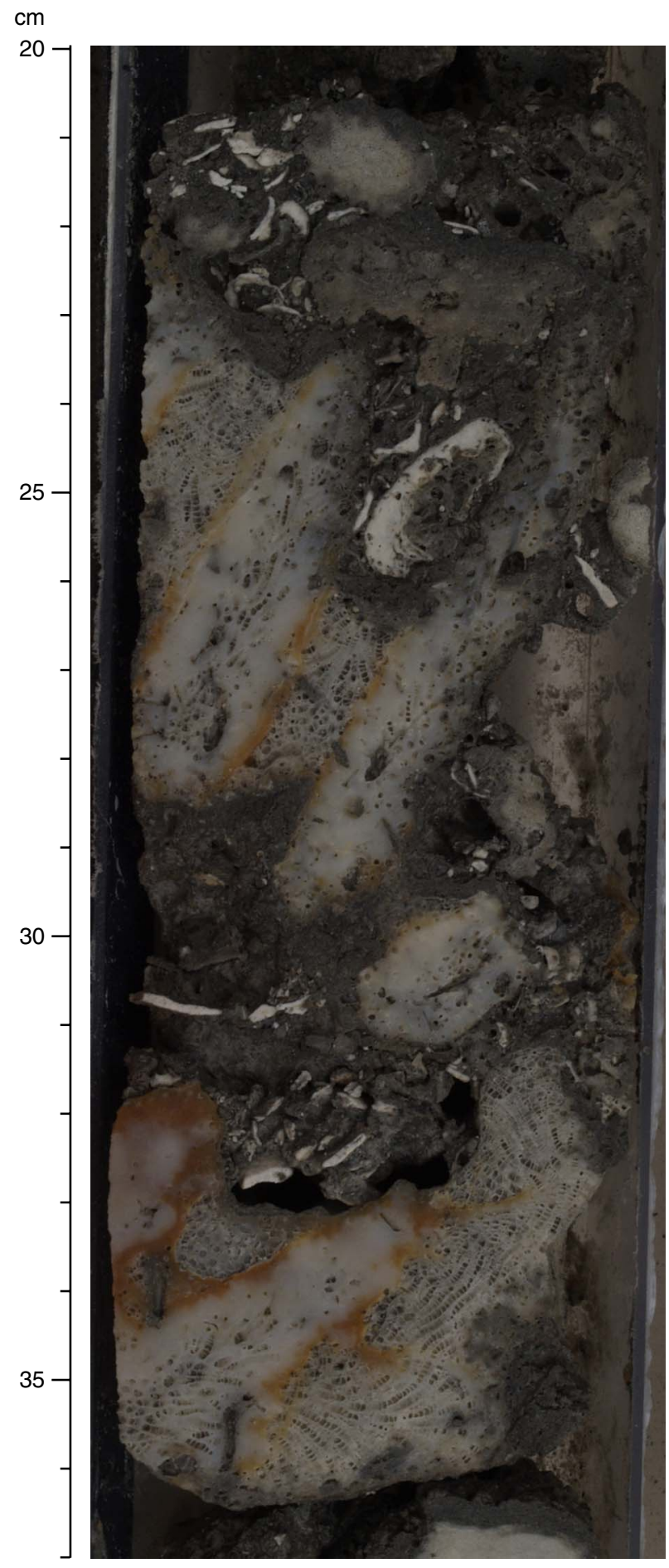


Figure F34. Coral framework of encrusting colonies of Psammocora with rubble of branching Pocillopora covered with thick microbialite masses. (Subunit IE; interval 310-M0009C-18R-1, 90-107 cm). Note primary open vugs.

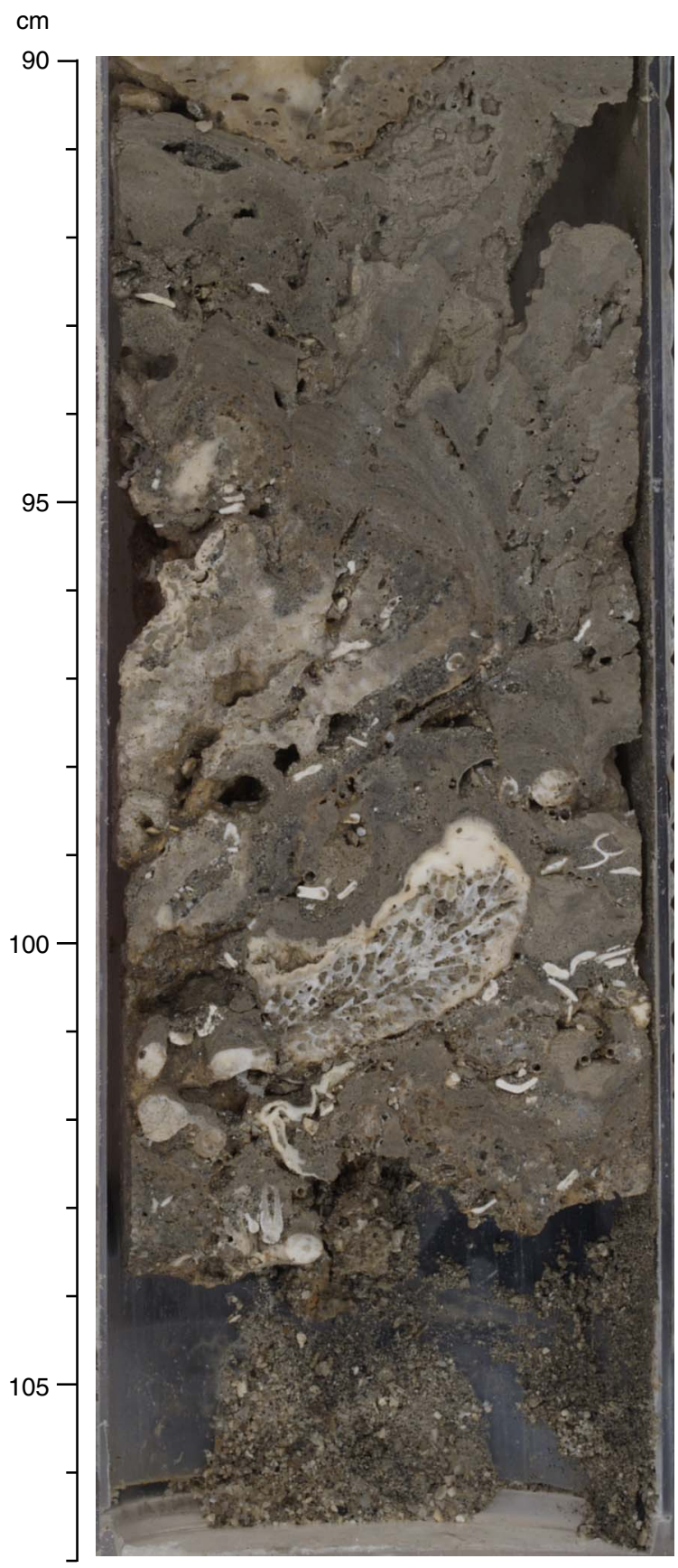


Figure F35. Halimeda rudstone with dissolution pores lined with cement (Unit II; interval 310-M0009C-20RCC, $108-123 \mathrm{~cm})$.

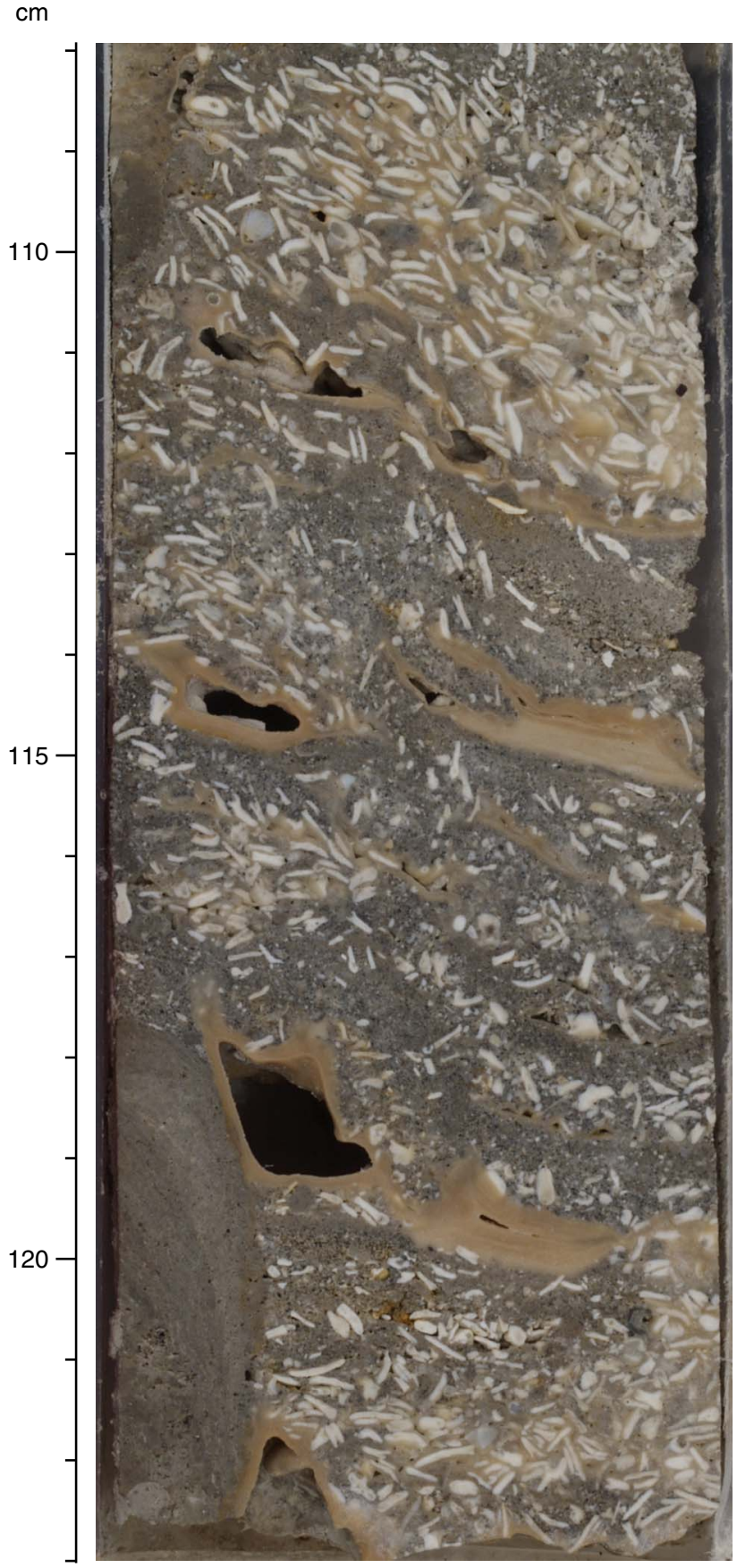


Figure F36. Poorly sorted coral rudstone with Halimeda segments (Unit II; interval 310-M0009D-14R-2, 48-54 $\mathrm{cm})$. Note cement linings in dissolution pores.

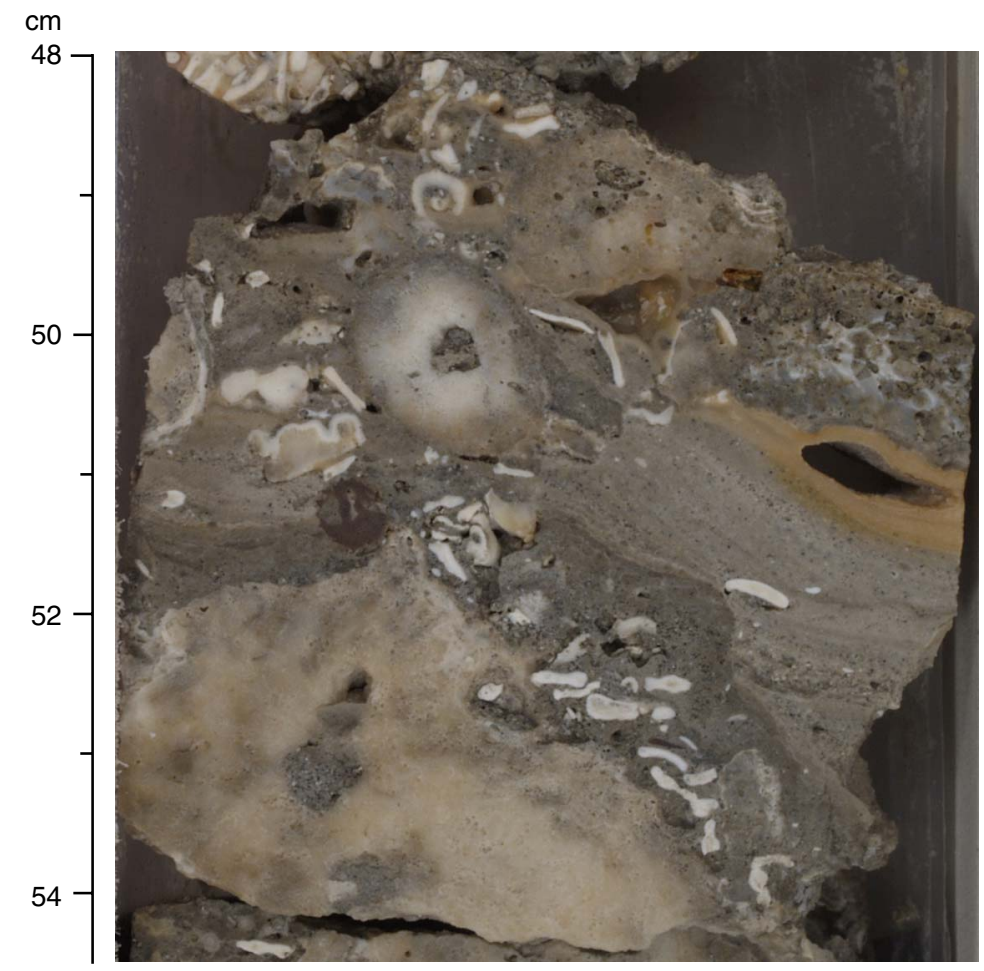


Figure F37. Cavity filled with sand rich in volcanic grains (Unit II; interval 310-M0021B-19R-1, 38-52 cm).

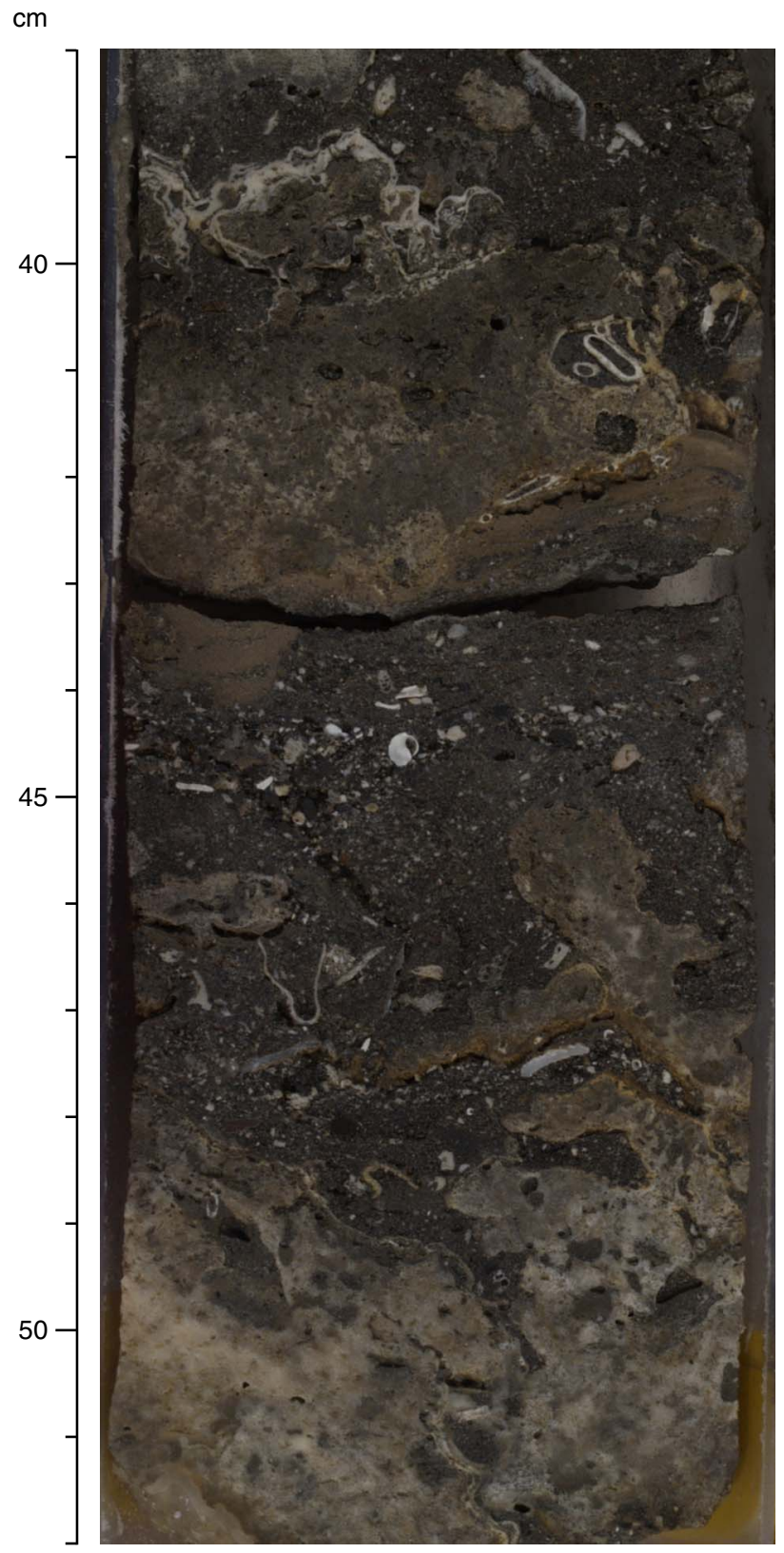


Figure F38. Volcanic gravel and pebbles in cavity in upper part of Unit II (Unit II; interval 310-M0025A-10R-1, $78-100 \mathrm{~cm})$.

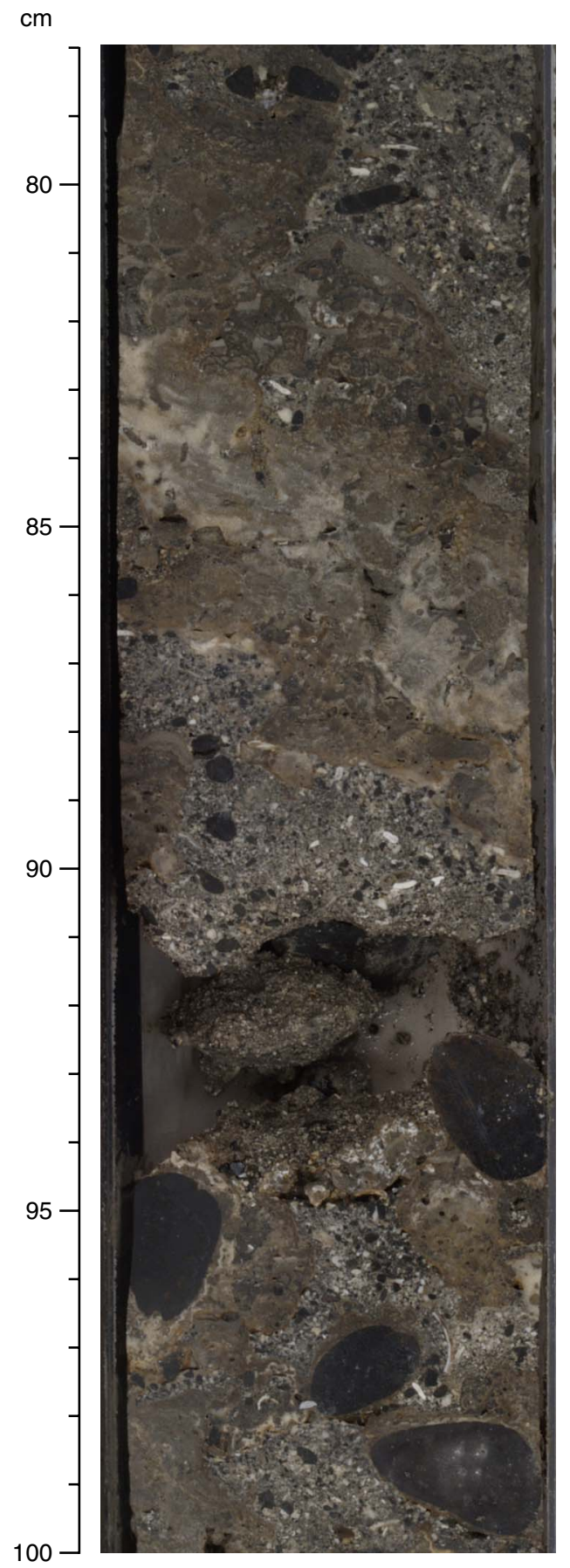


Figure F39. Top of Unit II with hardground at $25 \mathrm{~cm}$ (Unit II; interval 310-M0025A-10R-1, 22-37 cm). Note solution cavities below hardground.

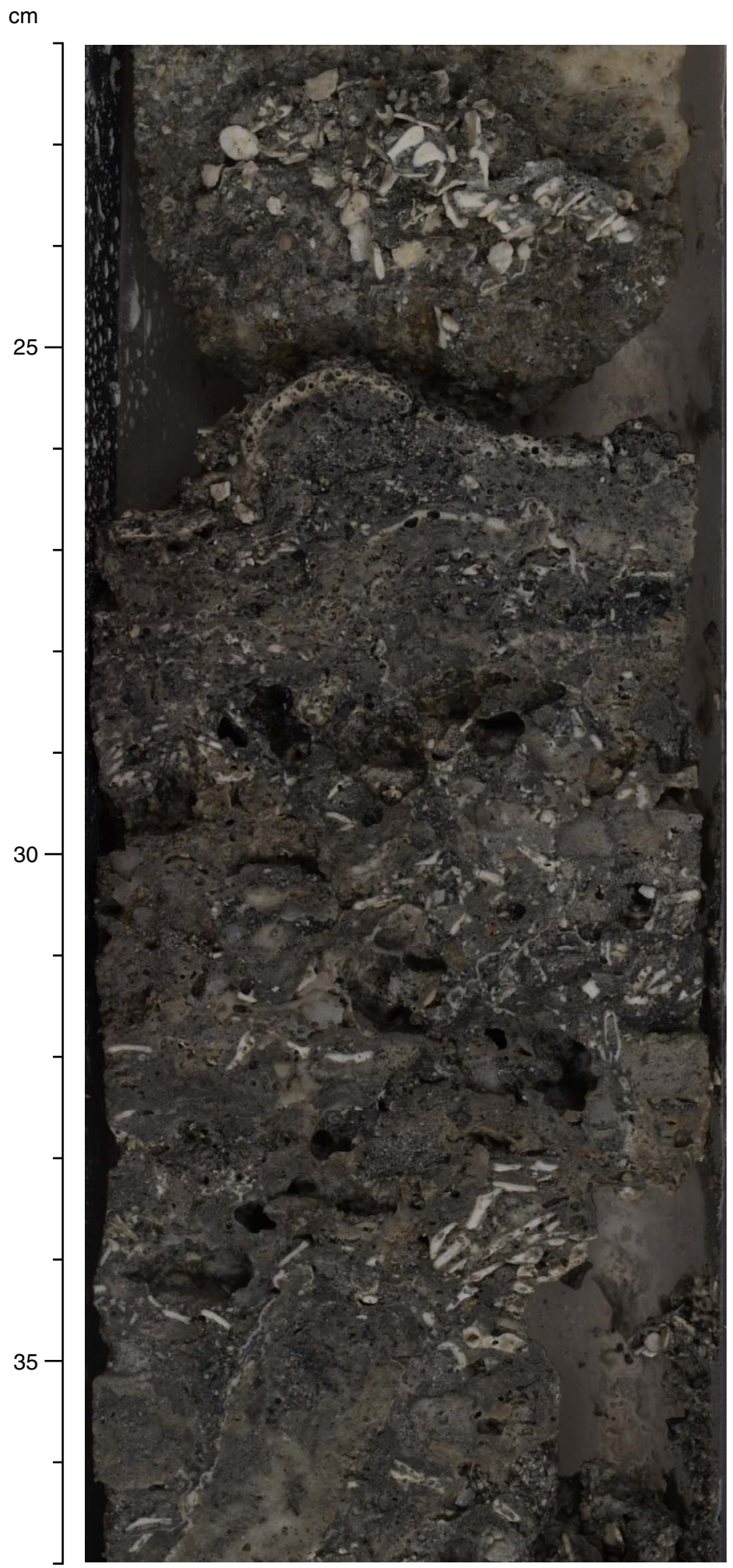


Figure F40. Complex sedimentary fabric including Halimeda-rich rudstone and very thick microbialite crusts (Unit II; interval 310-M0009C-20R-1, 84-104 cm). Note cement linings in secondary porosity.

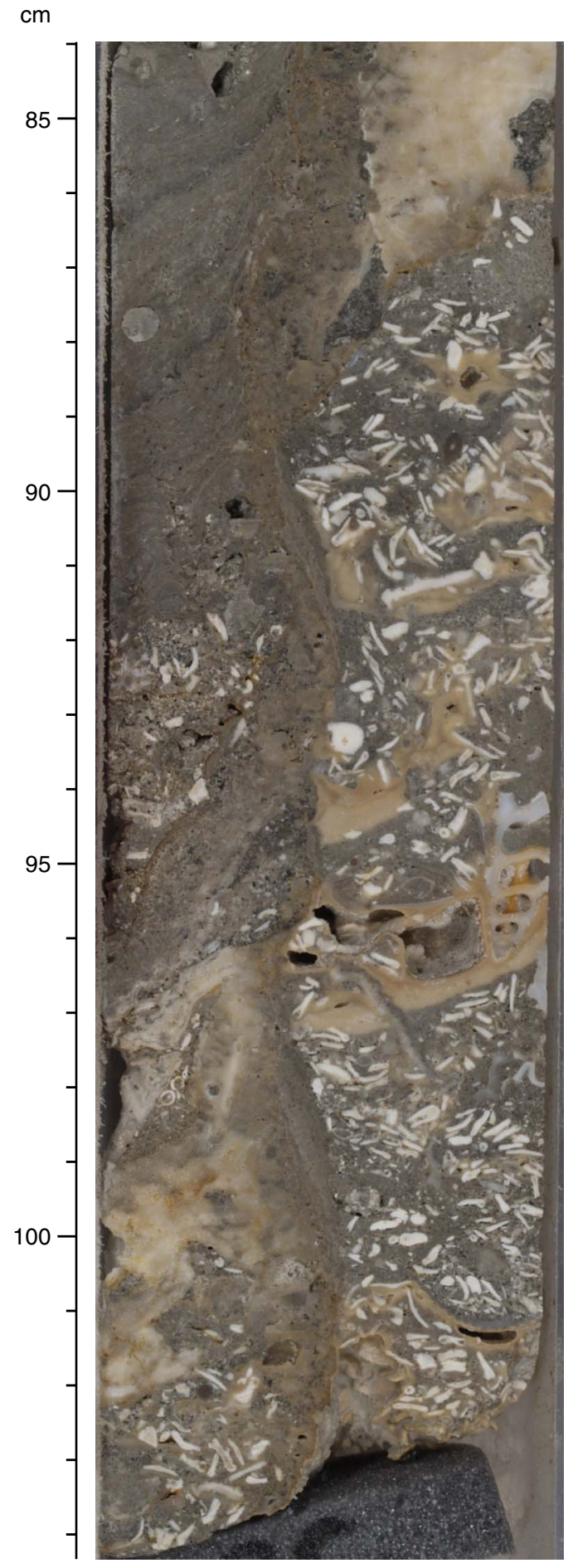


Figure F41. Coralgal framework of encrusting coral colonies (Montipora?) and abundant volcanic grains in matrix (Subunit IIA; interval 310-M0009A-14R-1, 5-23 cm).

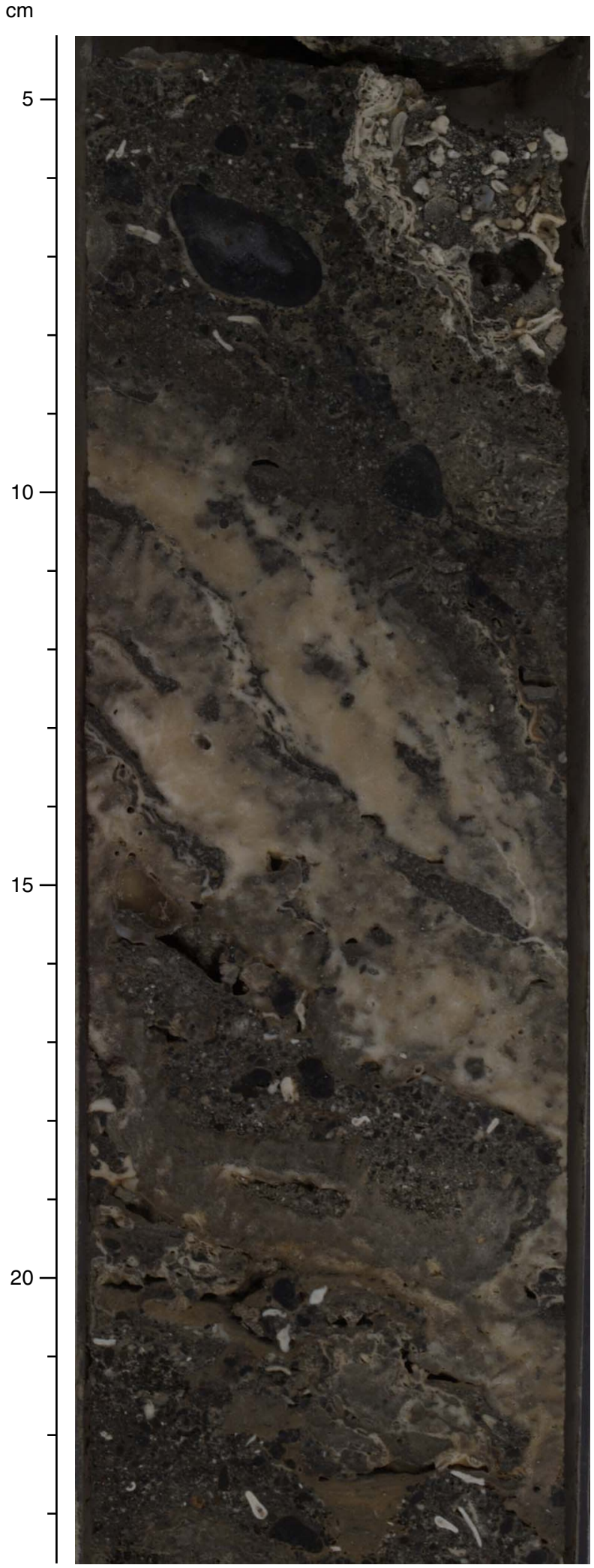


Figure F42. Boundstone formed by encrusting colonies of Pachyseris; cavities are partly filled with Halimedarich sediment and cement (Subunit IIA; interval 310-M0009D-18R-1, 13-31 cm).

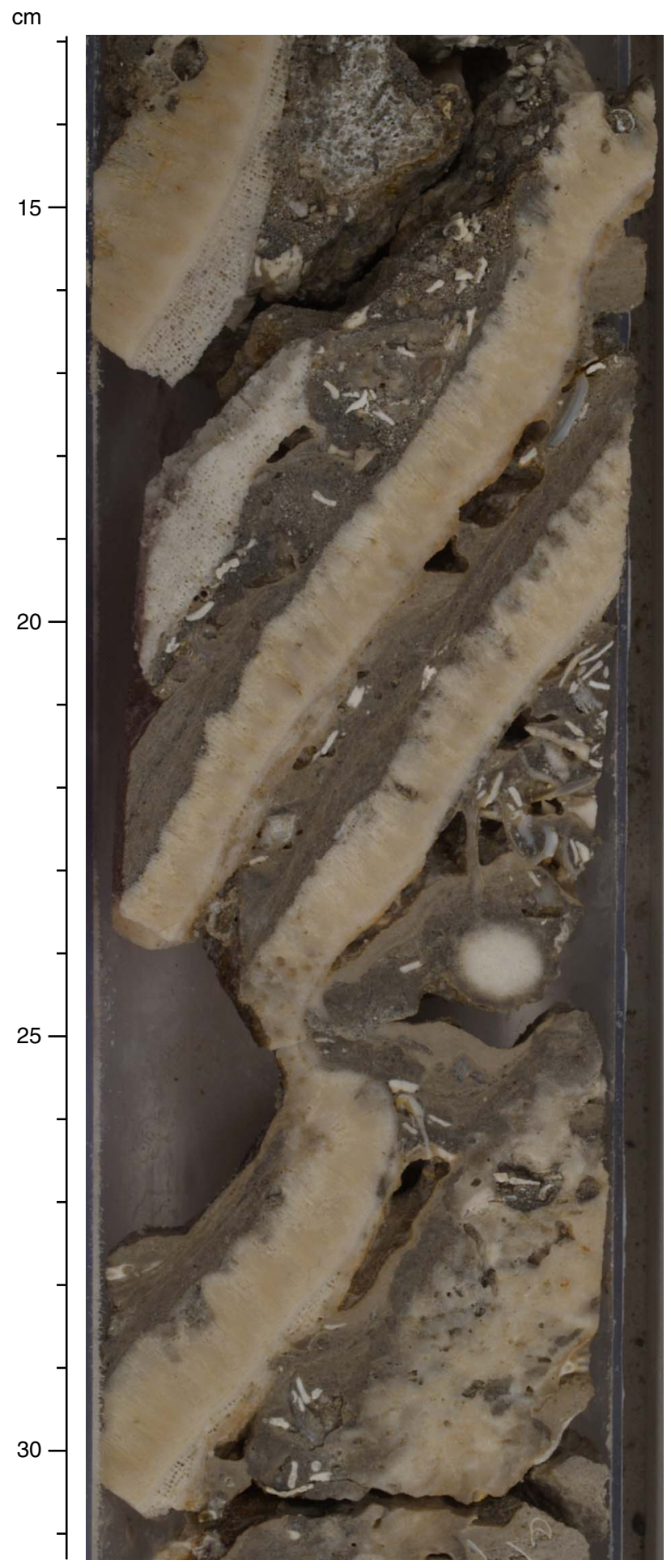


Figure F43. Coralgal framework of encrusting colonies of Pachyseris with multiple thin encrustations of coralline algae and Halimeda-rich sediment in primary pore spaces (Subunit IIA; interval 310-M0021A-22R-2, 60-80 $\mathrm{cm})$.

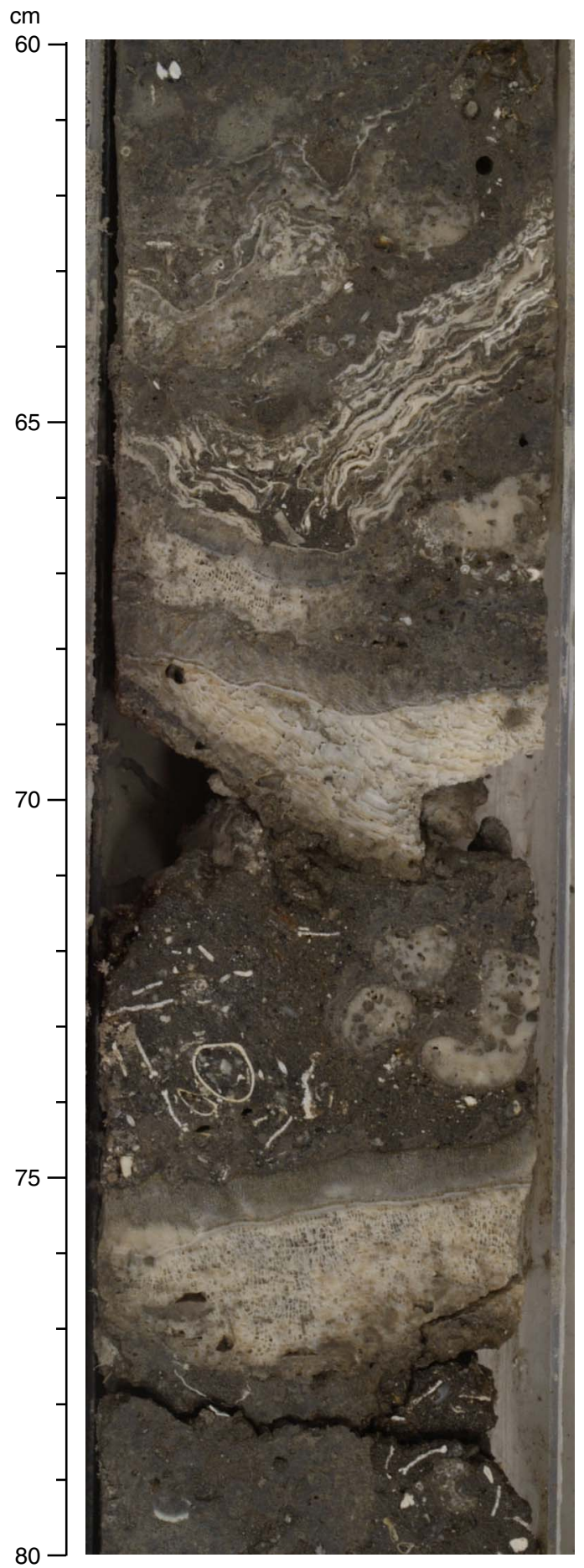


Figure F44. Coral framework of encrusting colonies of Montipora (Unit II; interval 310-M0021B-20R-1, 60-68 $\mathrm{cm})$.

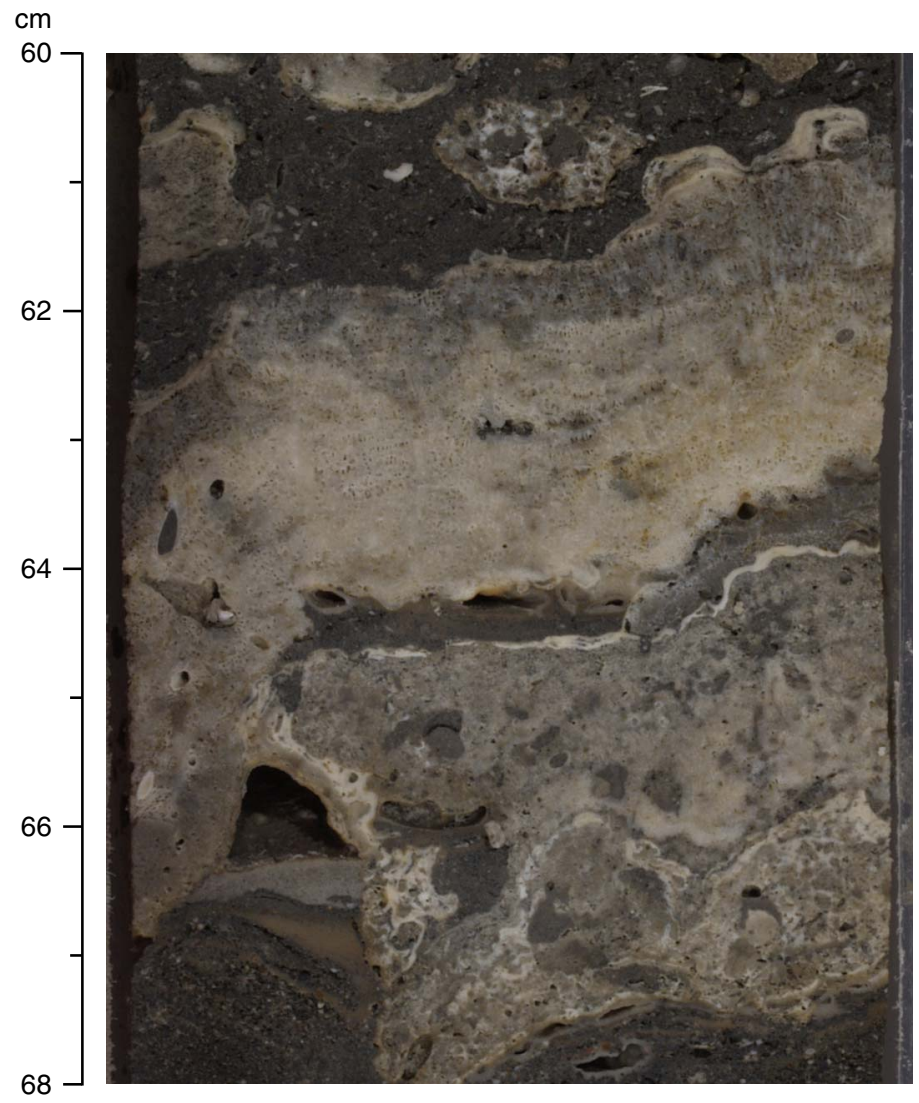


Figure F45. Coral framework of encrusting colonies of Leptastrea with thick crusts of coralline algae (Subunit IIA; interval 310-M0021B-20R-2, 0-10 cm). Note borings by bivalves. Matrix of framework is composed of skeletal sediment rich in volcanic grains.

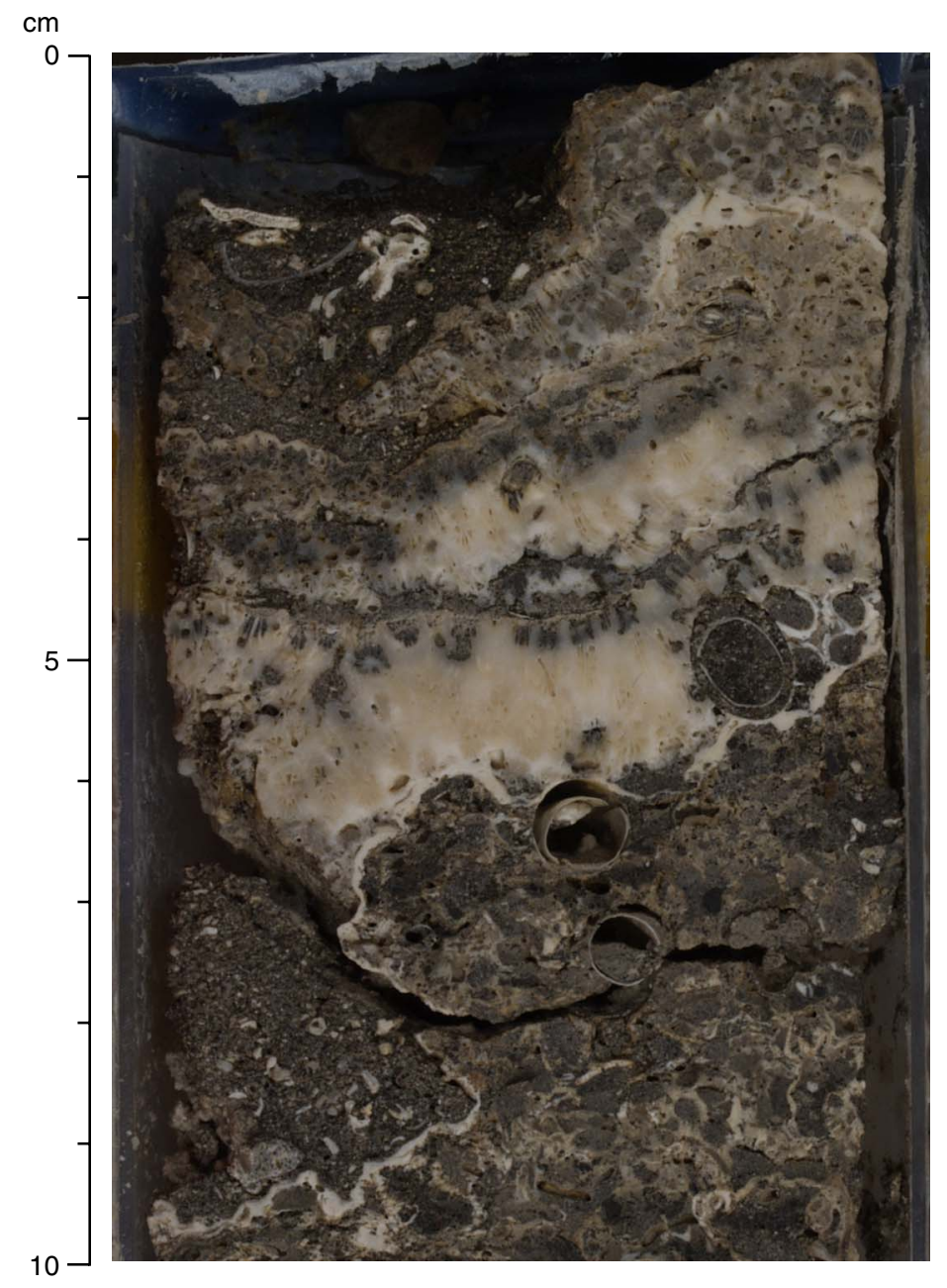


Figure F46. Encrusting colonies of Montipora (Subunit IIA; interval 310-M0025A-10R-1, 108-128 cm).

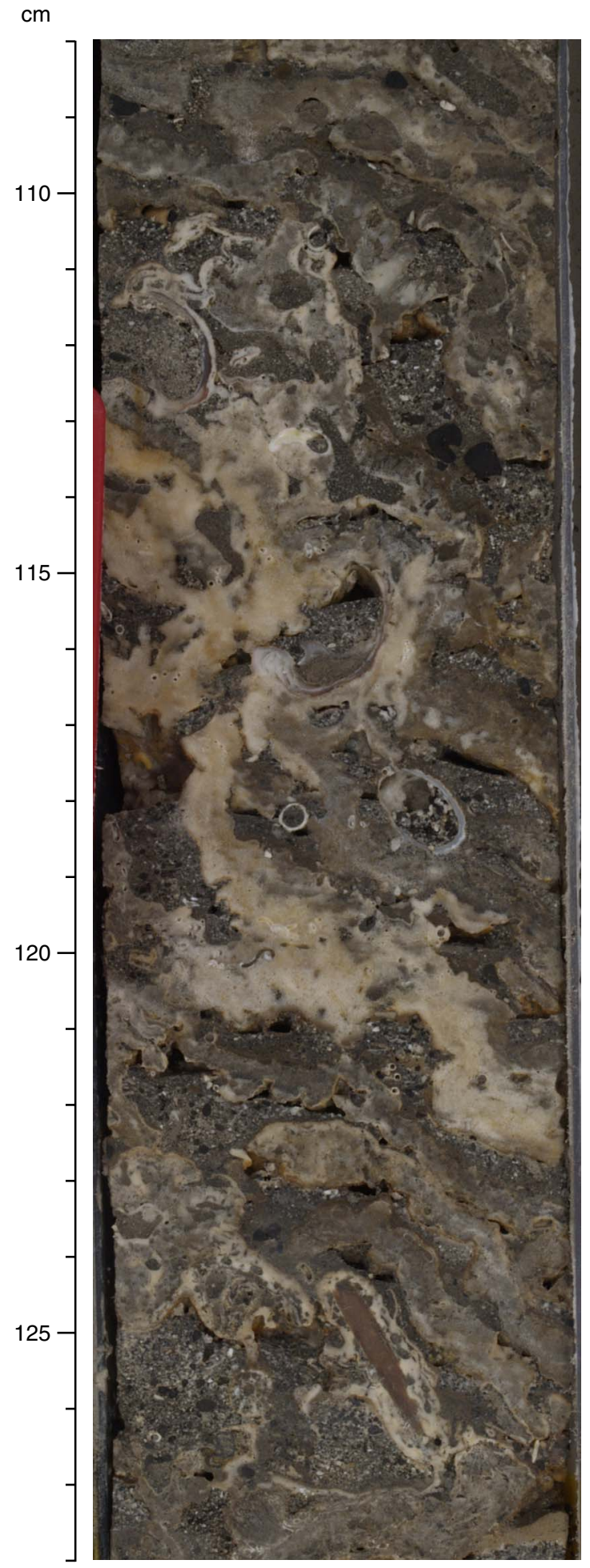


Figure F47. Tabular colony of Acropora covered with poorly sorted sediments, including volcanic gravels and pebbles (Subunit IIA; interval 310-M0025A-11R-1, 50-65 cm).

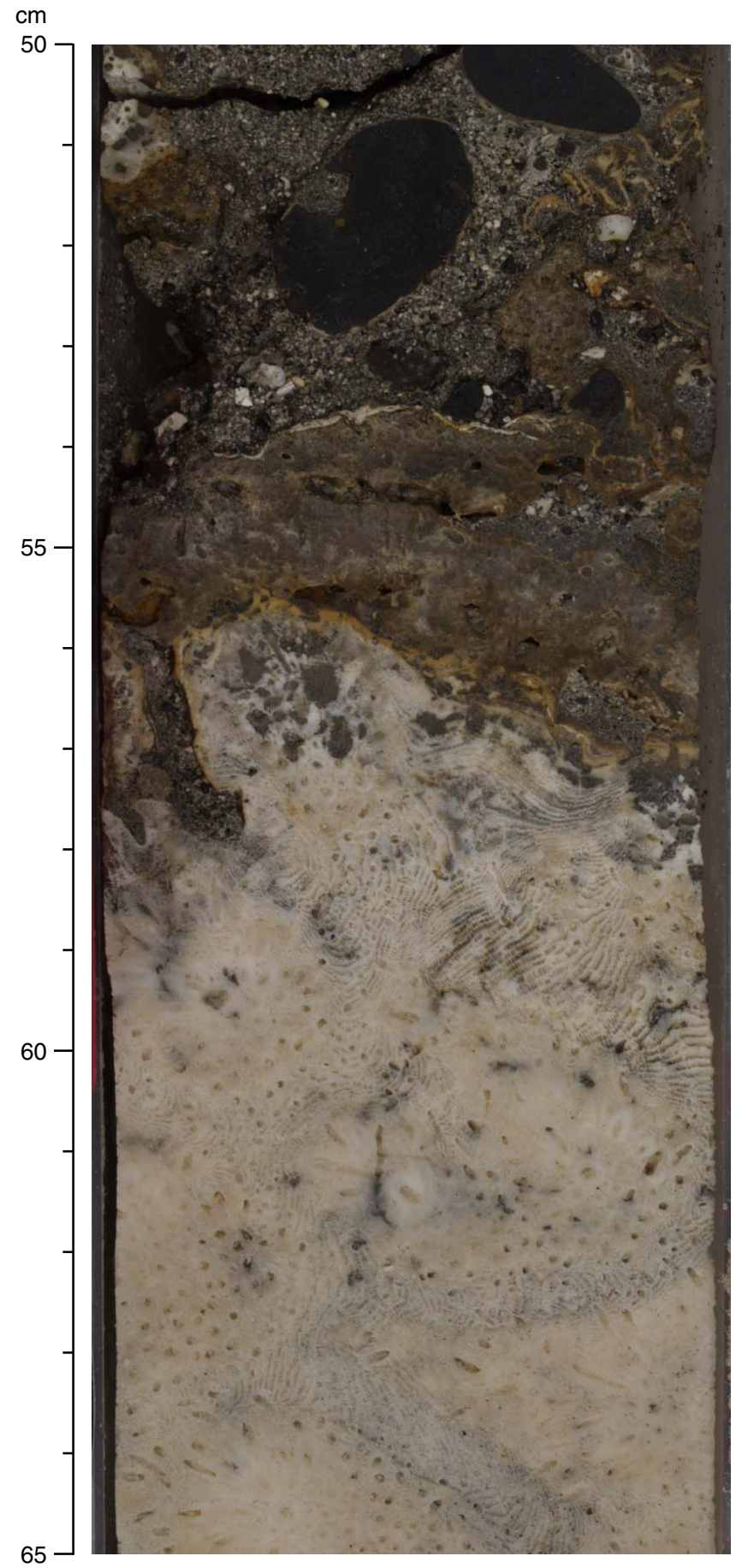


Figure F48. Very poorly sorted coral rudstone (Subunit IIA; interval 310-M0009B-16R-1, 35-60 cm). Matrix is rich in Halimeda segments.

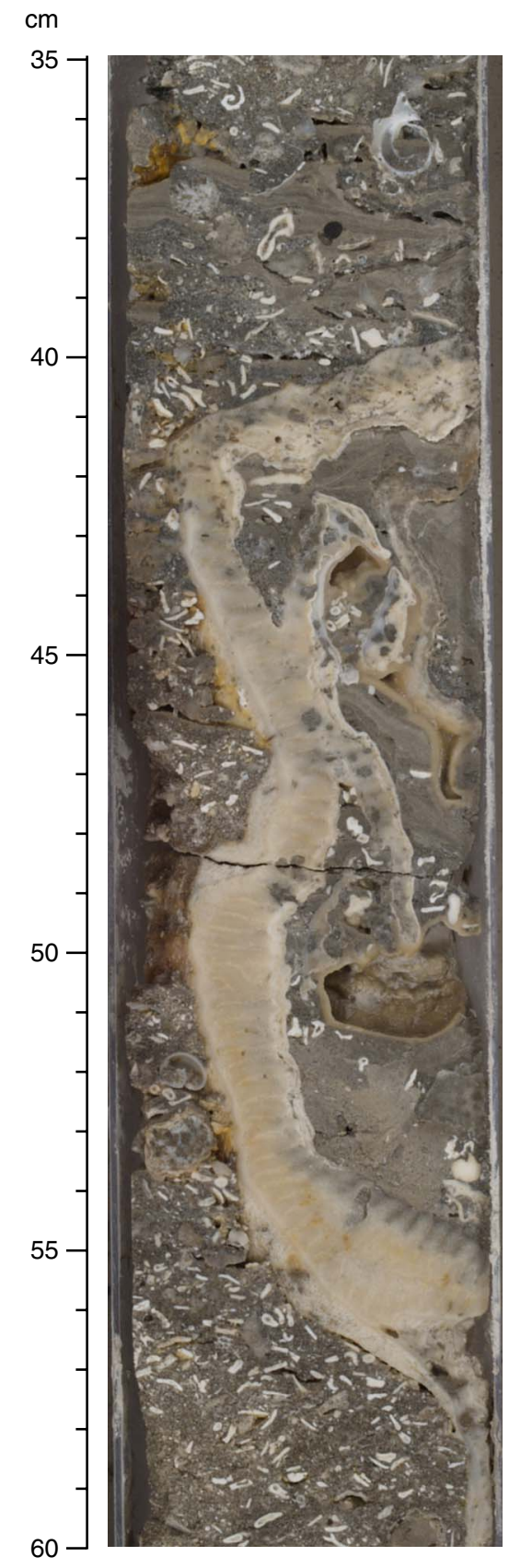


Figure F49. Sandy floatstone with fragments of branching corals and Halimeda segments (Subunit IIC; interval 310-M0009D-25R-1, 0-11 cm).

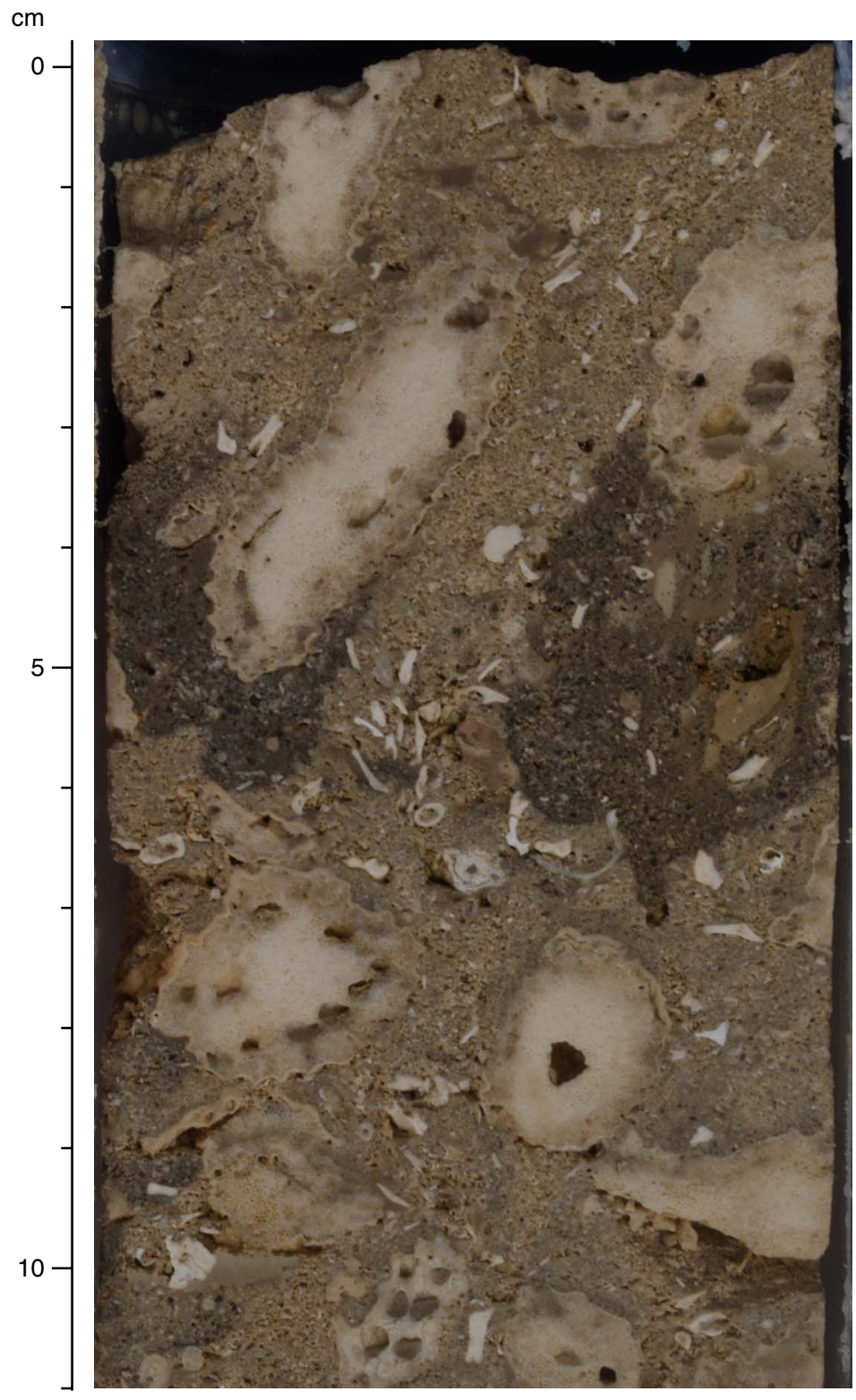


Figure F50. Massive colony of Porites encrusted with coralline algal crusts and Montipora (Subunit IIC; interval 310-M0009D-25R-1, 52-62 cm).

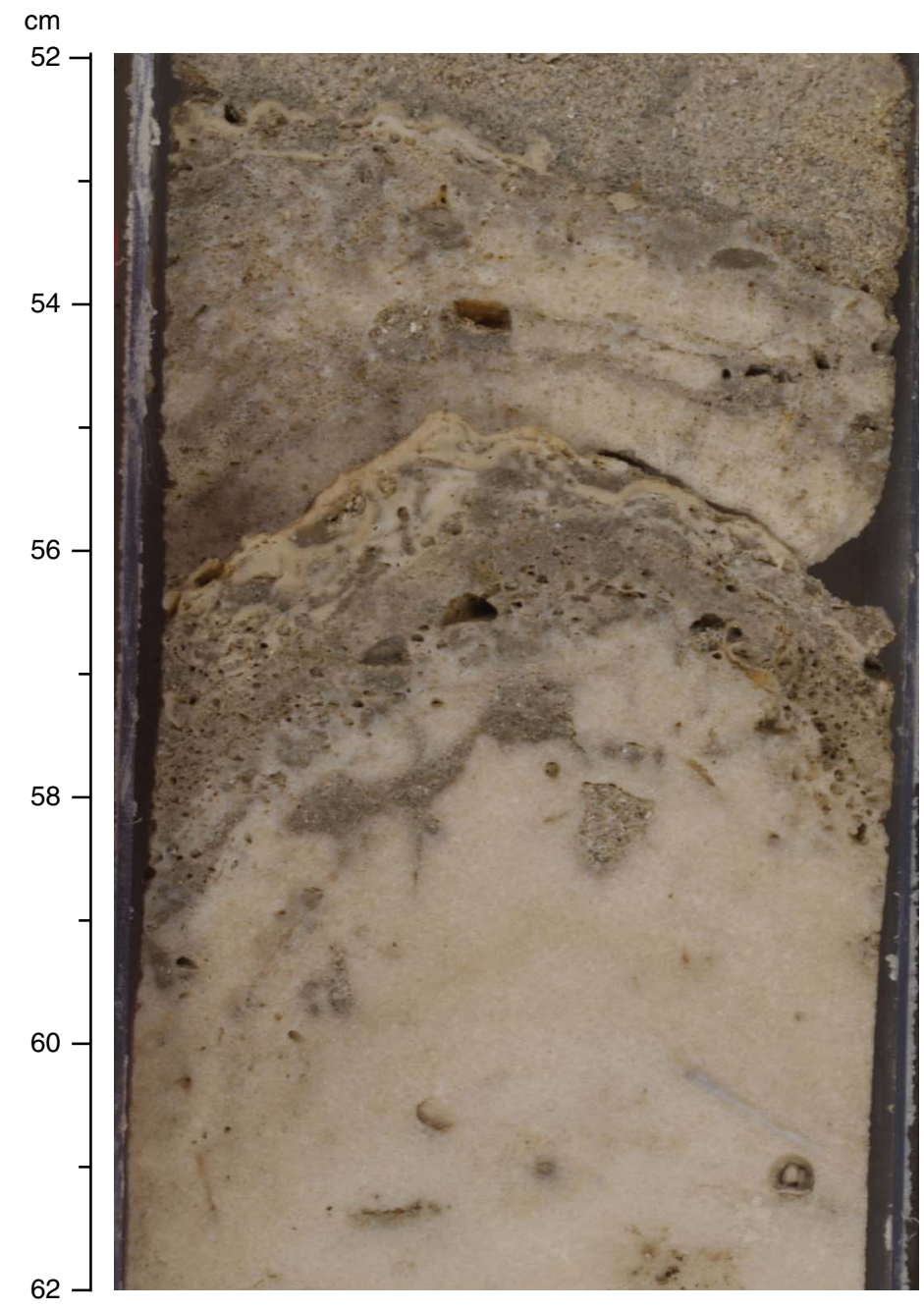


Figure F51. Tabular colony of Acropora (Subunit IIC; interval 310-M0009D-25R-1, 70-87 cm).

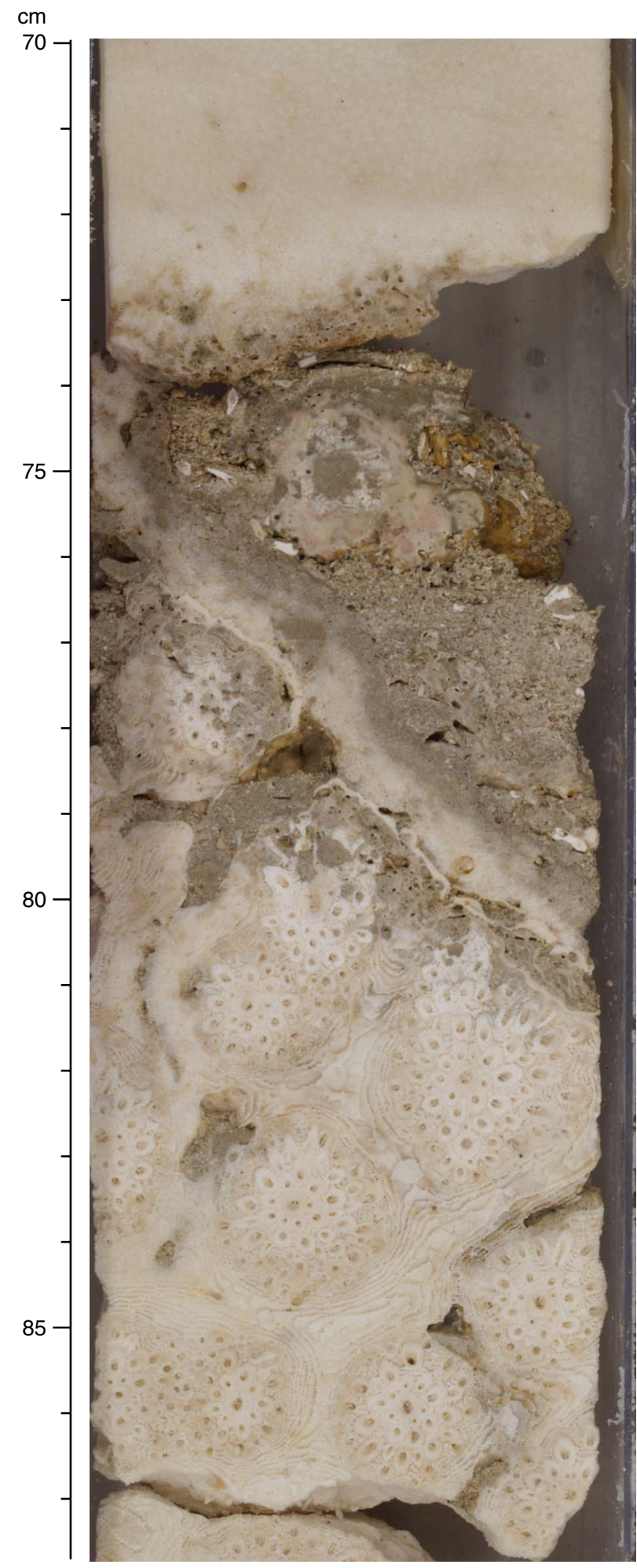


Figure F52. Siltstone to sandstone with large volcanic pebbles (Subunit IID; interval 310-M0009A-16R-1, 4-9 $\mathrm{cm})$.

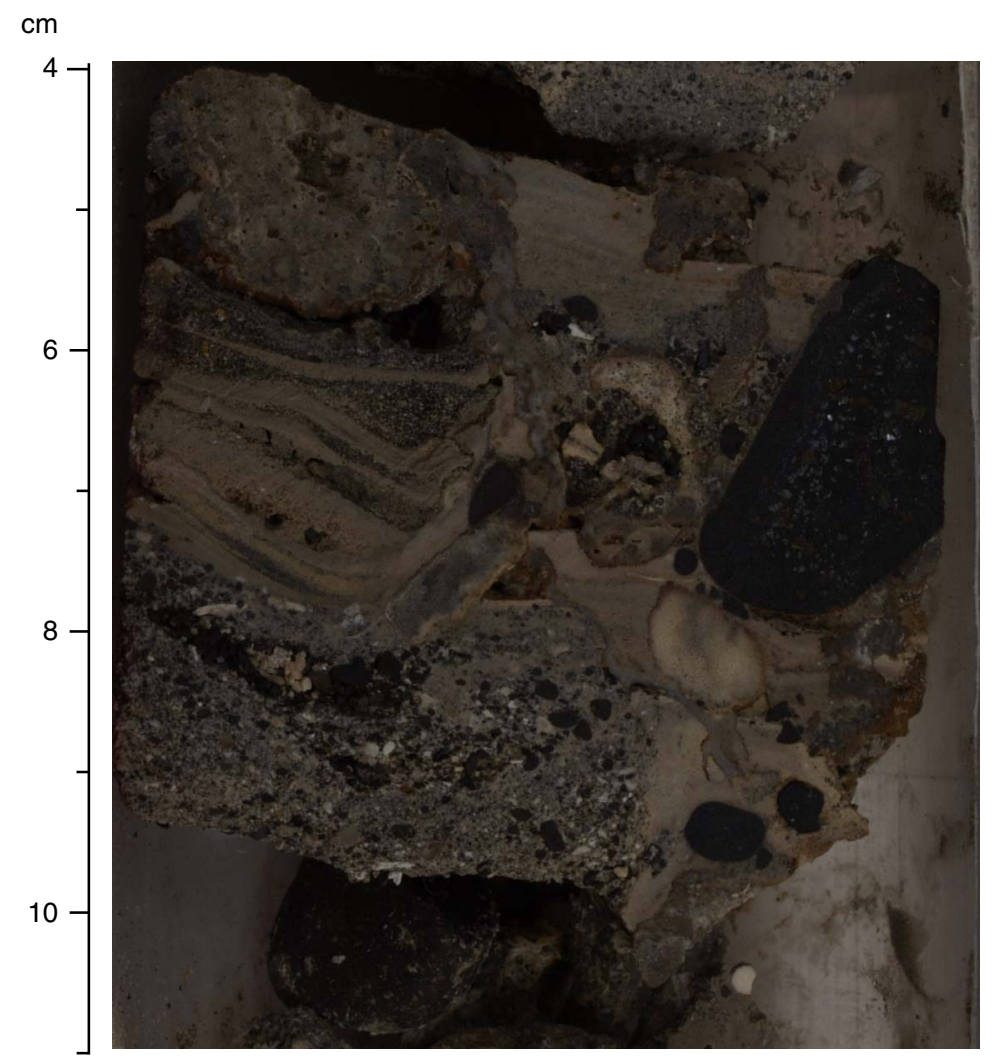


Figure F53. Poorly sorted grainstone with fragments of coralline algae and mollusks, crusts of coralline algae, and volcanic sand-sized grains and gravels (Subunit IID; interval 310-M0025A-11R-1, 72-86 cm).

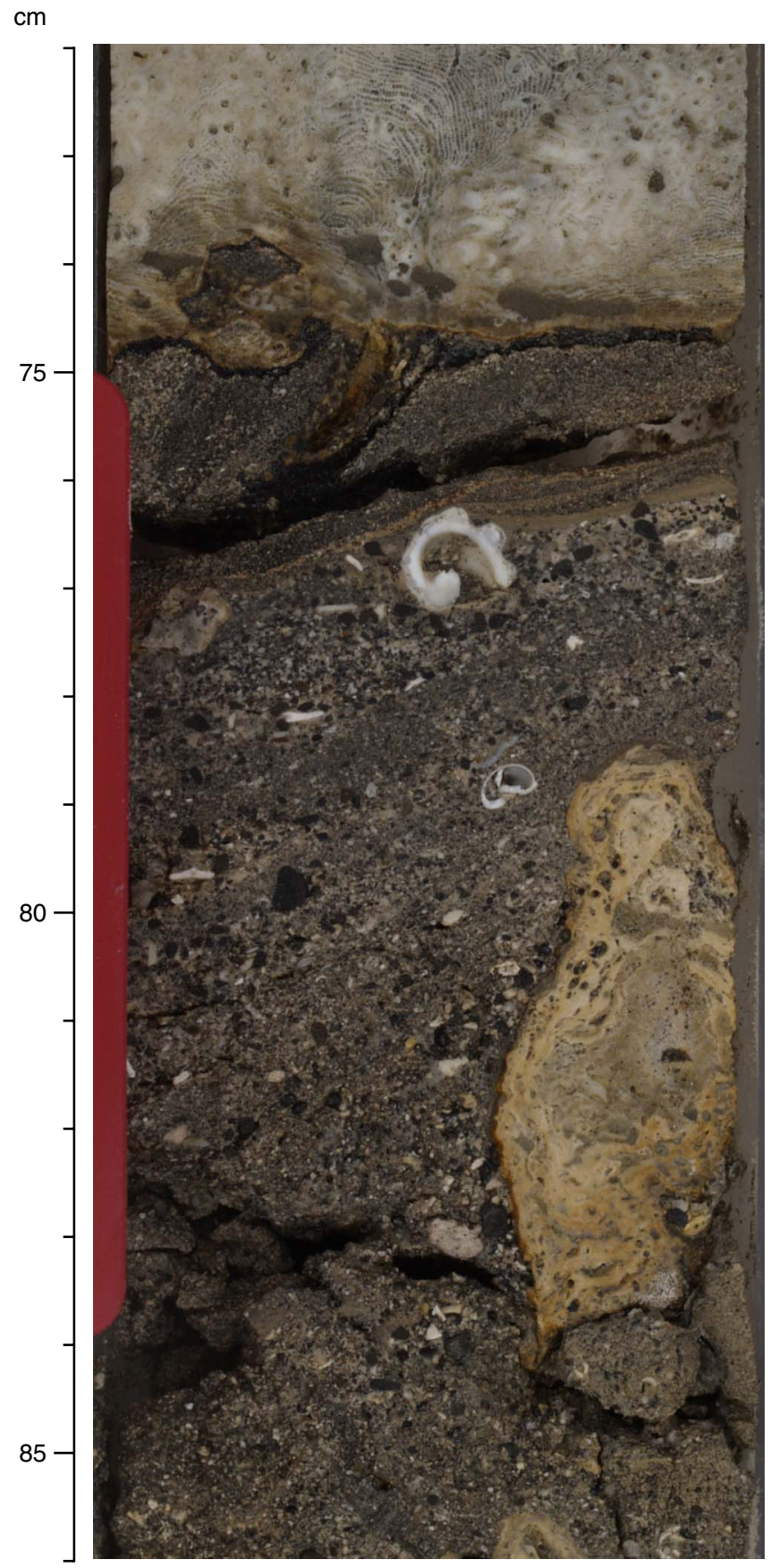


Figure F54. Volcanic-rich sediments with unsorted carbonate grains and encrustations of coralline algae (Subunit IID; interval 310-M0025A-11R-1, 85-107 cm).

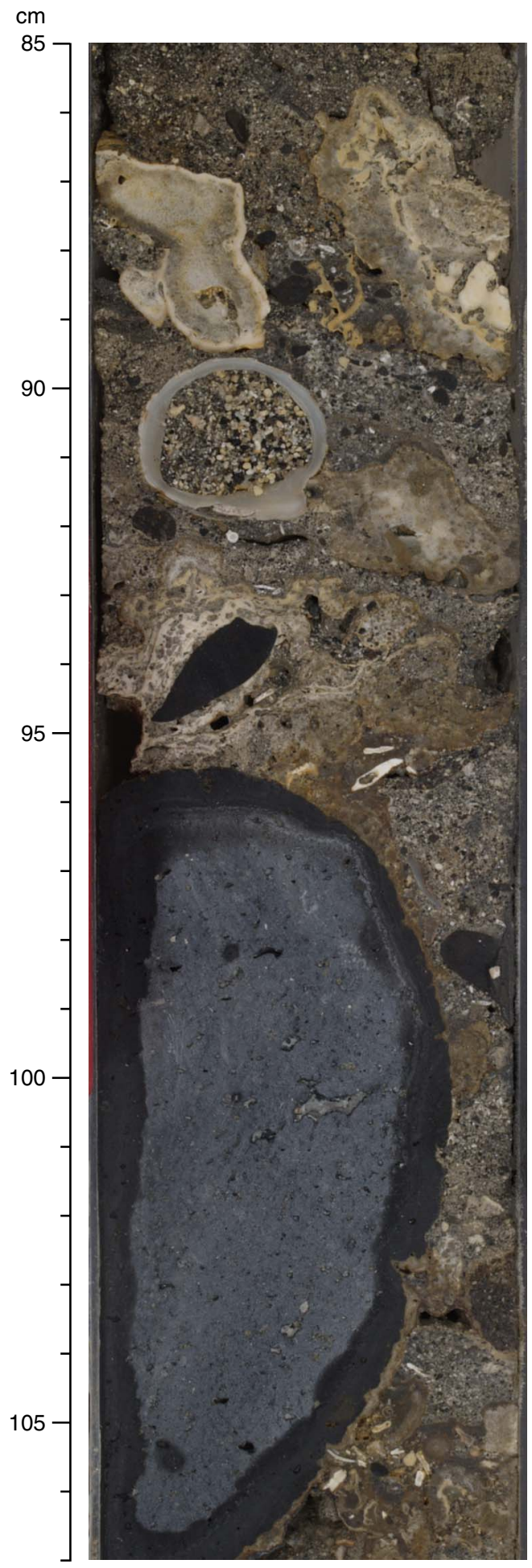


Figure F55. Volcanic-rich sediments with vugs infilled with finer sediment (Subunit IID; interval 310M0025A-12R-2, 70-85 cm).

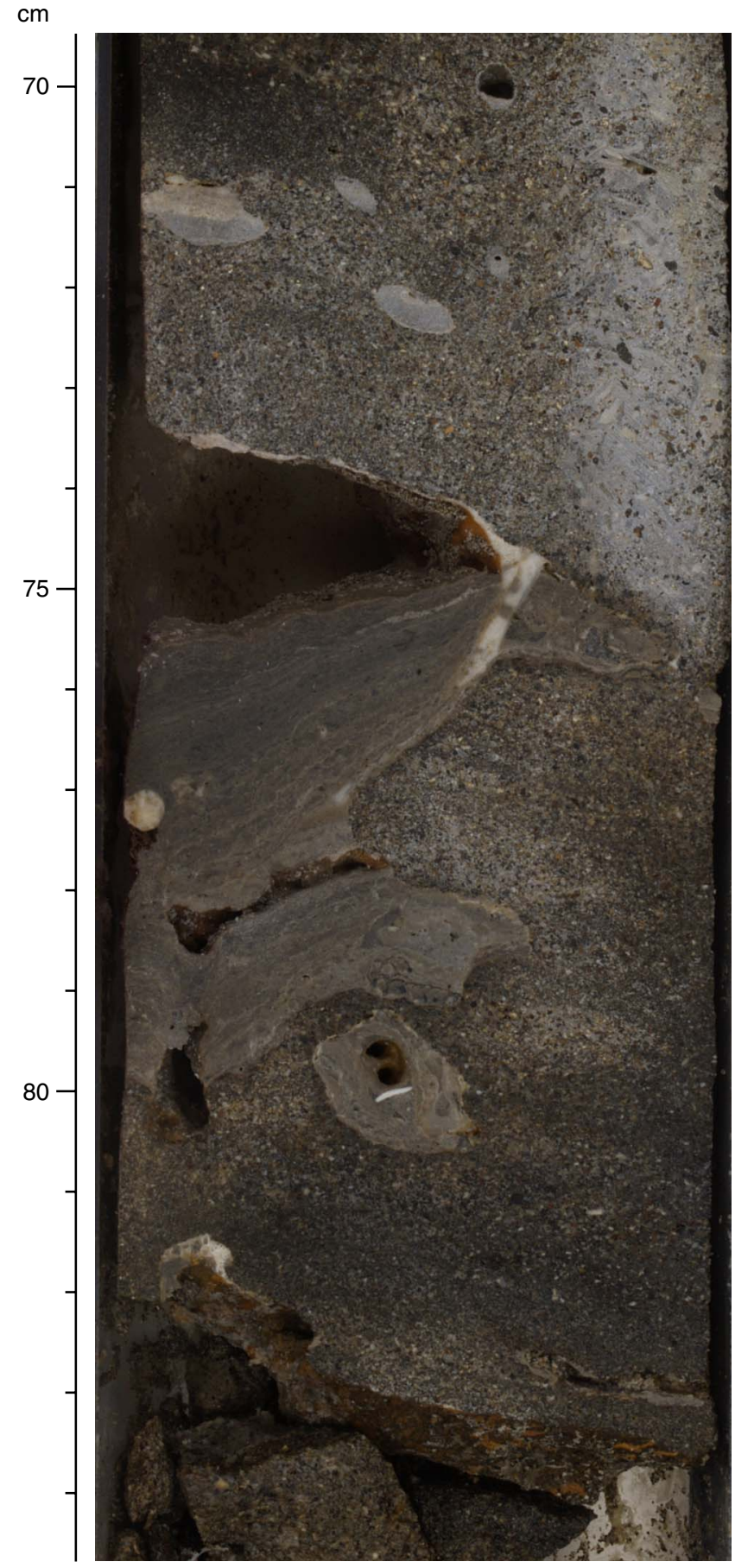


Figure F56. Volcaniclastic sediments with pockets of Halimeda segments (Subunit IID; interval 310-M0025B13R-1, 65-75 cm).

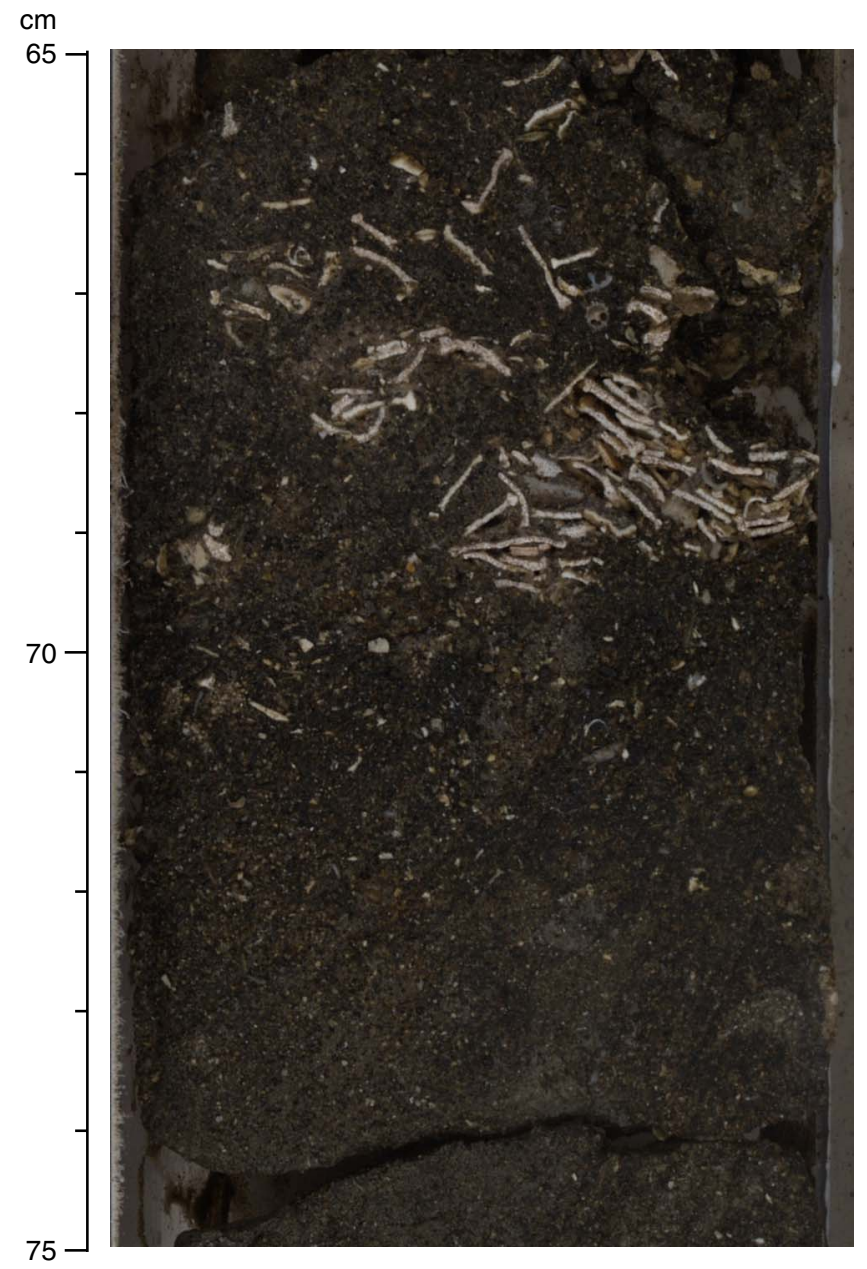


Figure F57. Velocity, bulk density, magnetic susceptibility, and porosity as a function of depth in Hole M0009A. Discrete measurements are superimposed (red circles).

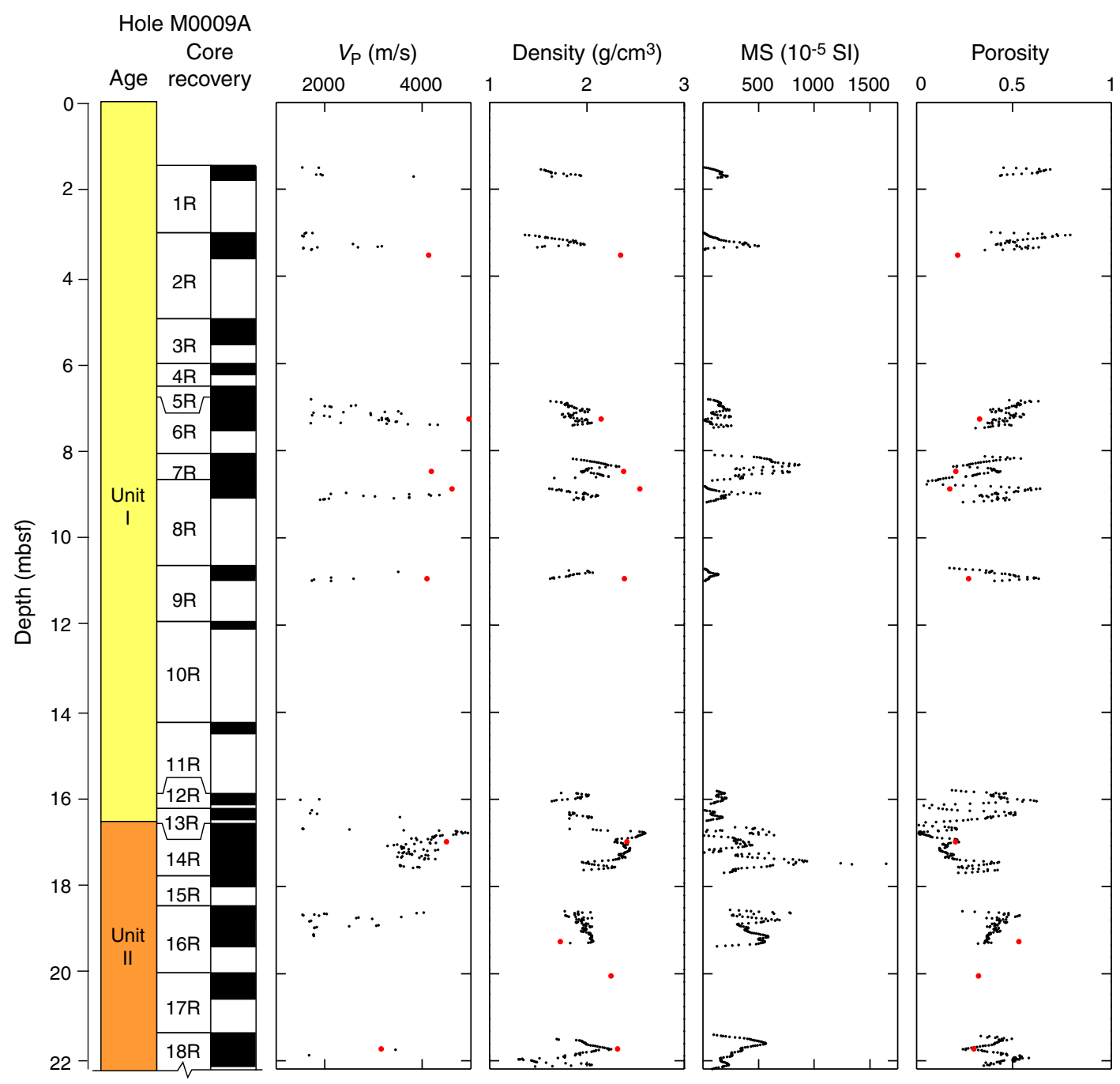


Figure F58. Velocity, bulk density, magnetic susceptibility, and porosity as a function of depth in Hole M0009C. Discrete measurements are superimposed (red circles).

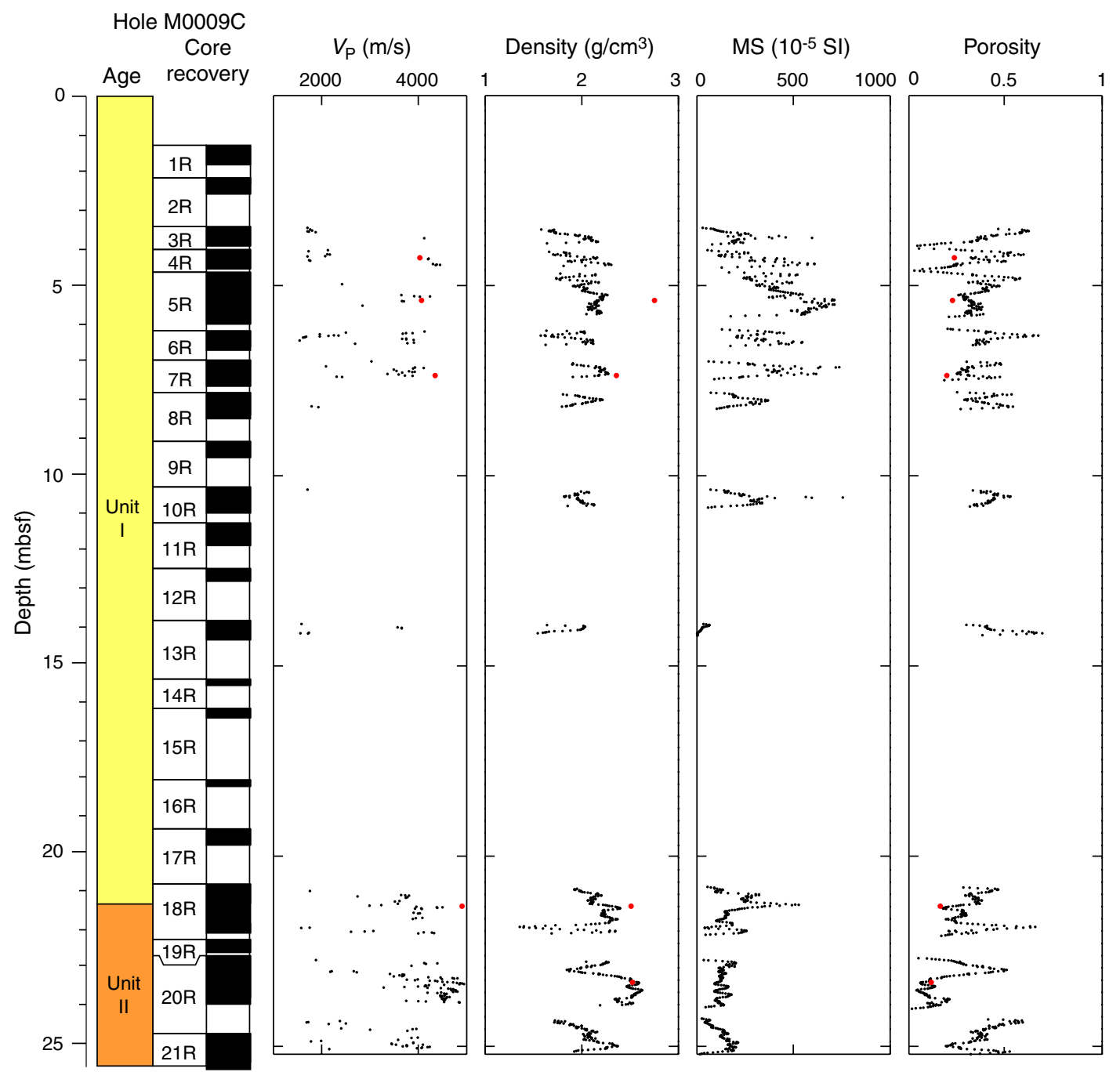


Figure F59. Velocity, bulk density, magnetic susceptibility, and porosity as a function of depth in Hole M0009D. Discrete measurements are superimposed (red circles).

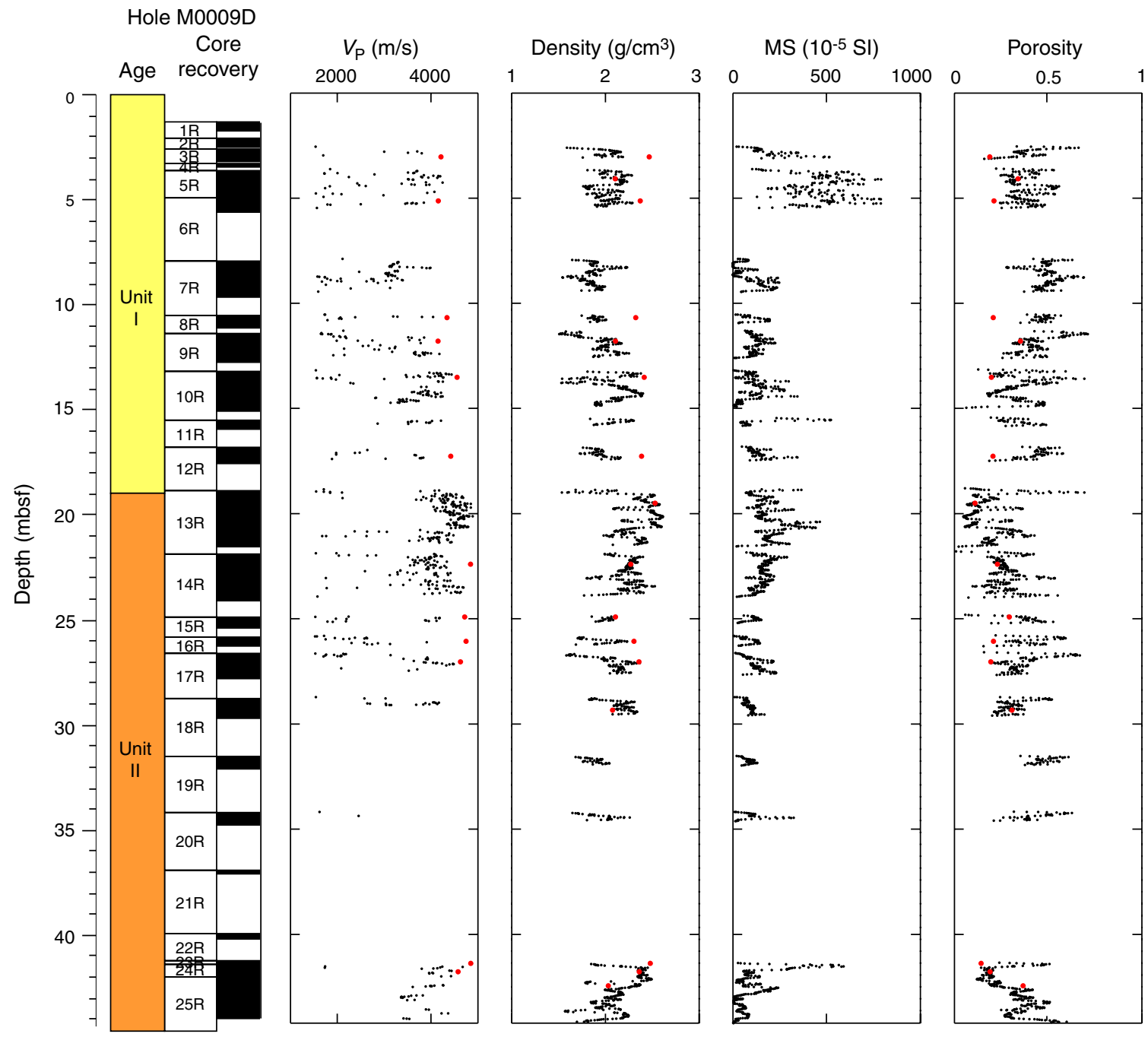


Figure F60. Velocity, bulk density, magnetic susceptibility, and porosity as a function of depth in Hole M0009B. Discrete measurements are superimposed (red circles).

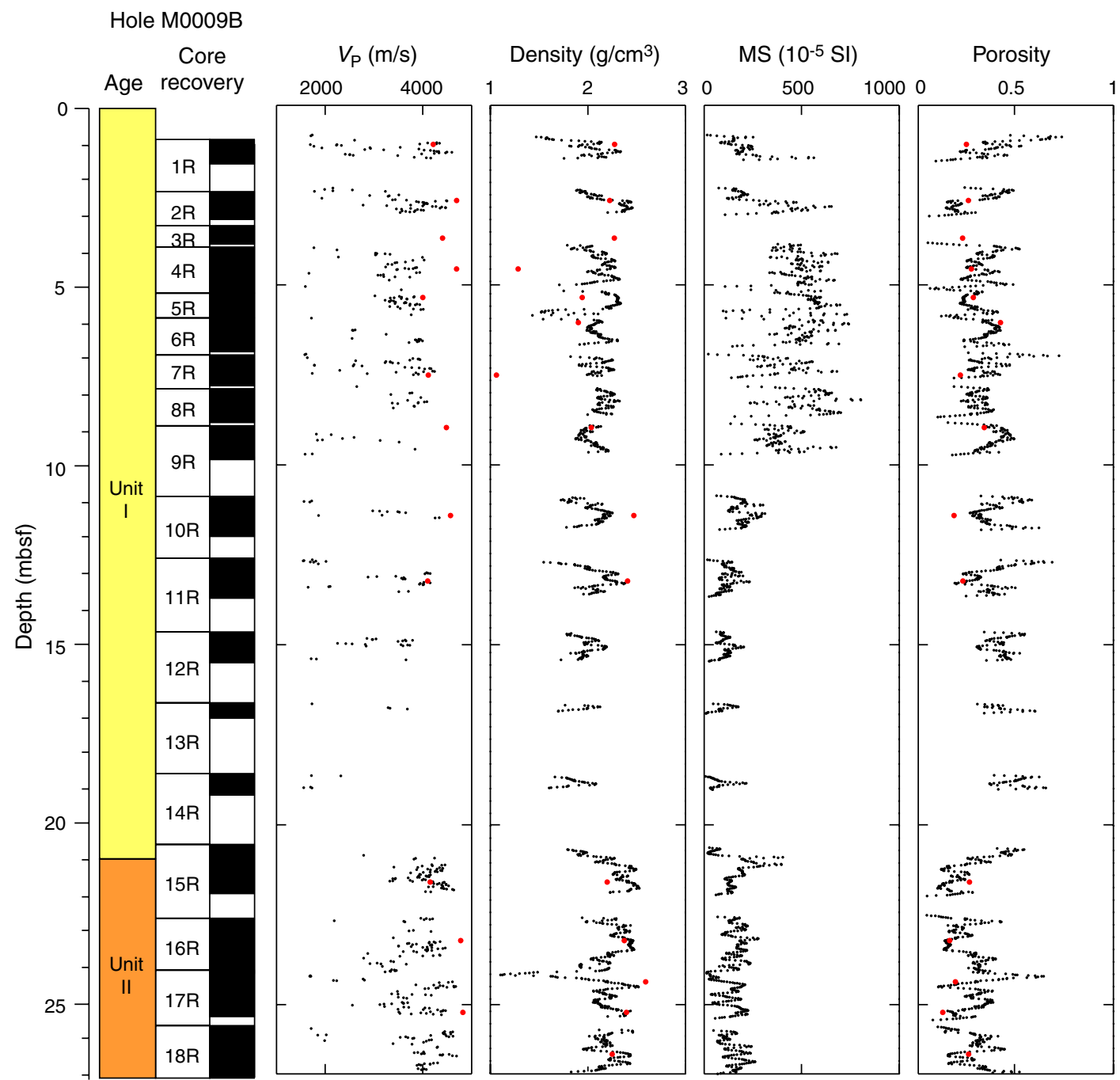


Figure F61. Velocity, bulk density, magnetic susceptibility, and porosity as a function of depth in Hole M0009E. Discrete measurements are superimposed (red circles).

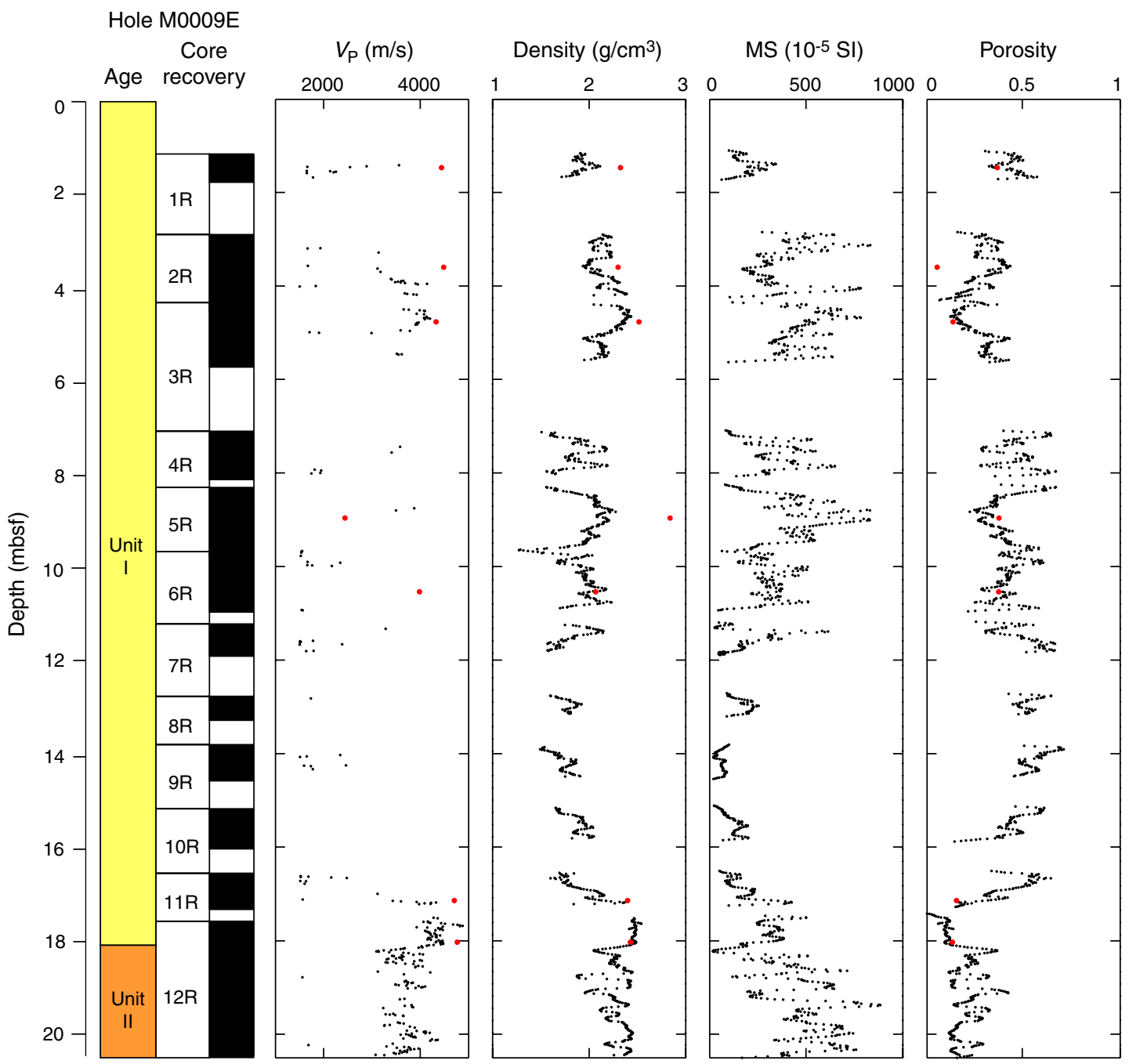


Figure F62. Velocity, bulk density, magnetic susceptibility, and porosity as a function of depth in Hole M0021A. Discrete measurements are superimposed (red circles).

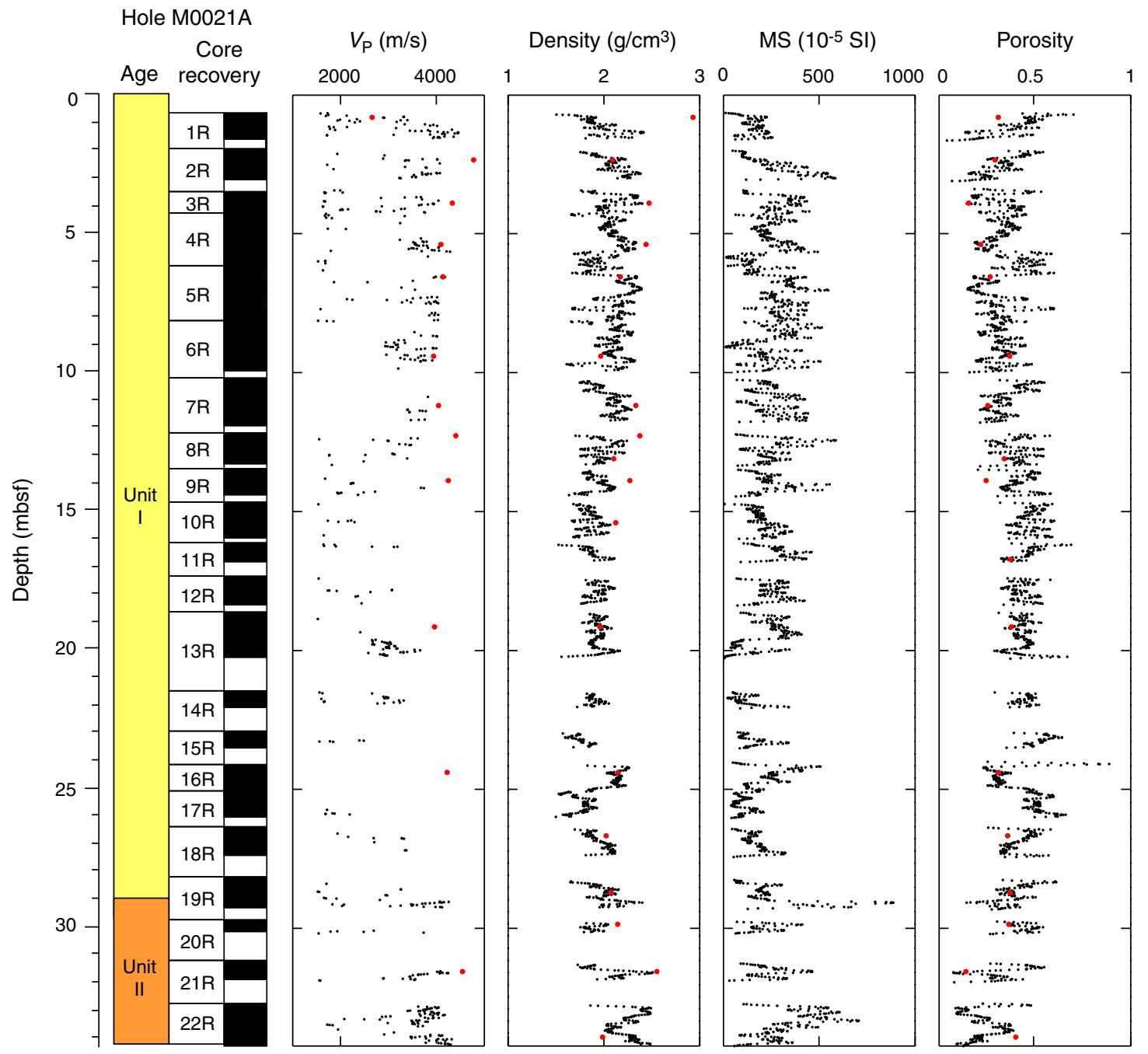


Figure F63. Velocity, bulk density, magnetic susceptibility, and porosity as a function of depth in Hole M0021B. Discrete measurements are superimposed (red circles).

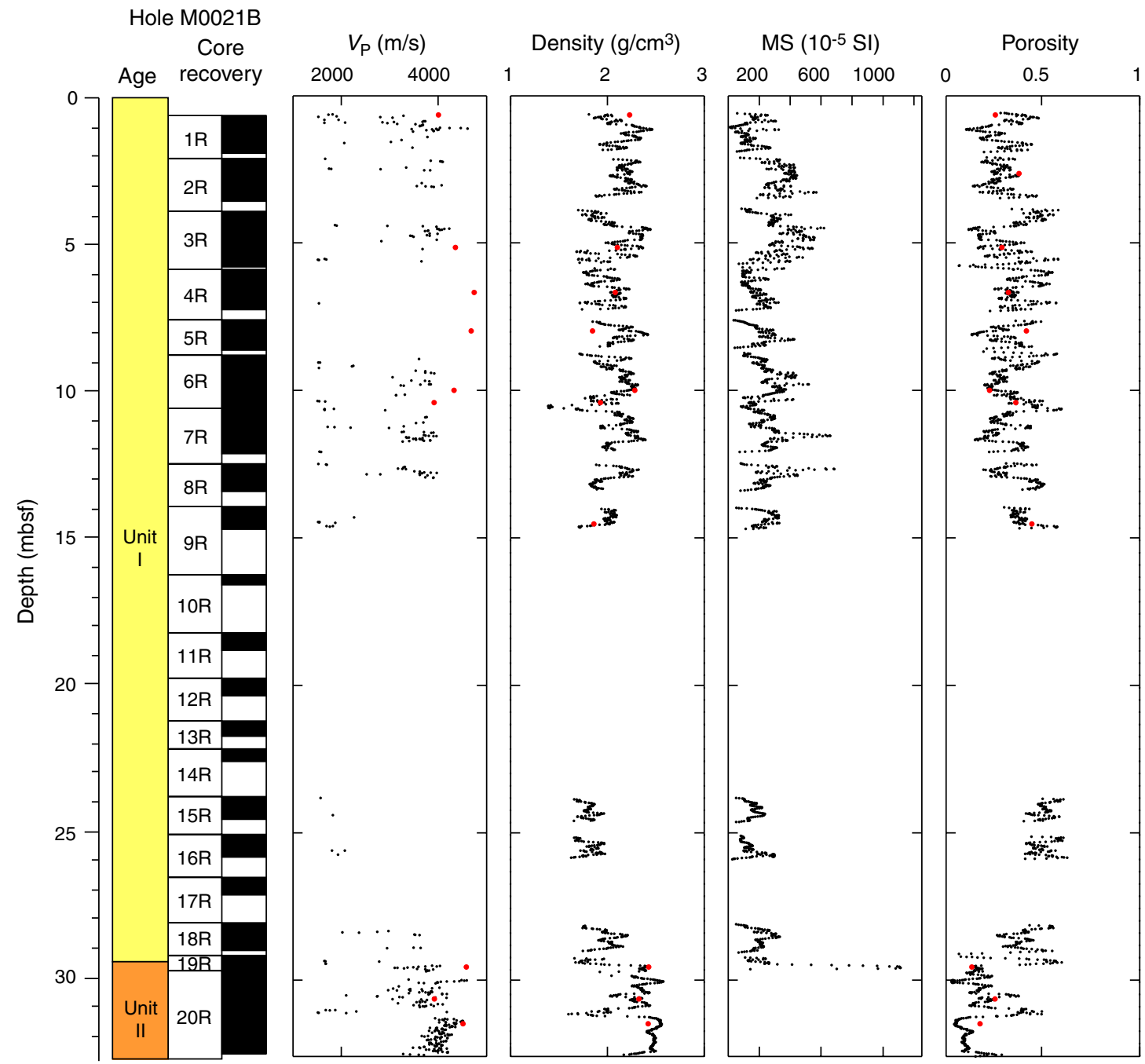


Figure F64. Velocity, bulk density, magnetic susceptibility, and porosity as a function of depth in Hole M0024A. Discrete measurements are superimposed (red circles).

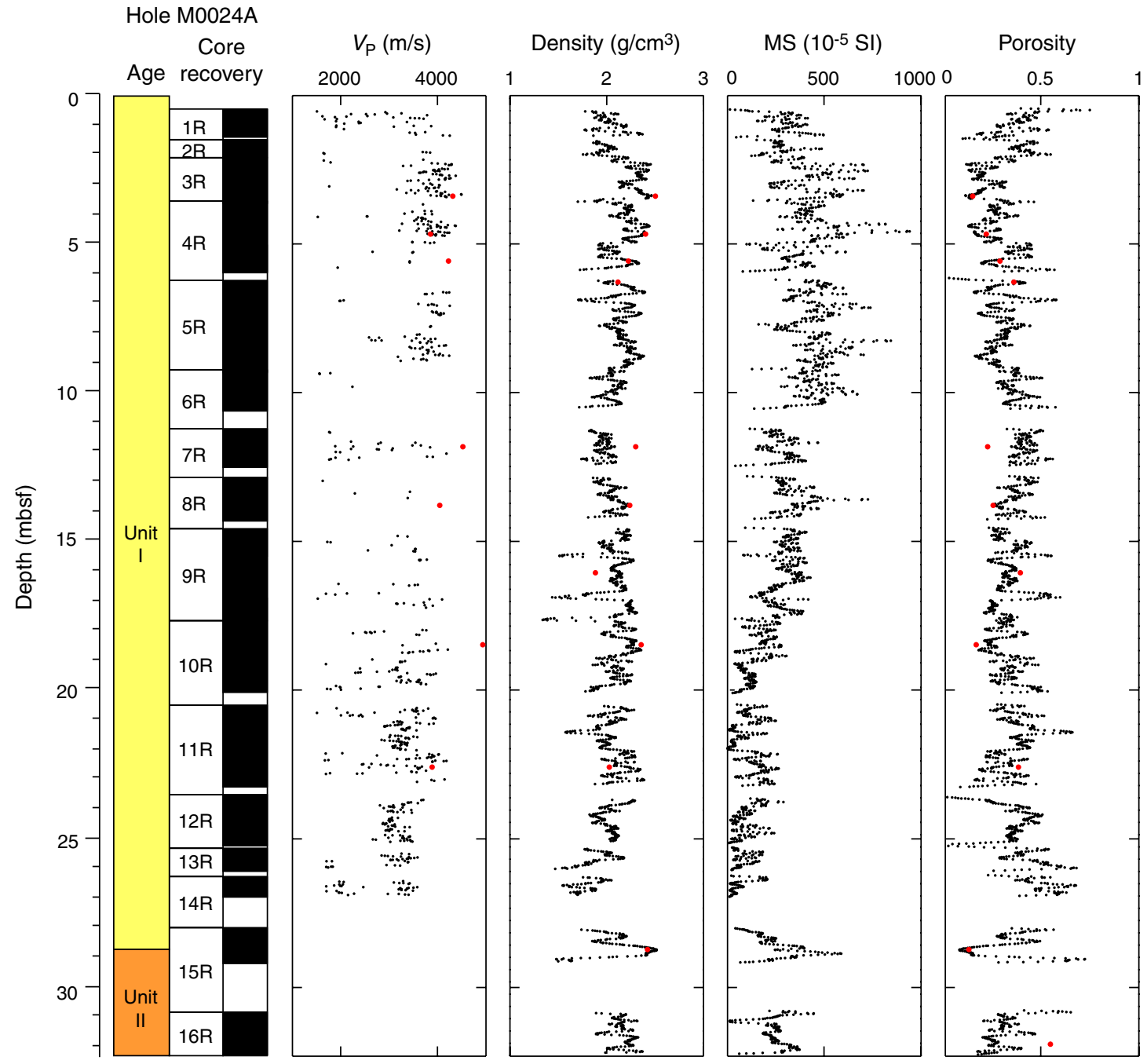


Figure F65. Velocity, bulk density, magnetic susceptibility, and porosity as a function of depth in Hole M0025A. Discrete measurements are superimposed (red circles).

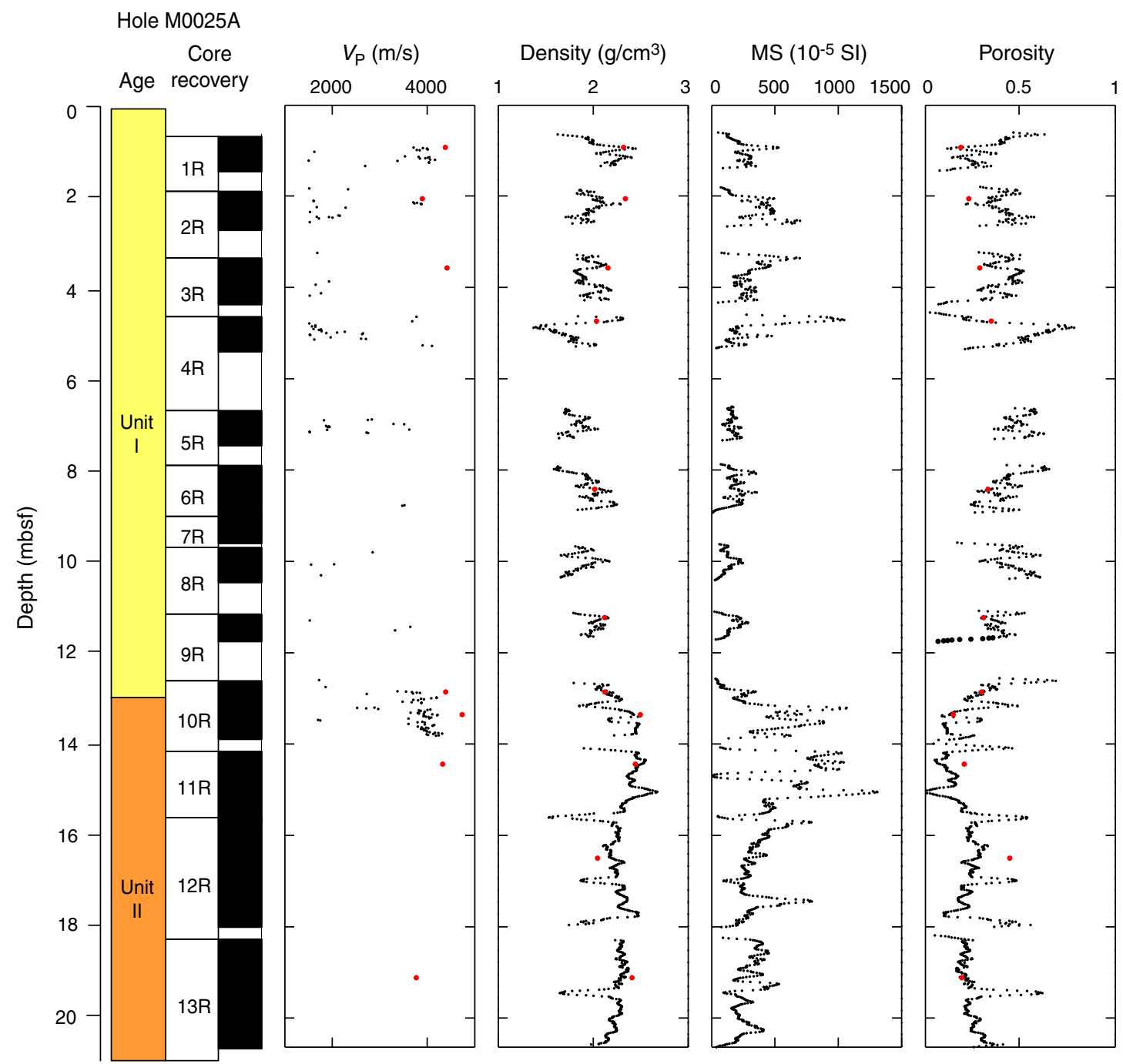


Figure F66. Velocity, bulk density, magnetic susceptibility, and porosity as a function of depth in Hole M0025B. Discrete measurements are superimposed (red circles). See text for discussion.

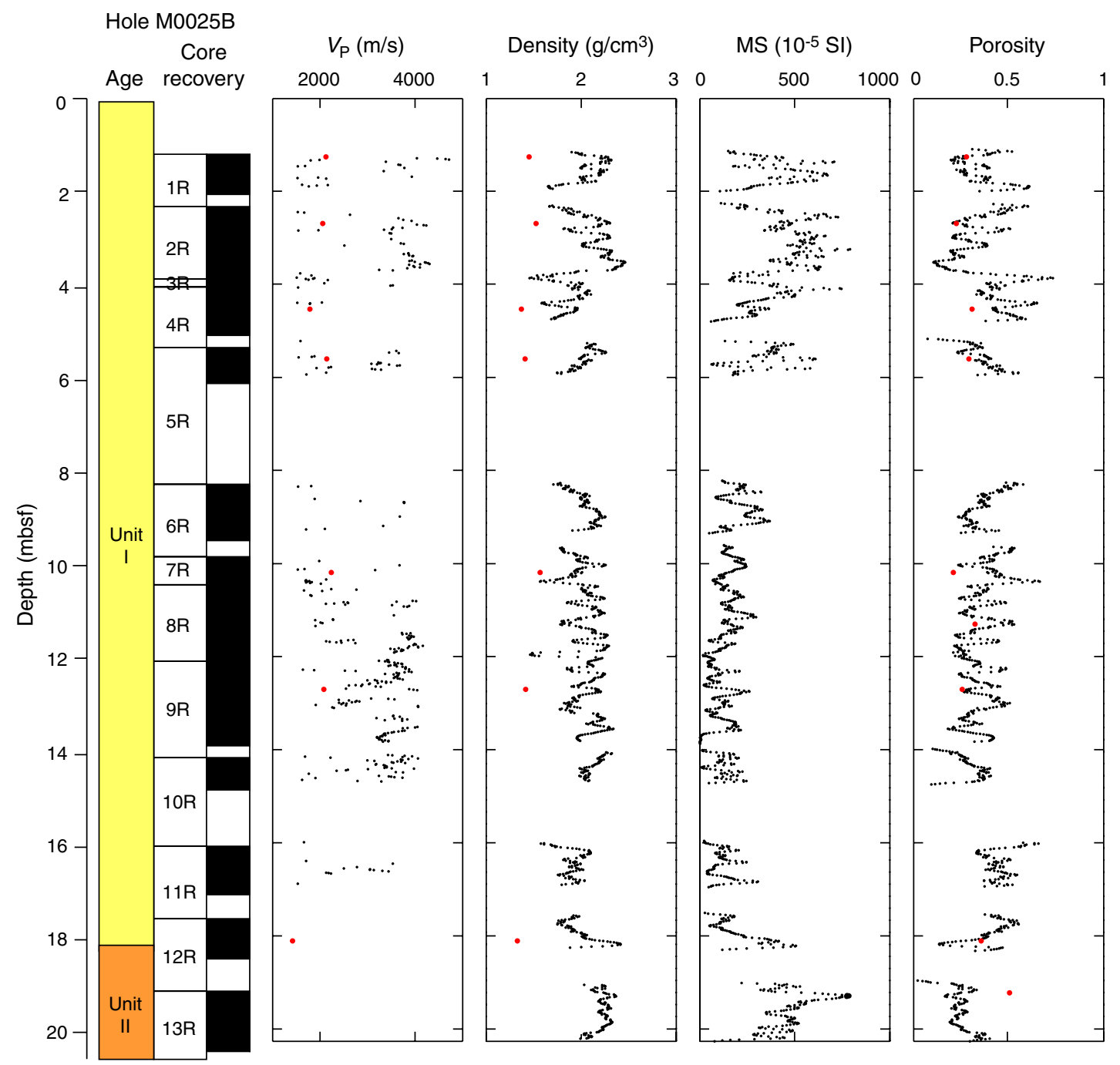


Figure F67. Velocity, bulk density, magnetic susceptibility, and porosity as a function of depth in Hole M0026A. Discrete measurements are superimposed (red circles).

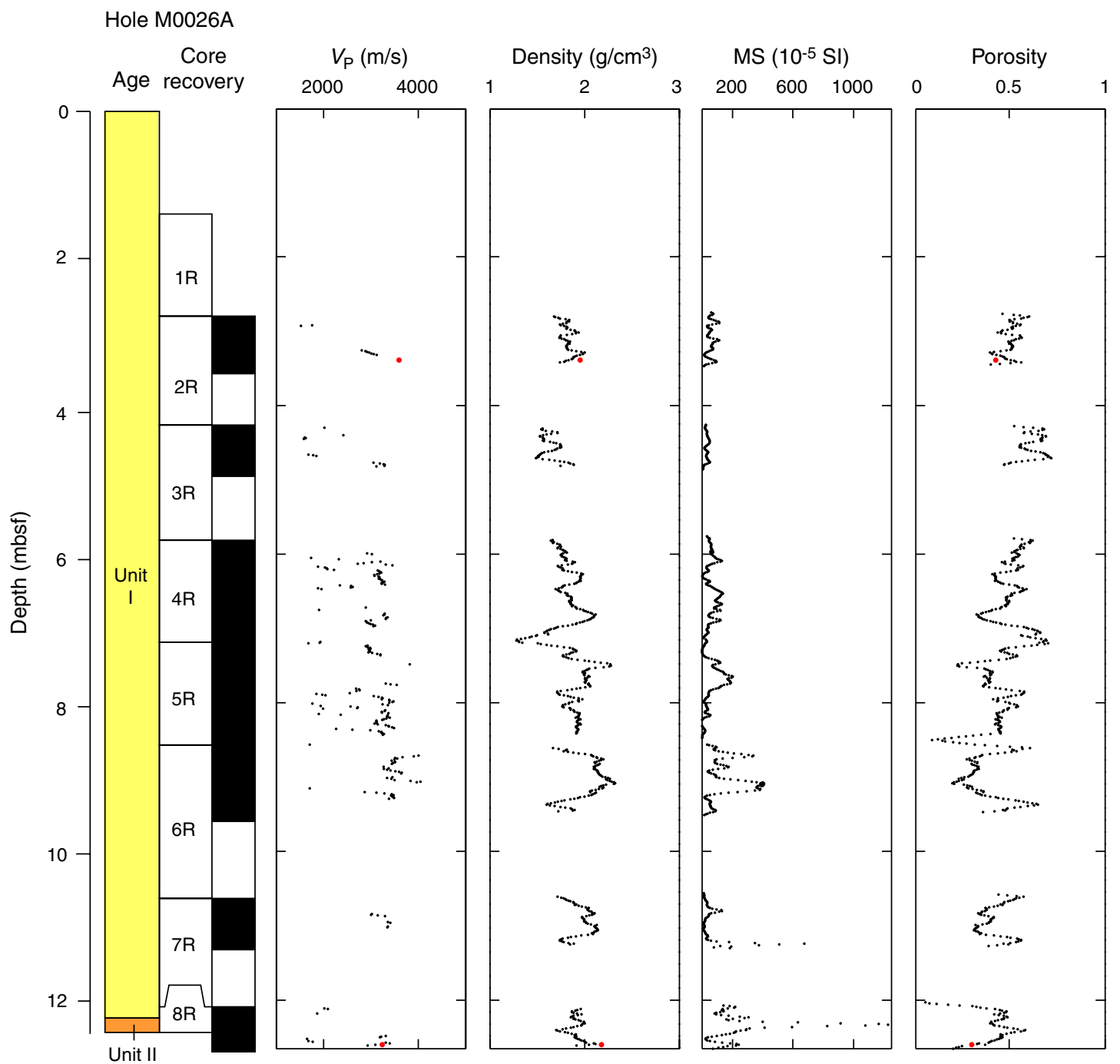


Figure F68. Cross plot of porosity with velocity for M0009, M0021, and M0024-M0026. Solid lines refer to the Wyllie time average equation (red) and Raymer modified time average equation (green) for a matrix velocity of calcite $(6530 \mathrm{~m} / \mathrm{s})$. Discrete measurements are superimposed (red circles).

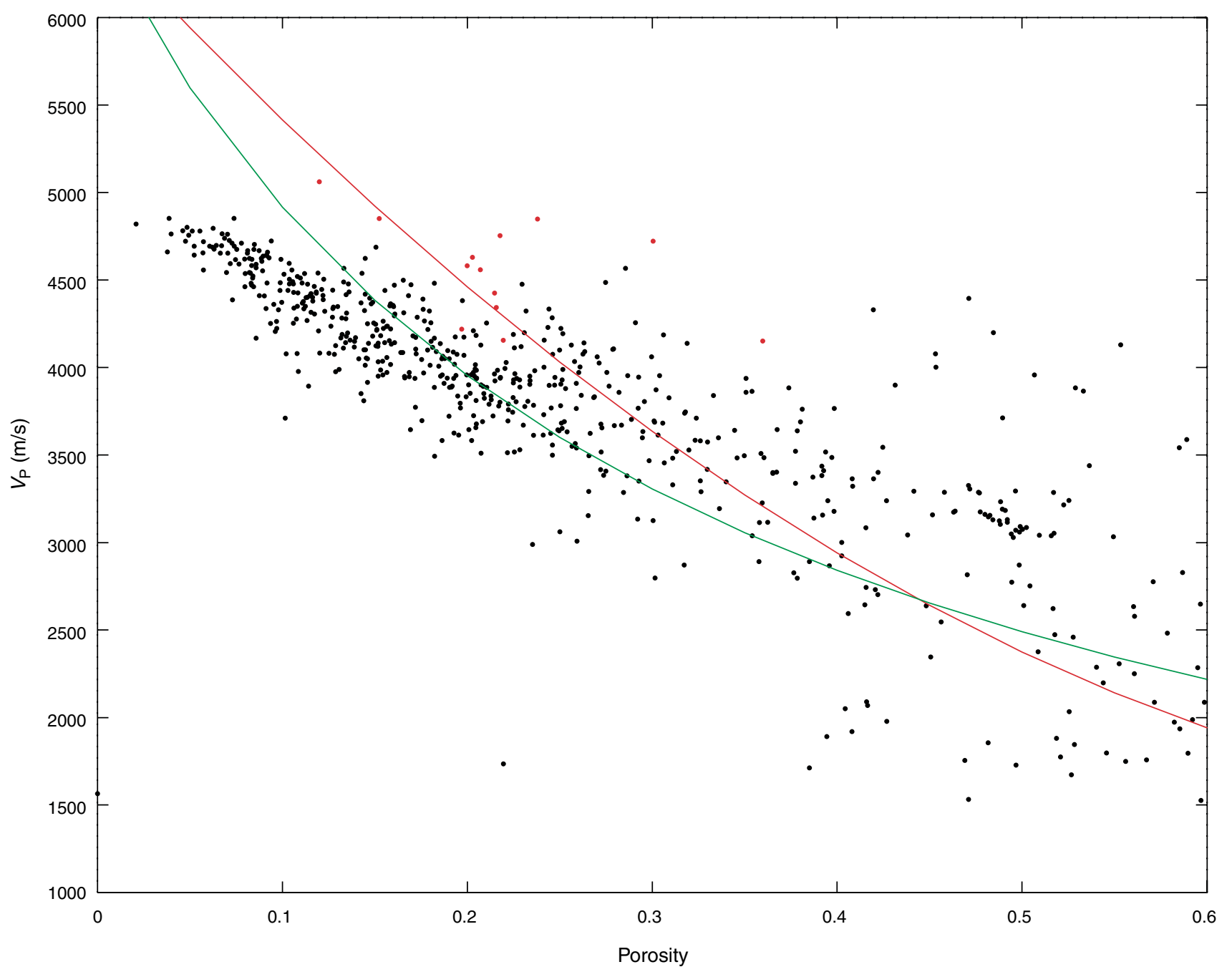


Figure F69. Comparison of MSCL velocity data (black circles), downhole sonic log data (blue line), and discrete measurements (red circles) as a function of depth for Sites M0009, M0021, and M0024-M0026.

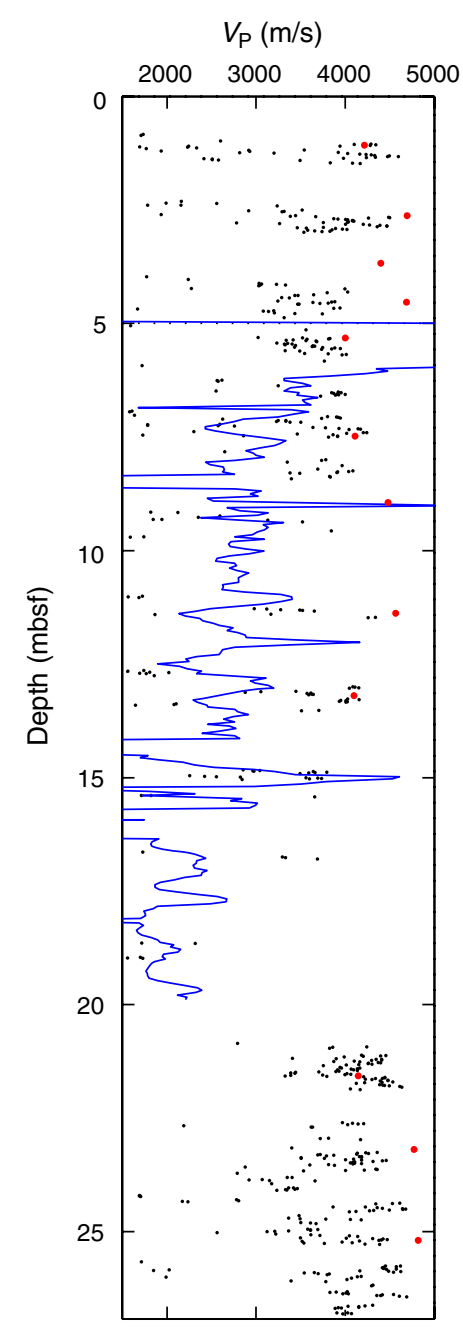


Figure F70. Color reflectance $\left(\mathrm{L}^{*}\right)$ data from Holes M0009A-M0009E, M00021A, M00021B, M0024A, M0025A, M0025B, and M0026A. For plotting purposes, Holes M0009B-M0009E, M00021A, M00021B, M0024A, M0025A, M0025B, and M0026A are offset from Hole M0009A by 40, 80, 120, 170, 220, 260, 310, 370, 410, and $460 \mathrm{~L}^{*}$ units, respectively.

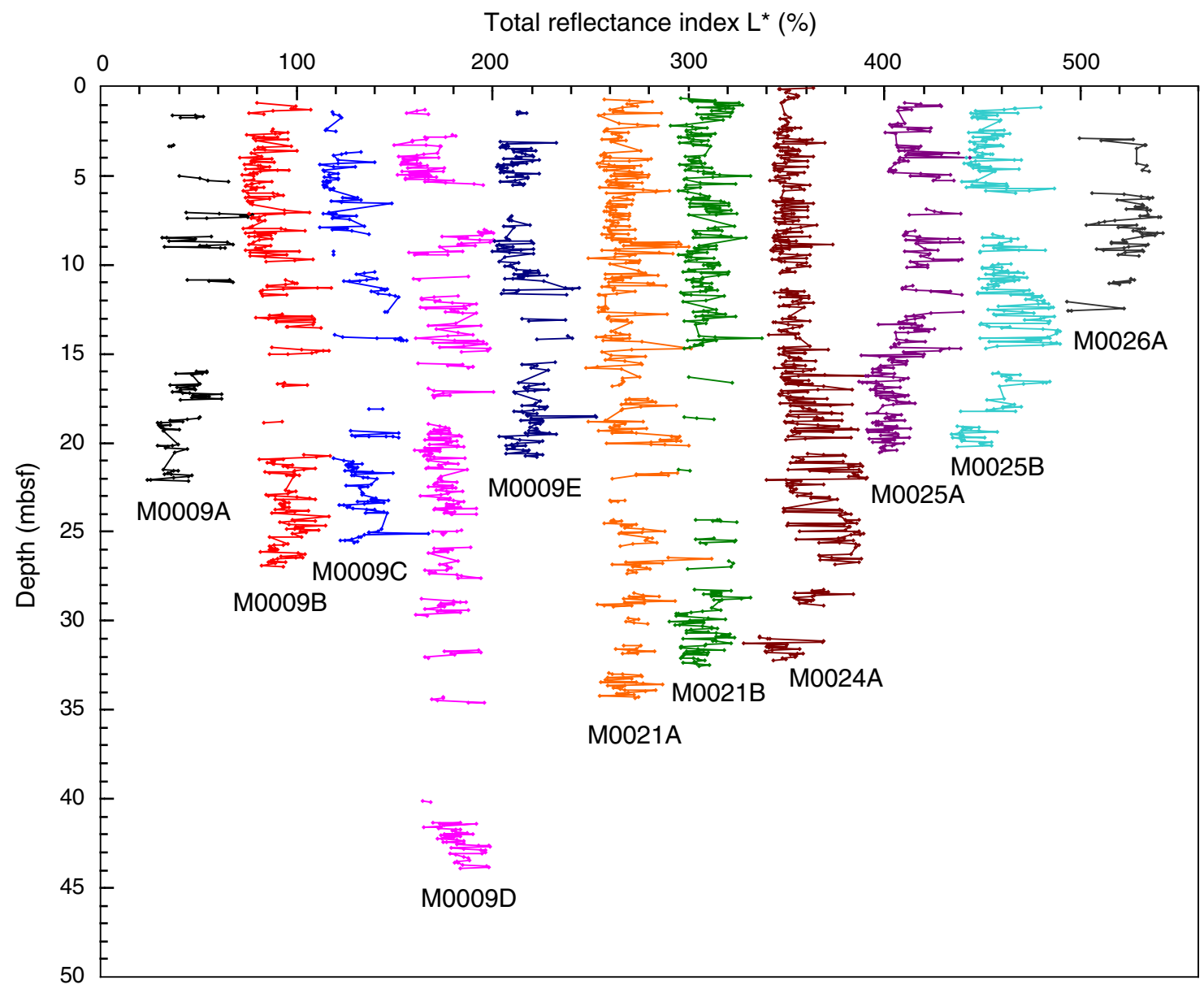


Figure F71. Wireline logging data for Hole M0009B. Ac. cal. $=$ acoustic caliper derived from ABI40, Mec. cal. = mechanical caliper, TGR = total gamma ray, res. = resistivity, $\mathrm{T}=$ borehole fluid temperature, $\mathrm{C}=$ borehole fluid conductivity.

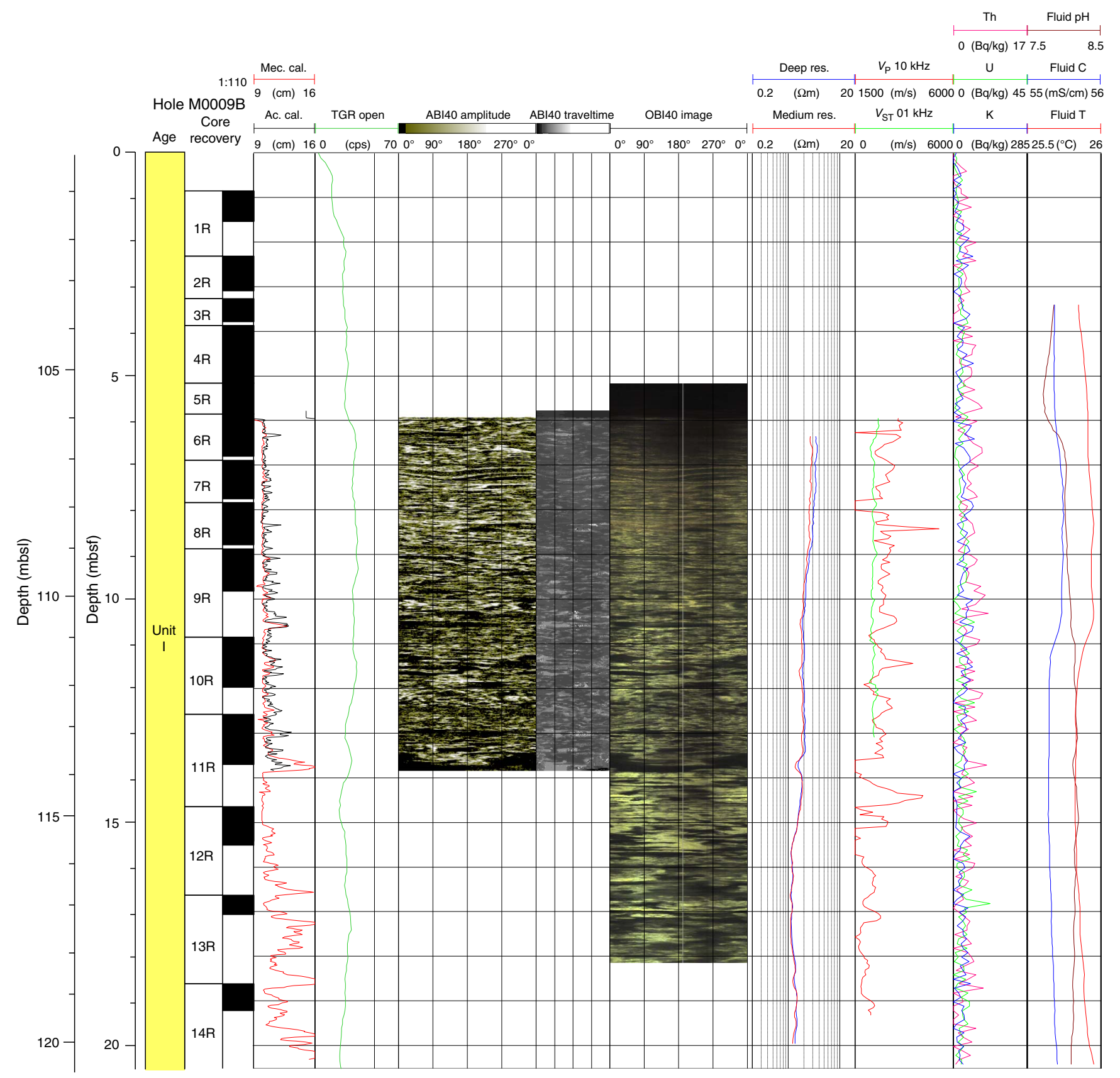


Figure F72. Wireline logging data for Hole M0009B. Mec. cal. $=$ mechanical caliper, Ac. cal. $=$ acoustic caliper derived from ABI40. (See the "DOWNHOLE" folder in "Supplementary Material" for the complete multipart figure in PDF format.)

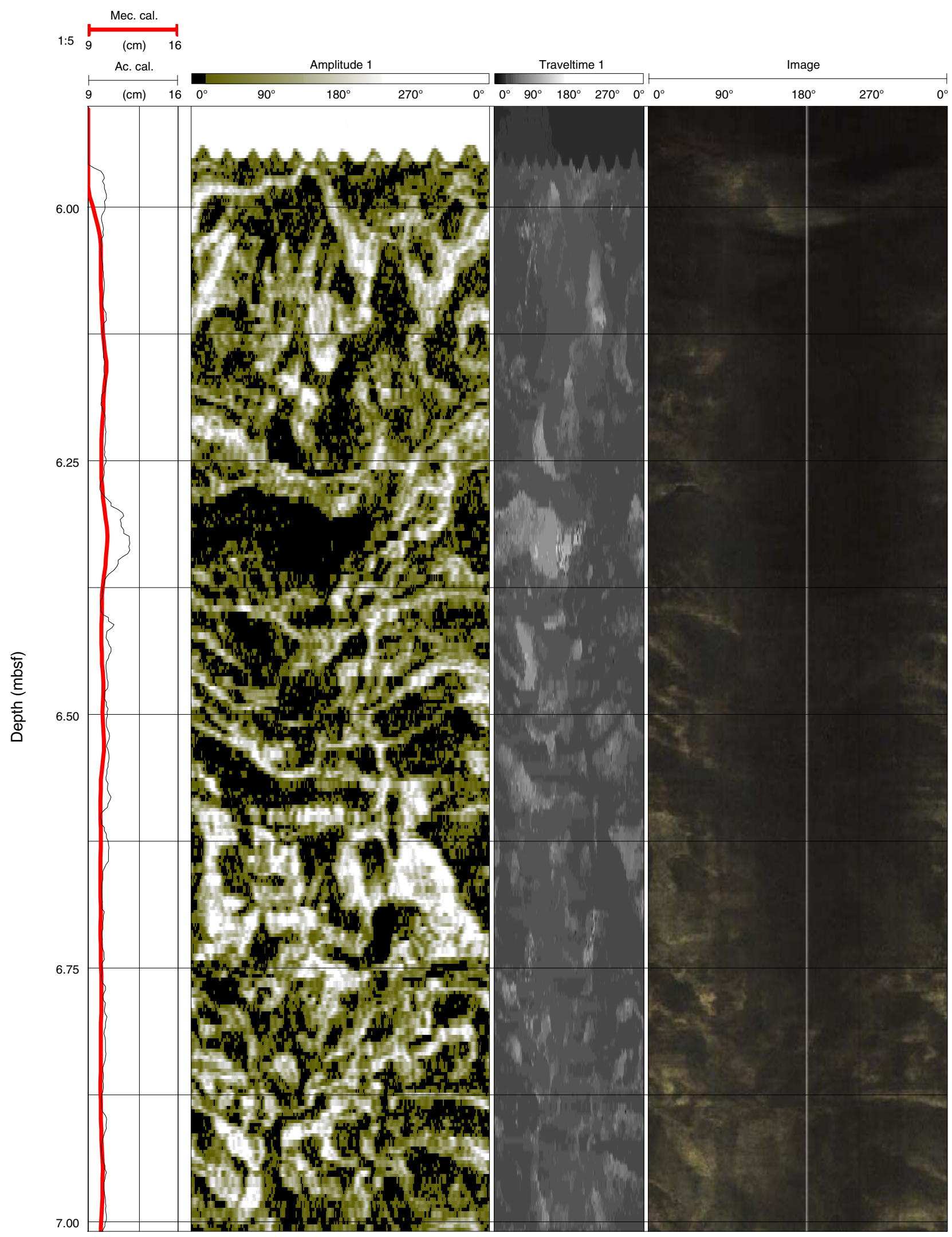


Figure F73. Wireline logging data for Hole M0009D. Ac. cal. $=$ acoustic caliper derived from ABI40, TGR = total gamma ray, res. = resistivity, $\mathrm{T}=$ borehole fluid temperature, $\mathrm{C}=$ borehole fluid conductivity.

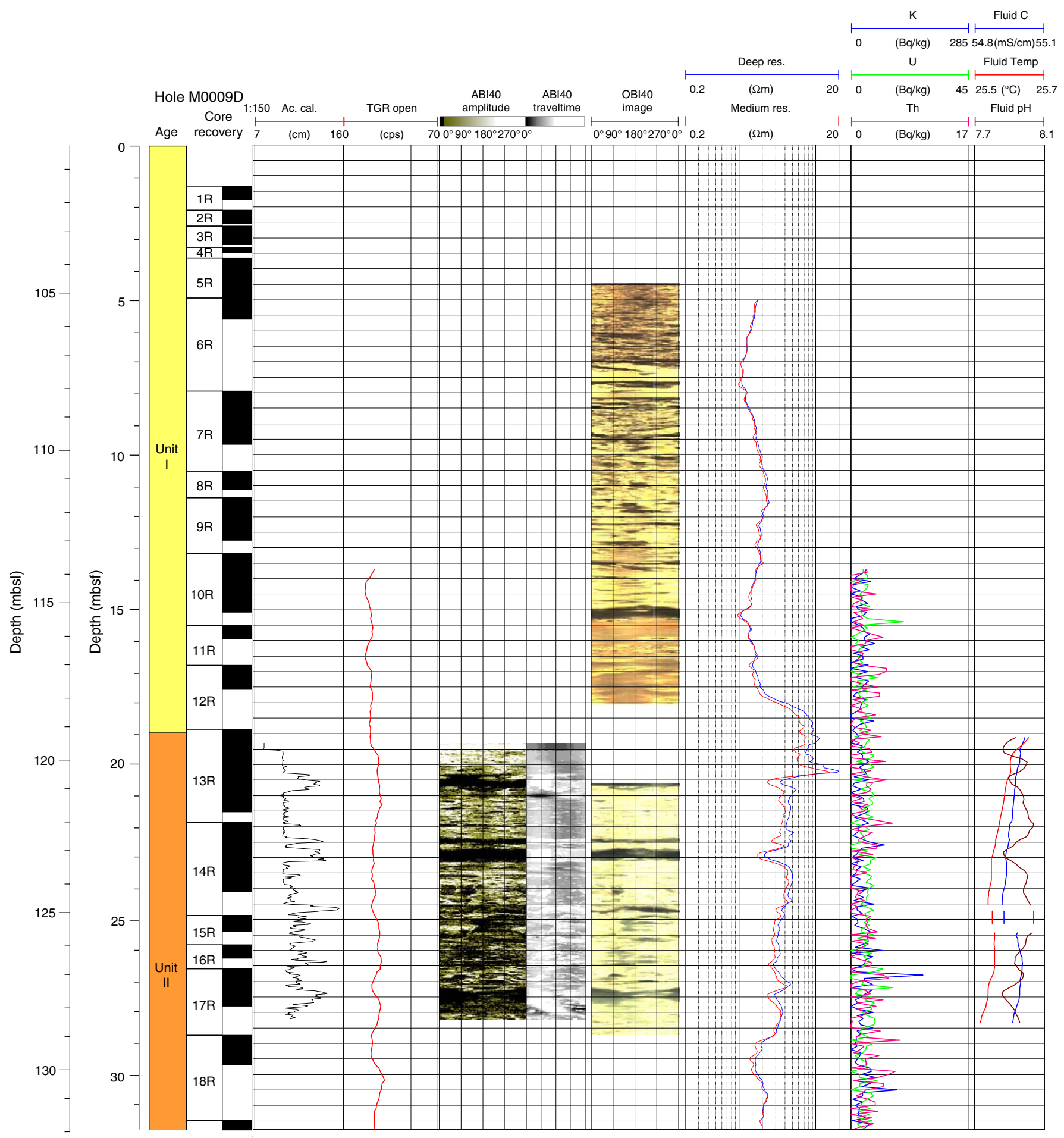


Figure F74. Wireline logging data for Hole M0009D. Ac. cal. = acoustic caliper derived from ABI40. (See the "DOWNHOLE" folder in "Supplementary Material" for the complete multipart figure in PDF format.)

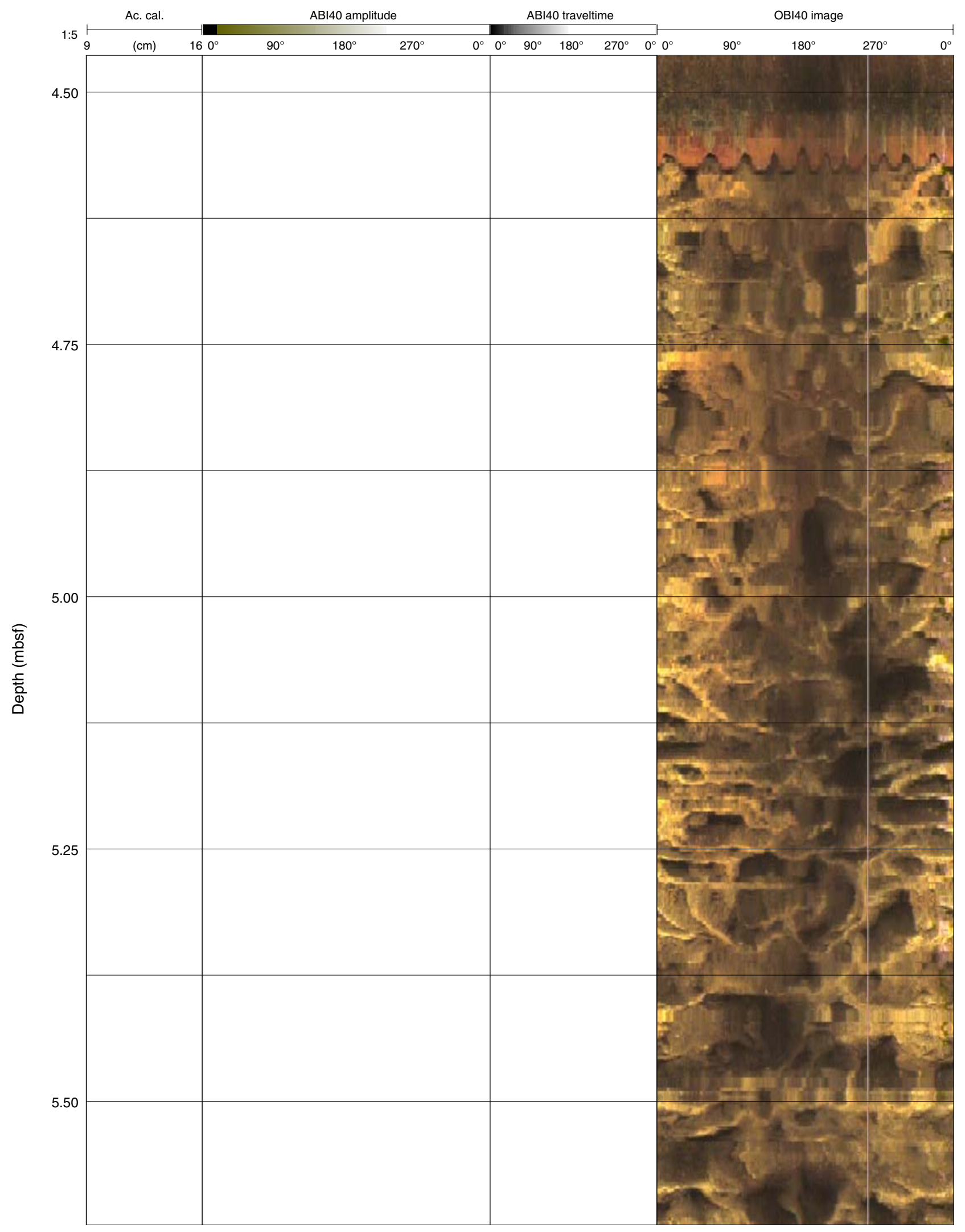


Figure F75. Wireline logging data for Hole M0009E. Ac. cal. $=$ acoustic caliper derived from ABI40, Mec. cal. = mechanical caliper. (See the "DOWNHOLE" folder in "Supplementary Material" for the complete multipart figure in PDF format.)

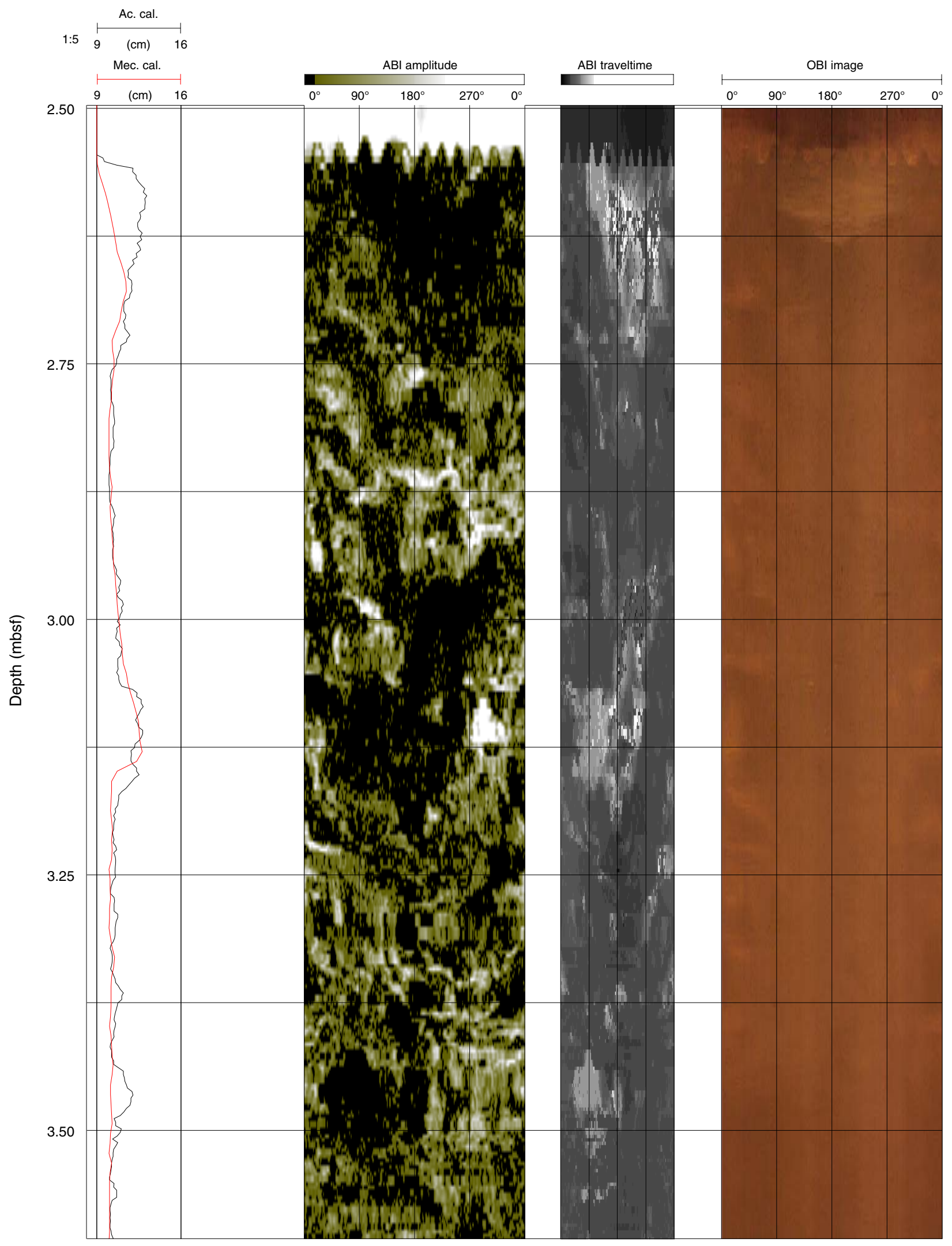


Figure F76. Wireline logging data for Hole M0009E. Ac. cal. $=$ acoustic caliper derived from ABI40, Mec. cal. = mechanical caliper, $\mathrm{TGR}=$ total gamma ray, res. $=$ resistivity, $\mathrm{T}=$ borehole fluid temperature, $\mathrm{C}=$ borehole fluid conductivity.

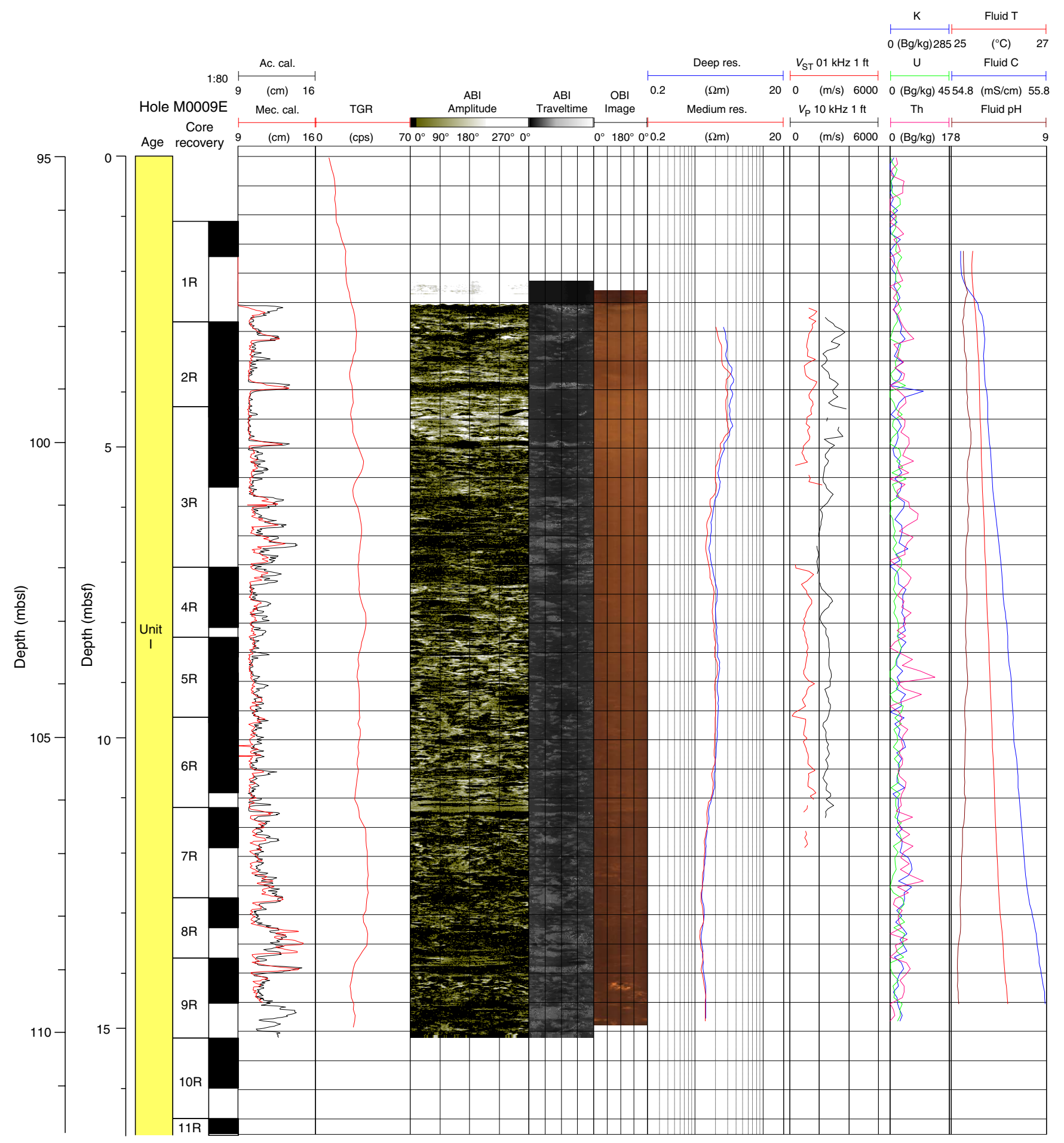


Figure F77. Wireline logging data for Hole M0021B. Ac. cal. $=$ acoustic caliper derived from ABI40, Mec. cal. = mechanical caliper, $\mathrm{TGR}=$ total gamma ray, res. $=$ resistivity, $\mathrm{T}=$ borehole fluid temperature, $\mathrm{C}=$ borehole fluid conductivity.

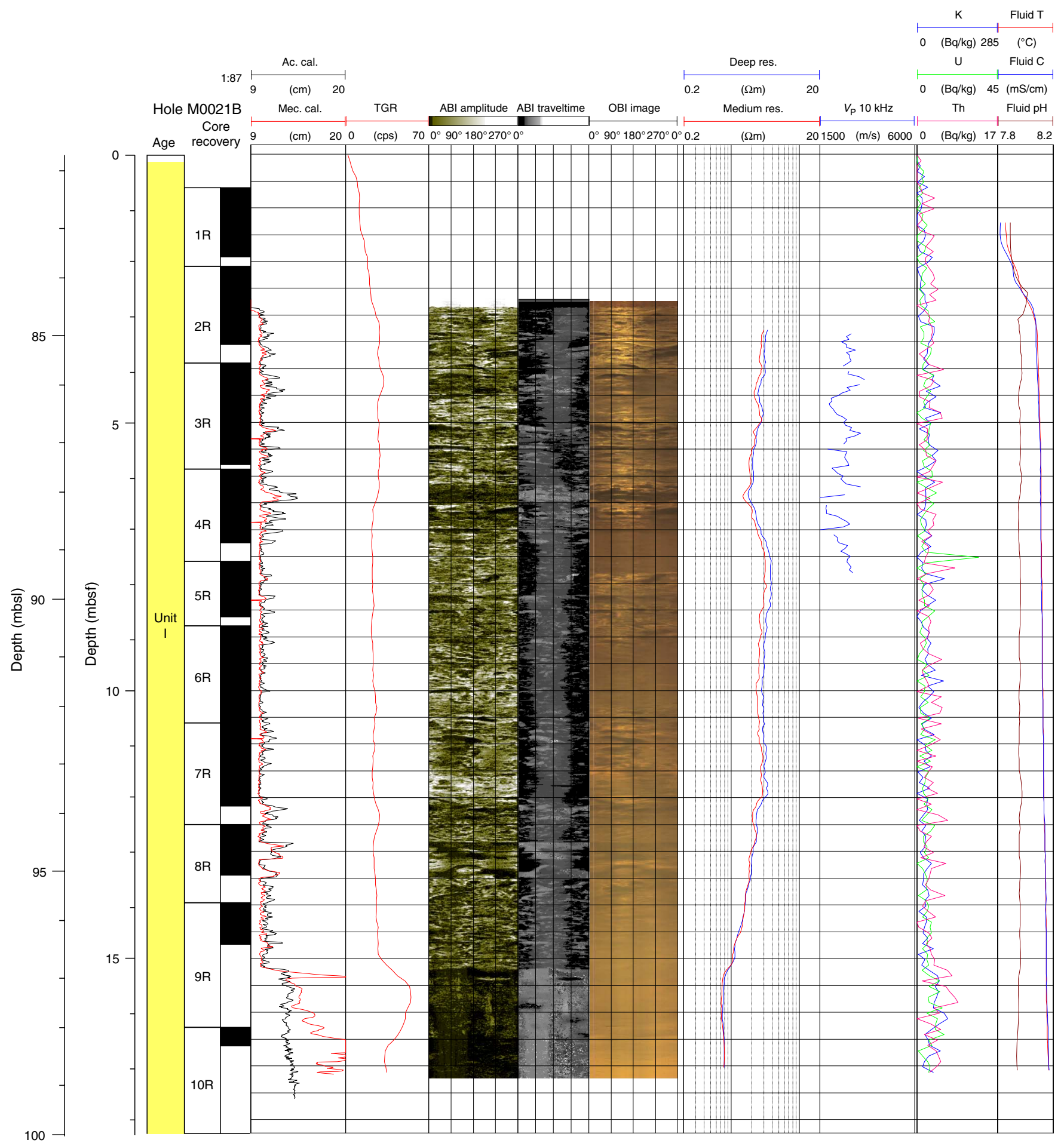


Figure F78. Wireline logging data for Hole M0021B. Ac. cal. $=$ acoustic caliper derived from ABI40, Mec. cal. = mechanical caliper. (See the "DOWNHOLE" folder in "Supplementary Material" for the complete multipart figure in PDF format.)

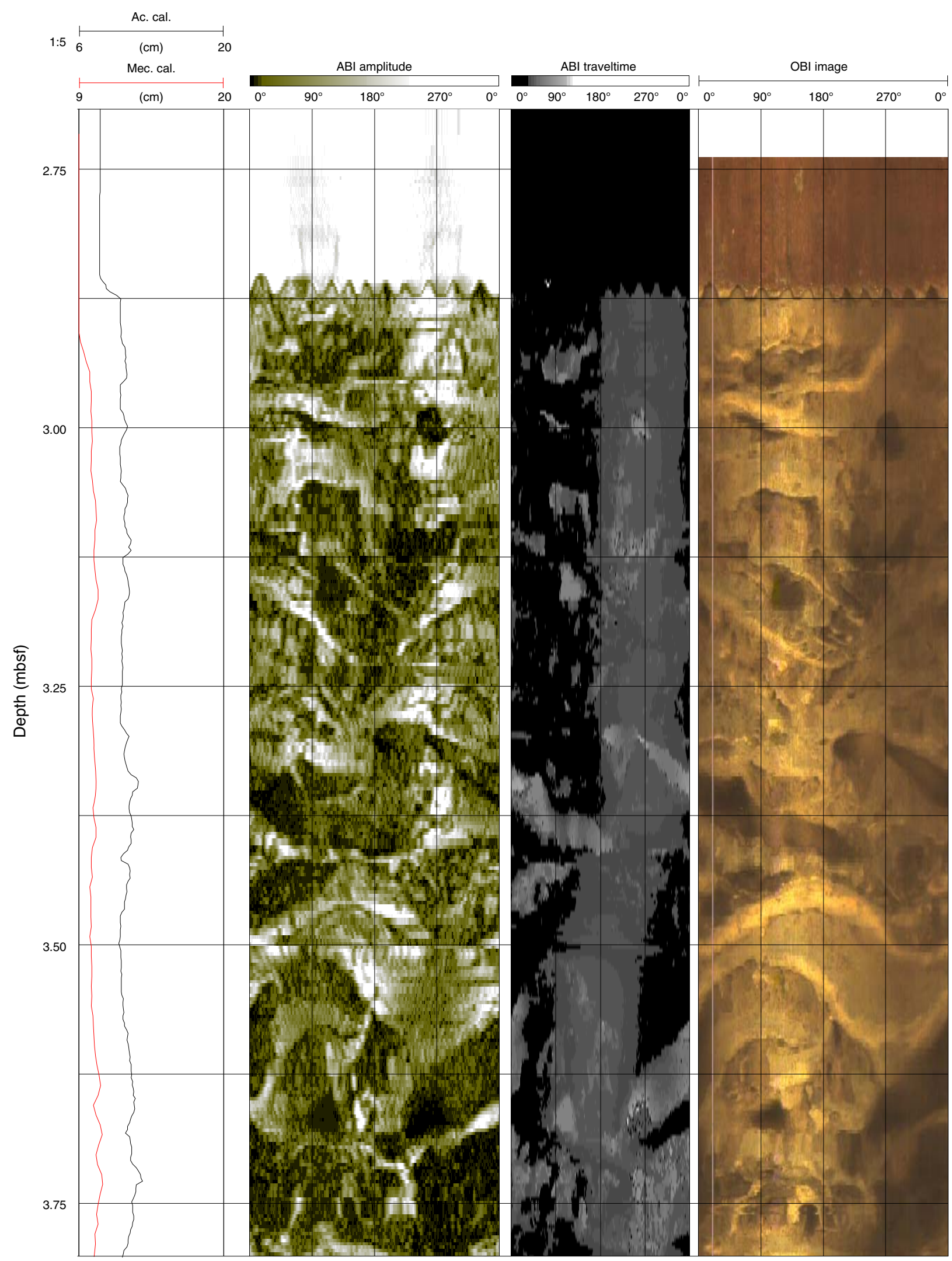


Figure F79. Wireline logging data correlation diagram for Tiarei outer ridge sites. TGR = total gamma ray.

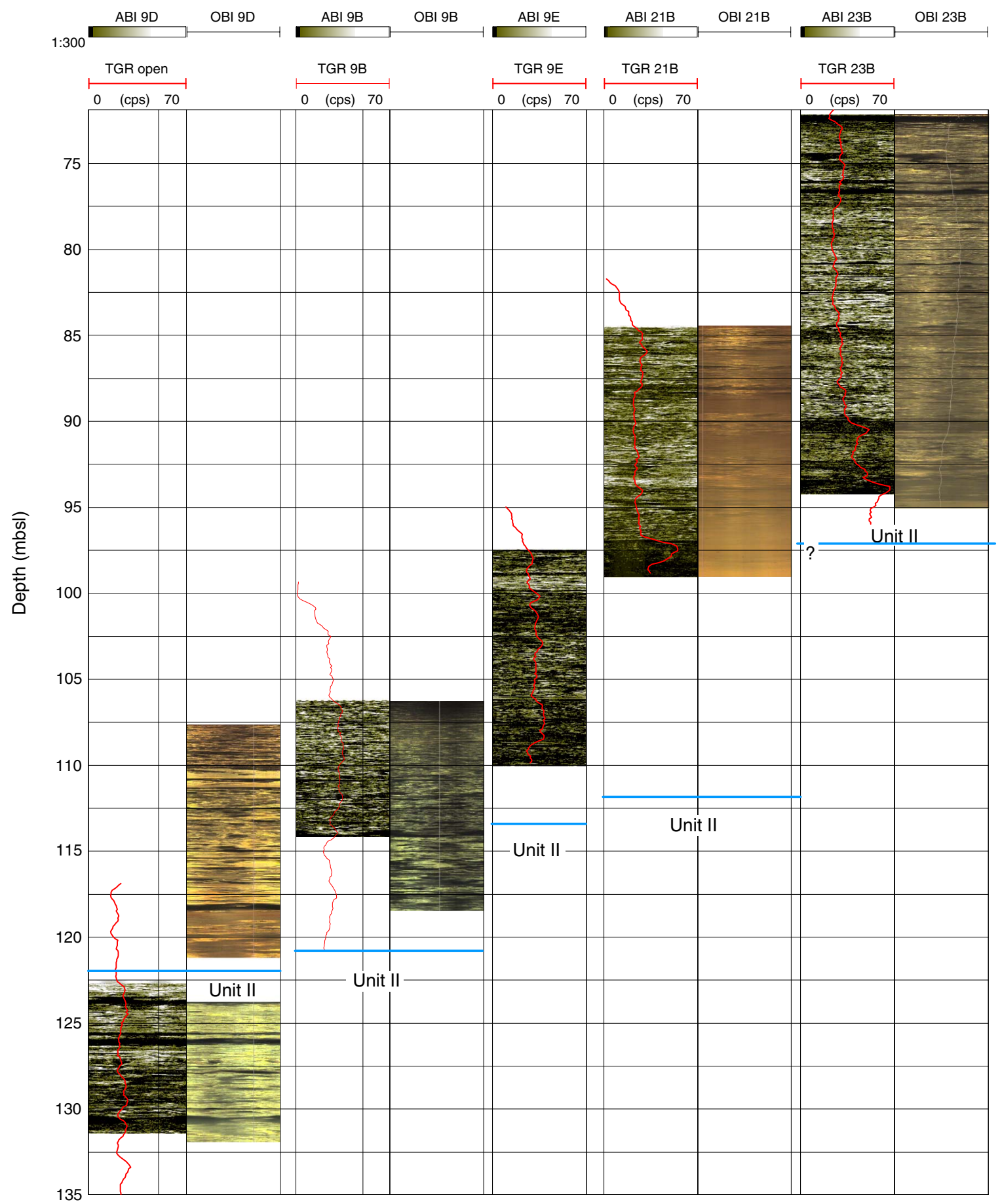


Figure F80. Wireline logging data correlation diagram for Tiarei outer ridge sites. Res. $=$ resistivity, ILD = induction electrical conductivity of greater investigation depth, ILM = induction electrical conductivity of medium investigation depth.

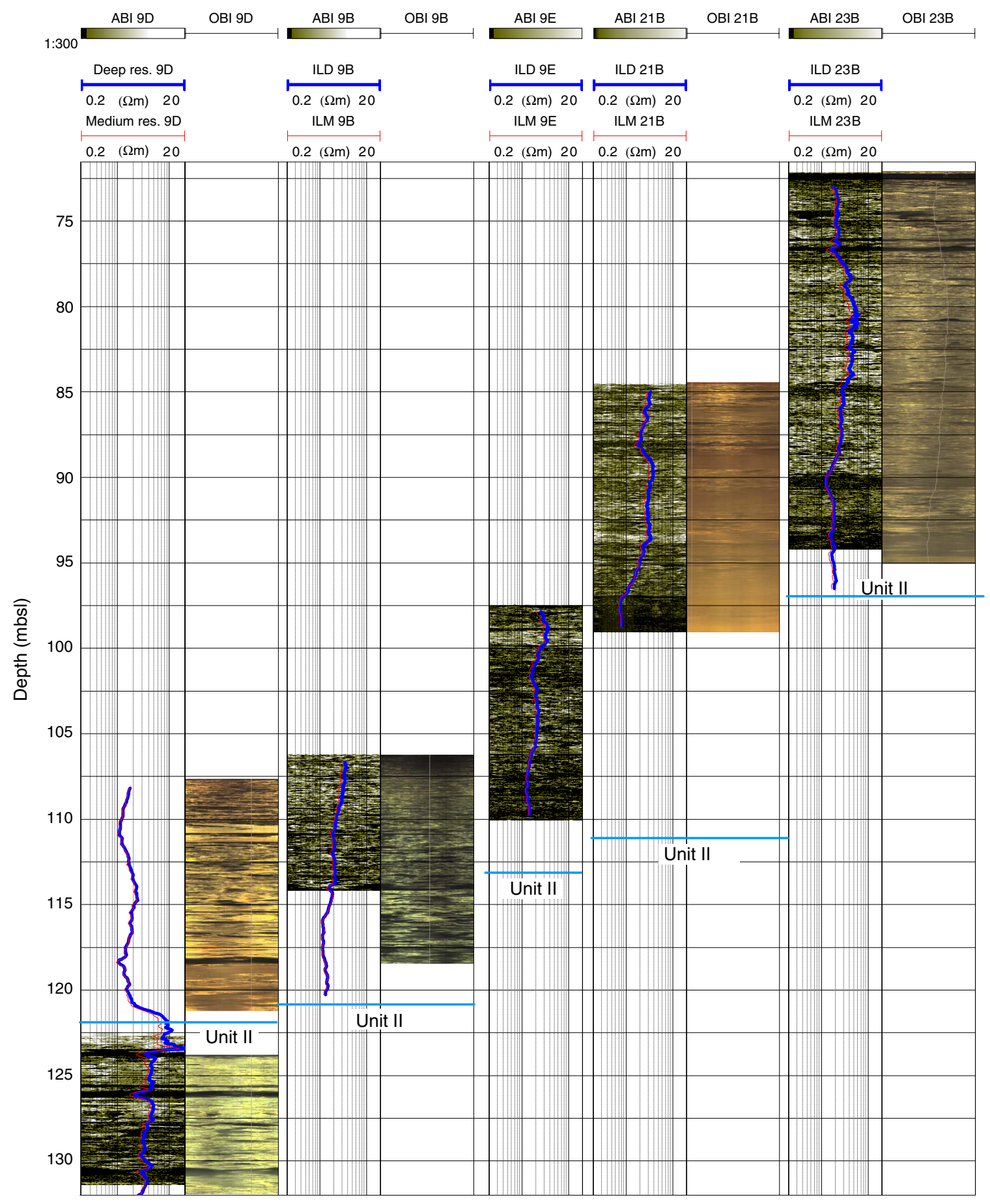


Figure F81. Tiarei Outer Ridge pore water chemicals. A. pH. B. Alkalinity. C. Calcium. D. Strontium. E. Lithium. F. Phosphorus. (Continued on next page.)
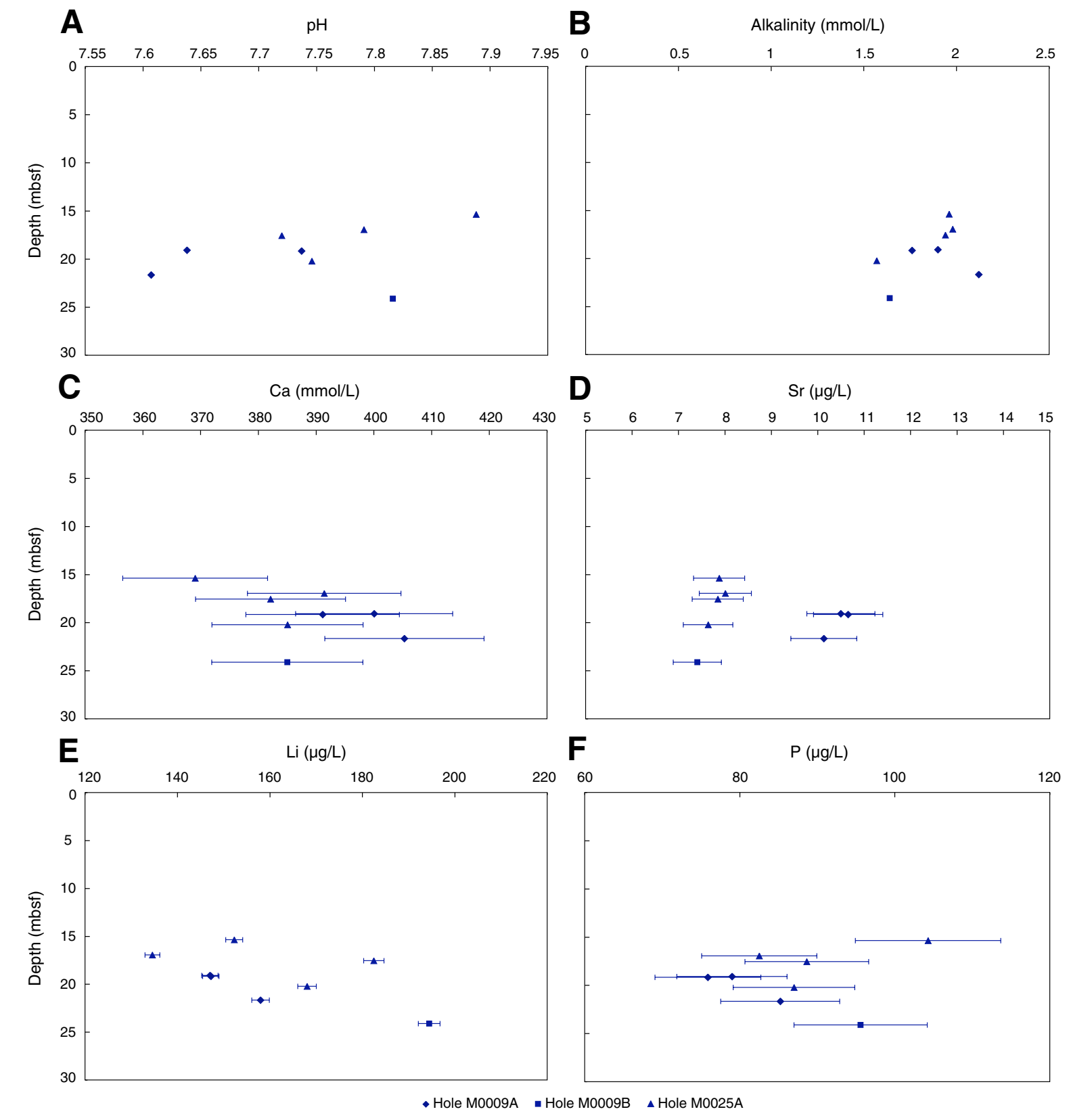
Figure F81 (continued). G. Manganese. H. Iron. I. Barium.
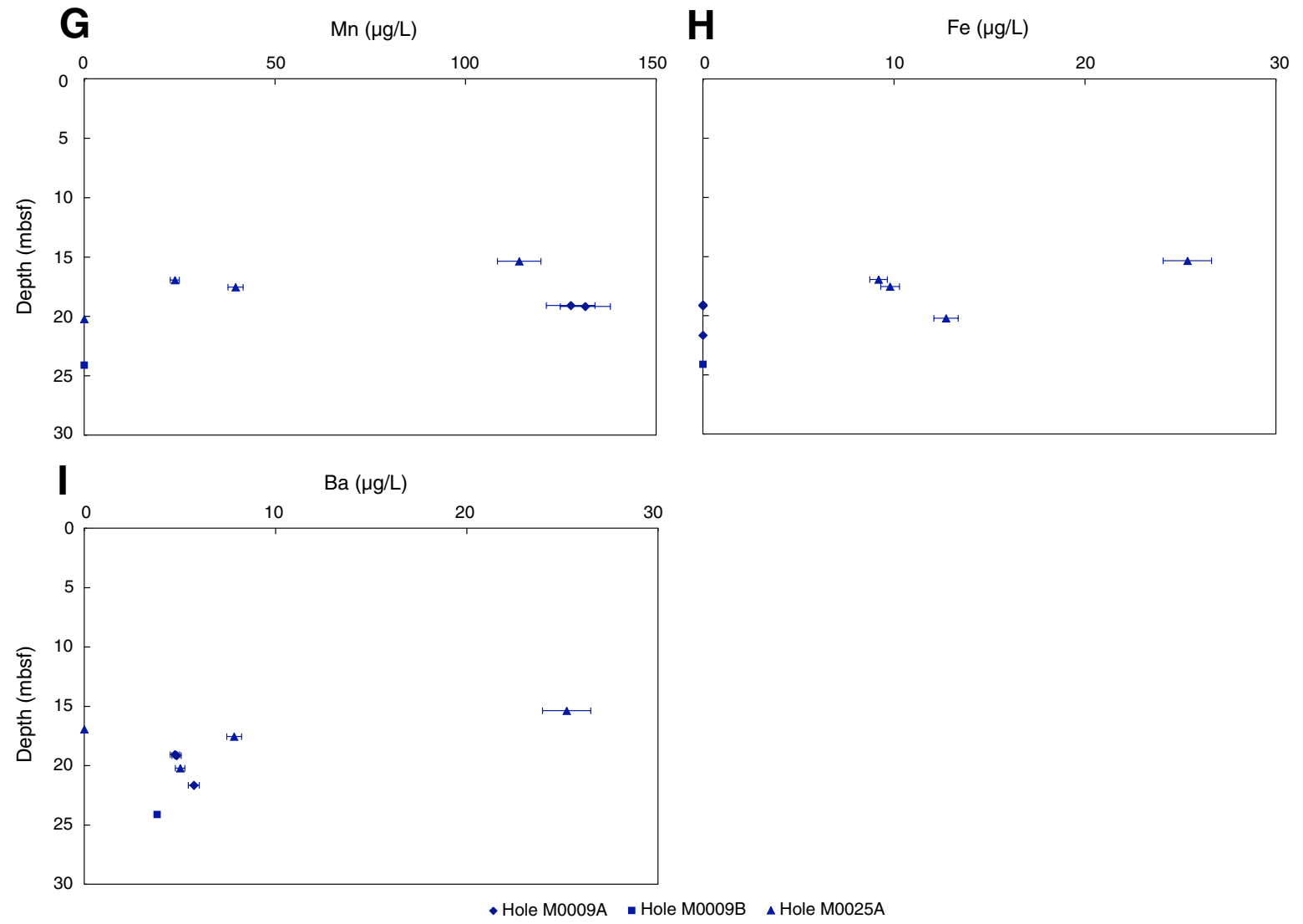